TEMPERATURE LEVELS

$$
\text { by }
$$

Hamidreza Akhlagh-Nejat

B.Sc. Civil Engineering,

Azad University of Tehran 1999

\author{
A thesis \\ presented to Ryerson University \\ in partial fulfillment of the \\ requirements for the degree of \\ Master of Applied Science \\ in the Program of \\ Civil Engineering. \\ Toronto, Ontario, Canada, 2009 \\ (C) Hamidreza Akhlagh-Nejat 2009
}




\section{AUTHOR'S DECLARATION}

I hereby declare that I am the sole author of this thesis.

I authorize Ryerson University to lend this thesis to other institution or individuals for the purpose of scholarly research.

I further authorize Ryerson University to reproduce this thesis by photocopying or by other means, in total or in part, at the request of other institution or individuals for the purpose of scholarly research. 


\section{BORROWERS PAGE}

\begin{tabular}{|c|c|c|}
\hline Name & Address & Date \\
\hline & & \\
\hline & & \\
\hline & & \\
\hline & & \\
\hline & & \\
\hline & & \\
\hline & & \\
\hline & & \\
\hline & & \\
\hline & & \\
\hline & & \\
\hline & & \\
\hline & & \\
\hline & & \\
\hline & & \\
\hline & & \\
\hline & & \\
\hline
\end{tabular}




\title{
INVESTIGATION OF INSTALLATION CHARACTERISTICS OF ASTM- F1852 TWIST-OFF TYPE TENSION CONTROL FASTENERS UNDER VARIOUS TEMPERATURE LEVELS
}

\author{
Hamidreza Akhlagh-Nejat, MASc., 2009
}

\author{
Department of Civil Engineering \\ Ryerson University
}

\begin{abstract}
Twist-off tension control method is one of the available and recognized methods for bolt pretensioning in the steel construction industry. Twist-off tension control bolts are commonly use in steel construction because they are fast, easy to utilize and convenient to inspect. Twist-off tension control is characterized by a spline at the end which can shear off at a circular notch (torque control groove) when the required preload is achieved. Preload in twist-off assemblies are based on torque control that can be affected by friction between components of the bolt assembly. This friction can be affected by any environmental condition or material property such as bolt material strength, geometric properties of the assembly, thread and lubrication conditions of the nut and bolt and installation temperature.
\end{abstract}

Earlier studies have shown that twist-off bolt assemblies used in the field and left exposed to weather for a period of time prior to applying the pretensioning force, demonstrate degradation in the achieved tensile force. This phenomenon formed a series of research concerning effects of moisture, delay installation and temperature levels on the achieved tensile force in the bolt. The effect of temperature levels in degradation of achieved tensile force forms the principal 
parameter of concern in the current research. Results showed that the twist-off bolt assemblies failed to achieve the minimum specified pretension for installation temperatures less than $0{ }^{\circ} \mathrm{C}$. Empirical equations were developed to provide engineers and fabricators of an estimate of the reduction in the achieved pretensioning force in twist-off bolt assemblies with the change in temperature levels at time of installation. 


\section{ACKNOWLEDEMENTS}

This thesis would not have been possible without the support and guidance of my supervisors, Dr. Peter C. Birkemoe from University of Toronto and Dr. Khaled Sennah from Ryerson University. Their invaluable assistance and insights throughout this period have helped me not only to develop an understanding of the topic but also to enhance my overall learning experience at the University. I greatly appreciate their help and guidance.

I would like to thank John MacDonald, Giovanni Buzzeo, Alan McClenaghan, Joel Babbin, Renzo Basset and Dr. K. D. Pressnail from University of Toronto for allowing me to use the equipments in the Building Science laboratory, also I would like to thank Mohammad Al-Dardari and Roger Smith from the Structures laboratory of Ryerson University for their support on conducting experiments on the MTS machine. This research was carried out with direct funding from the Research Council on Structural Connections (RCSC) and in-kind contribution from Walters Inc., Hamilton, Ontario, Benson Steel Ltd., Bolton, Ontario and Tresman Steel Ltd., Brampton, Ontario. Equipment and technical support were, in part, provided by Department of Civil Engineering, University of Toronto, Department of Civil Engineering, Ryerson University, and the inventory of specialty apparatus developed over the years with the support of The Natural Sciences and Engineering Research Council of Canada and the Structural Steel Education Foundation of the Canadian Institute of Steel Construction. 


\section{TABLE OF CONTENTS}

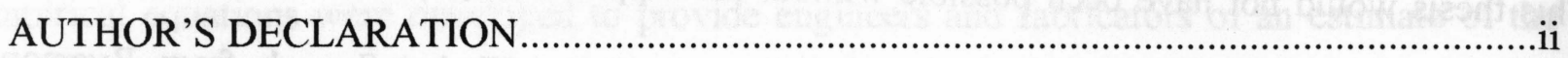

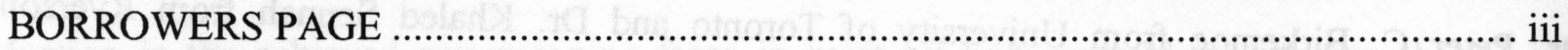

ABSTRACT …

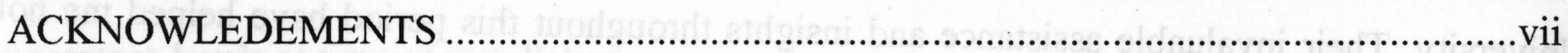

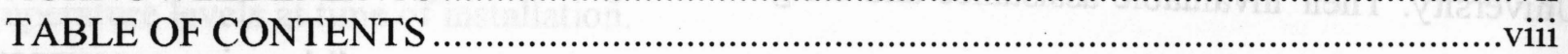

LIST OF TABLES .

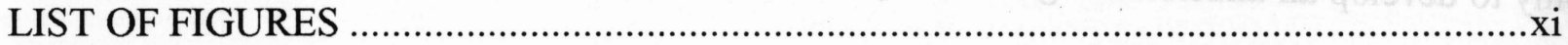

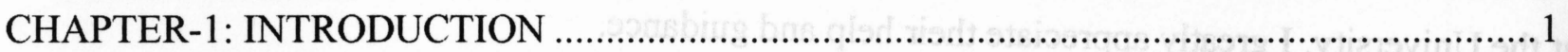

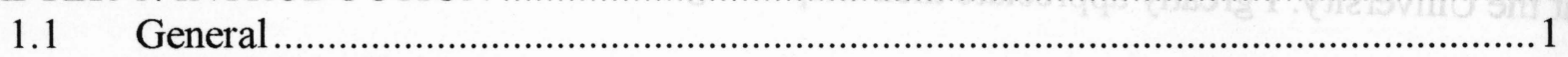

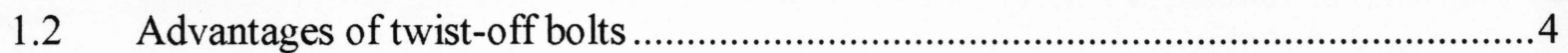

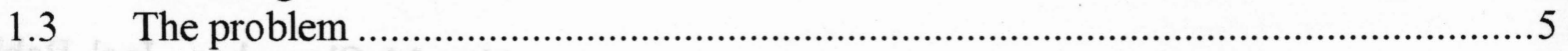

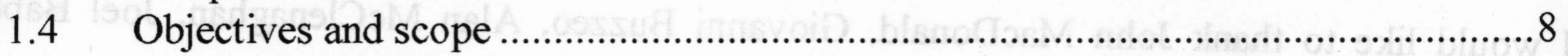

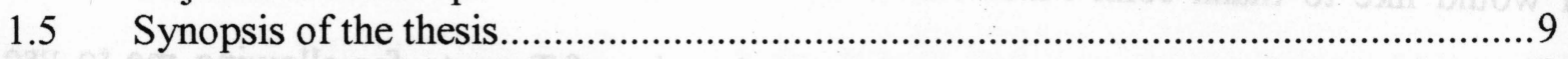

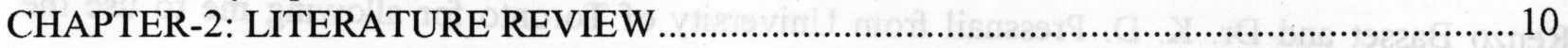

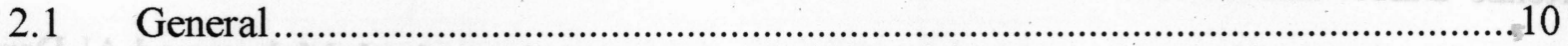

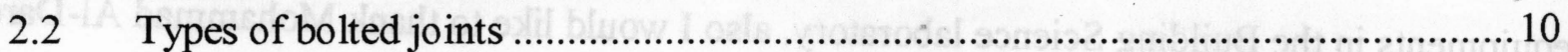

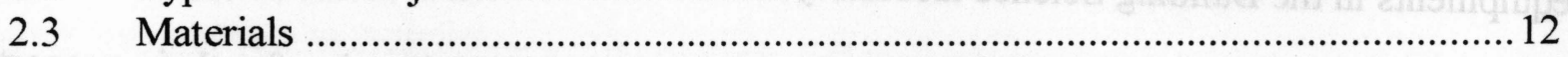

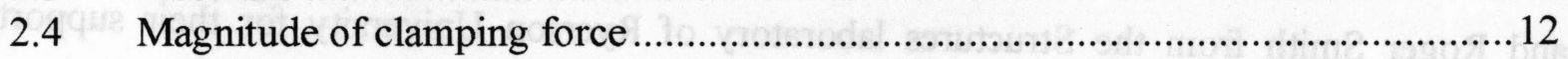

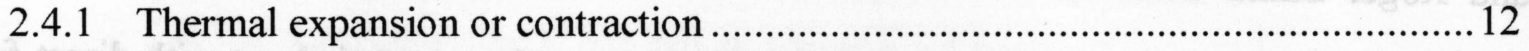

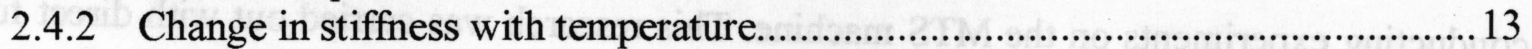

2.4.3 Proof strength and yield strength of bolting materials.......................................13

2.4.4 Effect of temperature on material properties................................................... 14

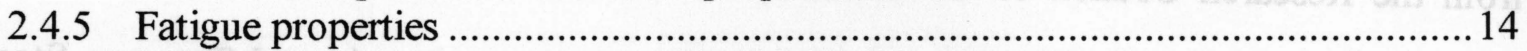

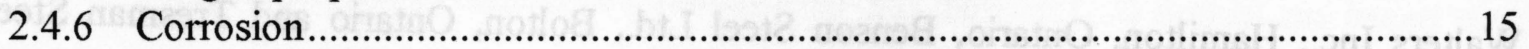

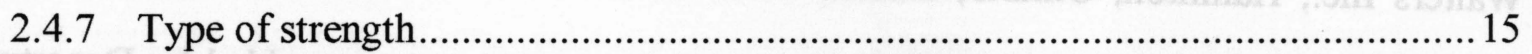

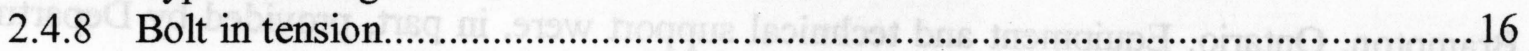

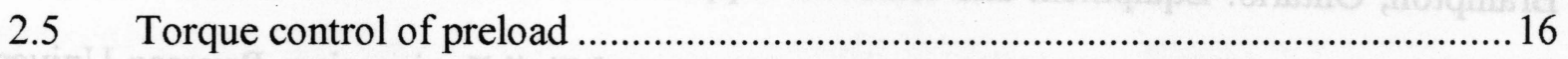

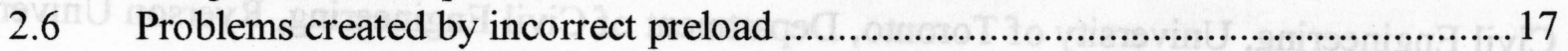

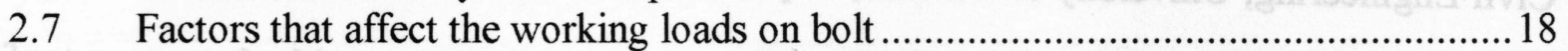

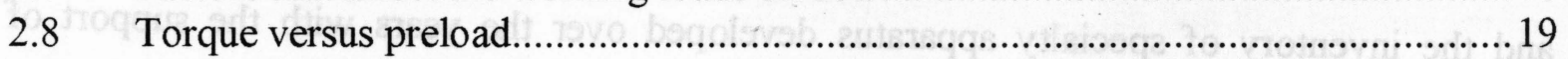

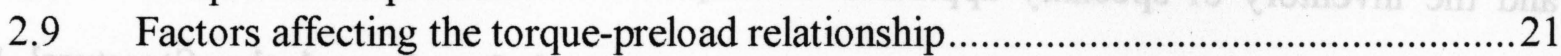

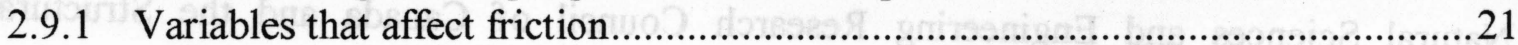

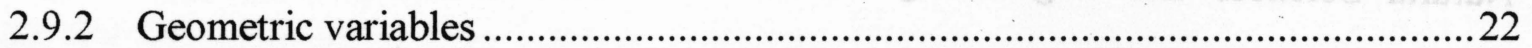

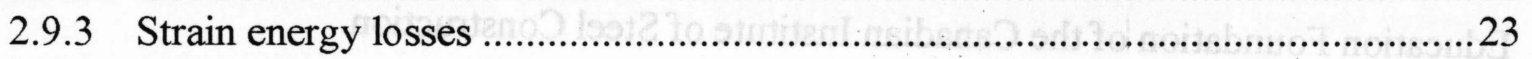

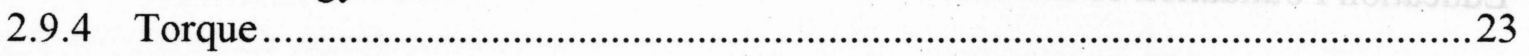

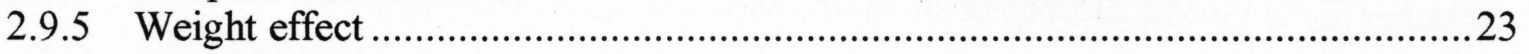

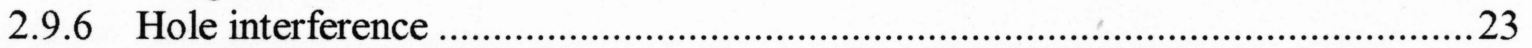

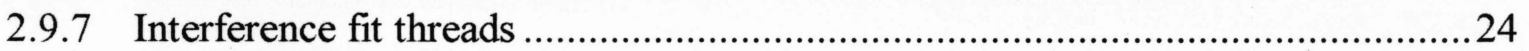

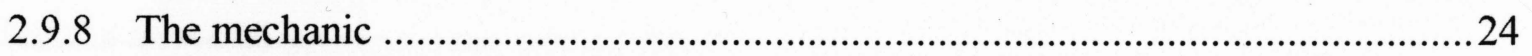

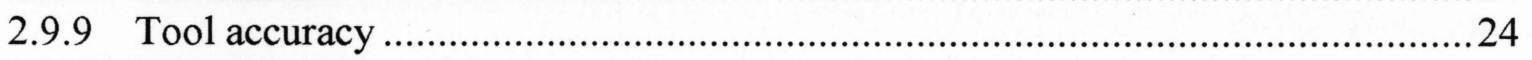

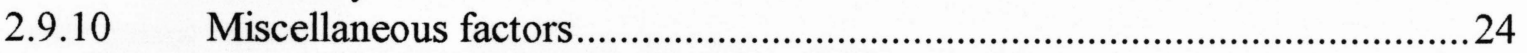

2.10 Torque versus preload (the short form equation) ……..........................................24 


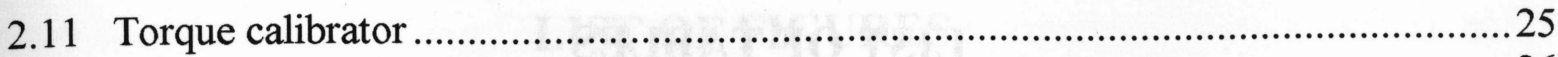

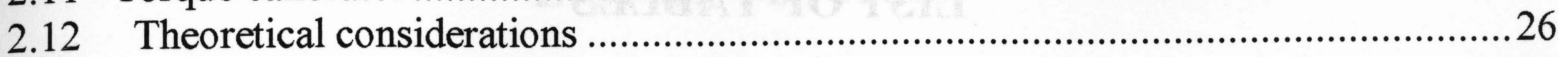

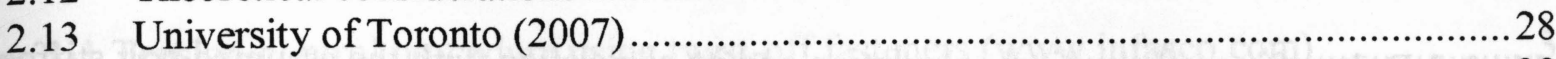

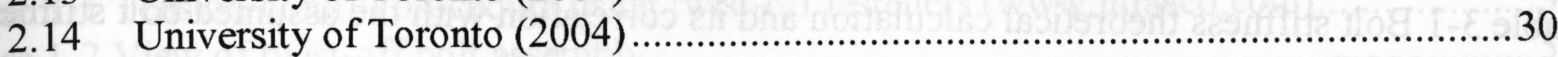

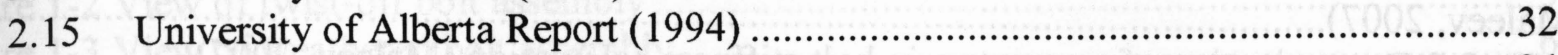

2.16 Virginia Polytechnic Institute and State University Report (2003)...........................34

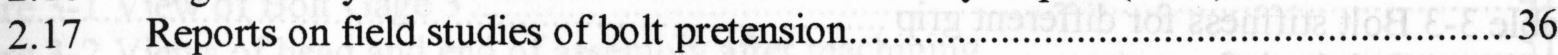

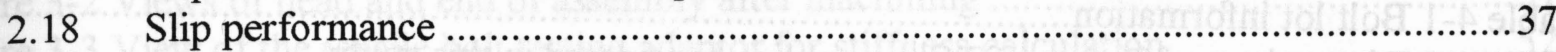

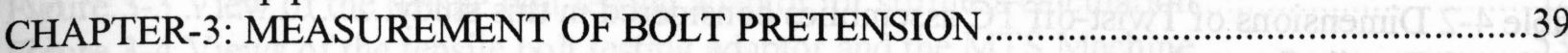

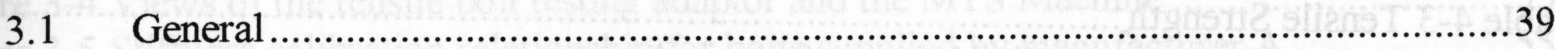

3.2 Basic concept: Stretch control method ………...................................................40

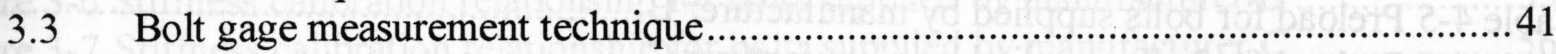

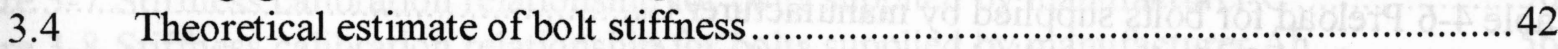

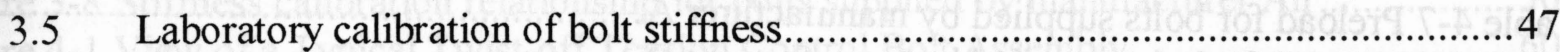

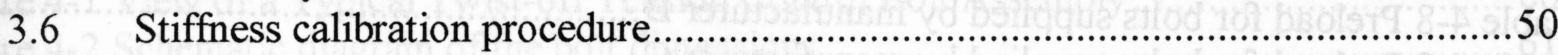

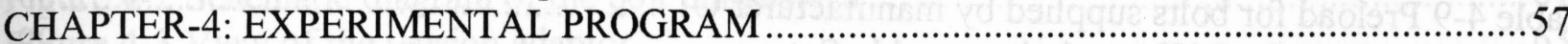

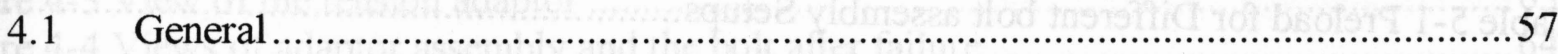

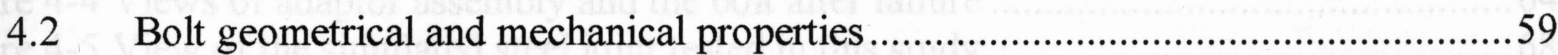

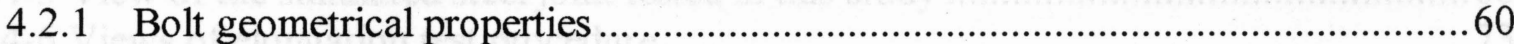

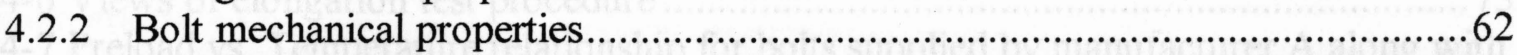

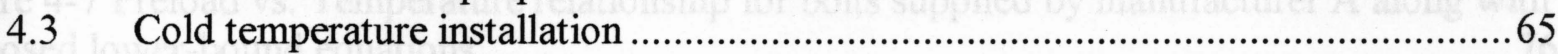

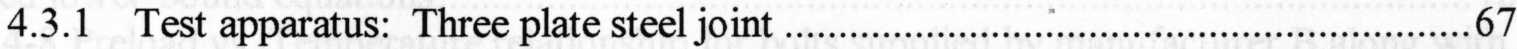

4.3.2 Cold temperature installation test parameters ...................................................68

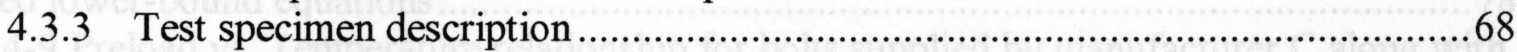

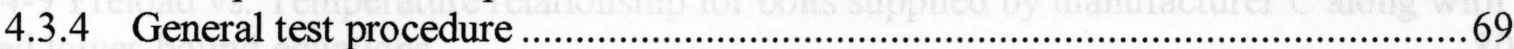

4.3.5 Results from cold temperature installation experiments.....................................74

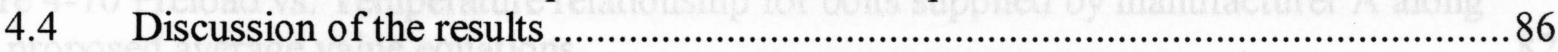

4.5 Empirical equation for achieved pretension based on installation temperature.........89

4.5.1 Equations for bolts supplied by manufacturer A, B and C ..............................8 89

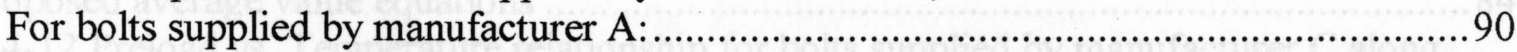

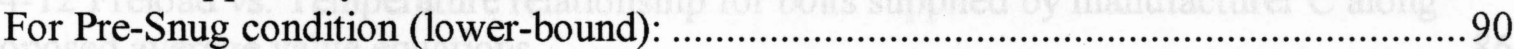

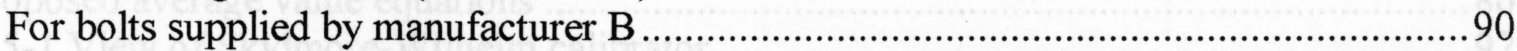

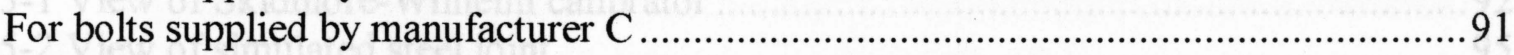

4.5.2 General equations for Pre-Snug and Cold-Snug conditions ..............................91

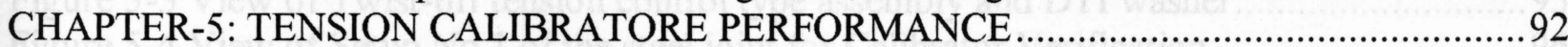

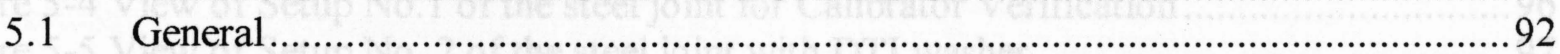

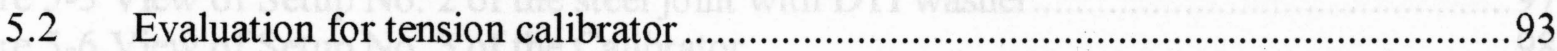

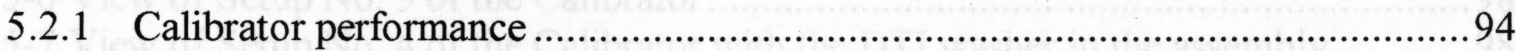

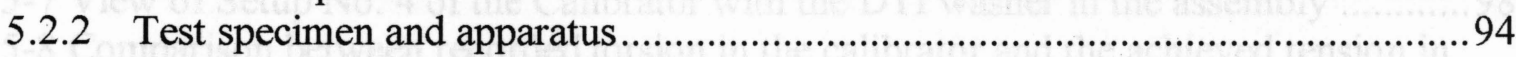

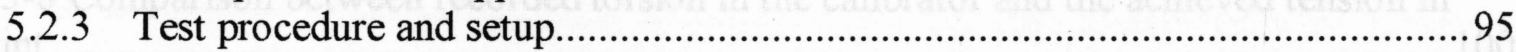

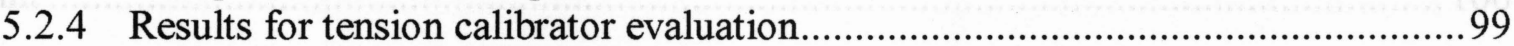

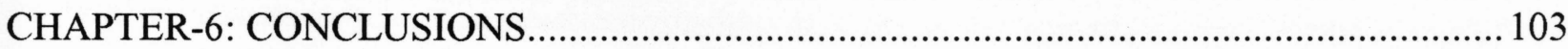

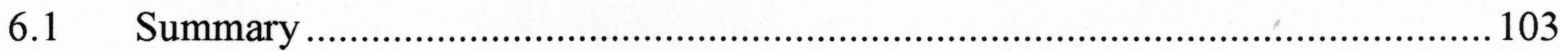

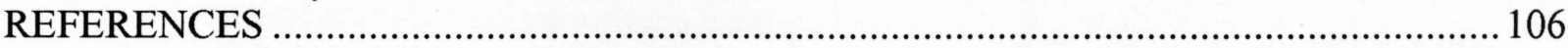




\section{LIST OF TABLES}

Table 3-1 Bolt stiffness theoretical calculation and its correlation with the assumed bolt stiffness (Maleev, 2007).

Table 3-2 Determination of parameters in bolt stiffness calculation (Maleev, 2007) ...................47

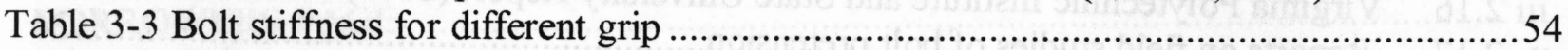

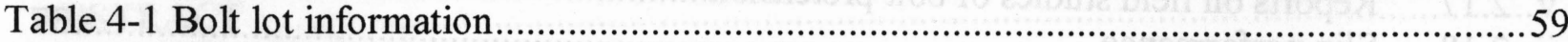

Table 4-2 Dimensions of Twist-off TC assemblies considered in this study ...............................62

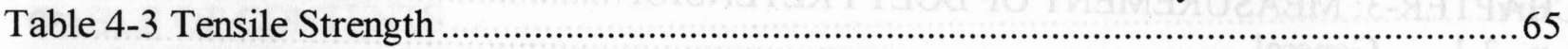

Table 4-4 Preload for bolts supplied by manufacturer A ...........................................................

Table 4-5 Preload for bolts supplied by manufacturer B ..........................................................7

Table 4-6 Preload for bolts supplied by manufacturer C .......................................................... 79

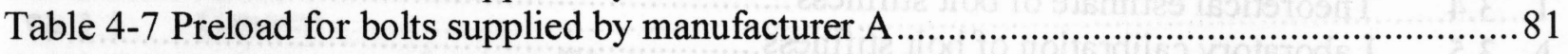

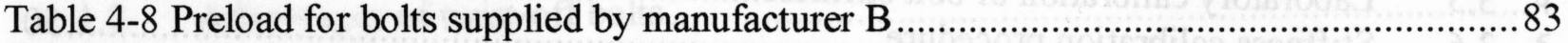

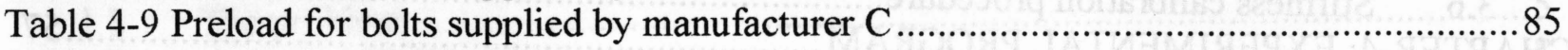

Table 5-1 Preload for Different bolt assembly Setups ..............................................................99 


\section{LIST OF FIGURES}

Figure 1-1 Tension-control procedure using twist-off fasteners (www.infasco.com).....................

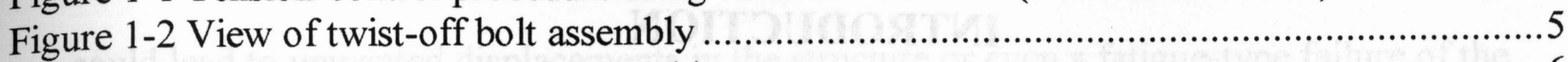

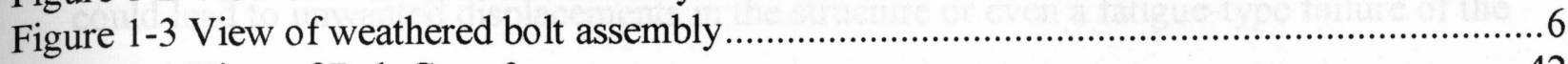

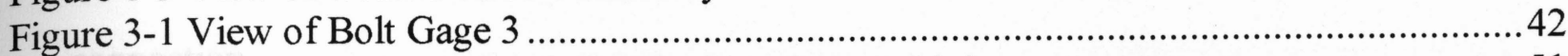

Figure 3-2 Views of head and end of assembly after machining ...............................................51

Figure 3-3 View of the tensile bolt testing adaptor for stiffness calculation ...............................52

Figure 3-4 Views of the tensile bolt testing adaptor and the MTS Machine ...............................53

Figure 3-5 Stiffness calibration relationship for bolts supplied by manufacturer A .....................55

Figure 3-6 Stiffness calibration relationship for bolts supplied by manufacturer B .....................55

Figure 3-7 Stiffness calibration relationship for bolts supplied by manufacturer C ....................56

Figure 3-8 Stiffness calibration relationship for bolts supplied by manufacturer Ah ....................56

Figure 4-1 View of a Typical Twist-off Tension Control Bolt Assembly ....................................60

Figure 4-2 Schematic diagram of the bolt dimensions ...............................................................61

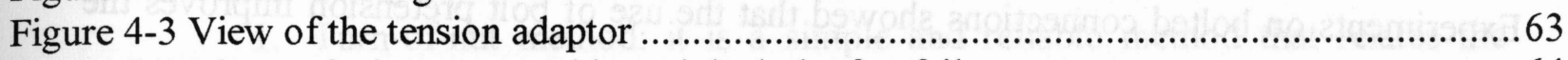

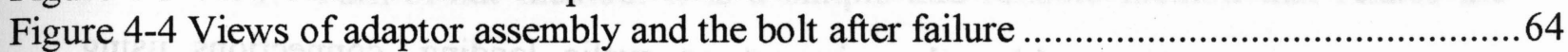

Figure 4-5 View of the simulated steel joint tested in this study …….........................................6

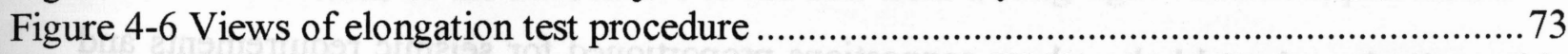

Figure 4-7 Preload vs. Temperature relationship for bolts supplied by manufacturer A along with

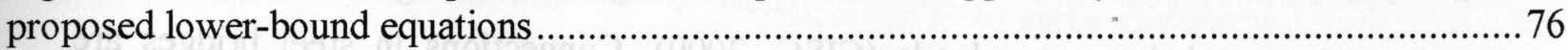

Figure 4-8 Preload vs. Temperature relationship for bolts supplied by manufacturer B along with

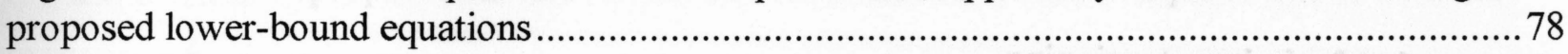

Figure 4-9 Preload vs. Temperature relationship for bolts supplied by manufacturer $\mathrm{C}$ along with

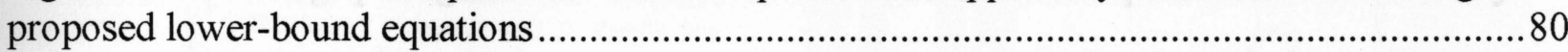

Figure 4-10 Preload vs. Temperature relationship for bolts supplied by manufacturer A along

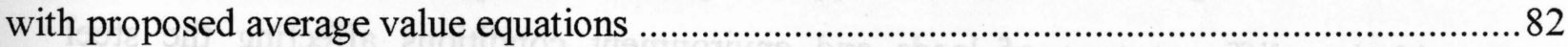

Figure 4-11 Preload vs. Temperature relationship for bolts supplied by manufacturer B along

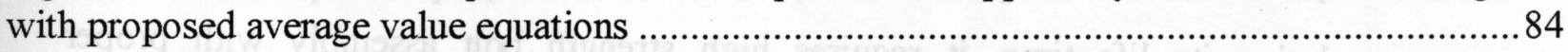
Figure 4-12 Preload vs. Temperature relationship for bolts supplied by manufacturer $\mathrm{C}$ along

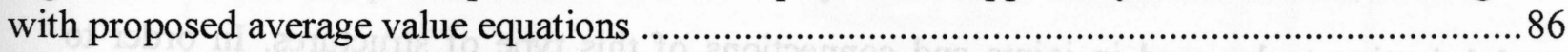

Figure 5-1 View of Skidmore-Wilhelm calibrator .................................................................92

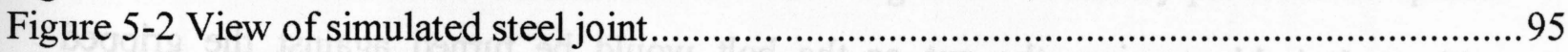

Figure 5-3 View of Twist-off tension control type assembly and DTI washer............................95

Figure 5-4 View of Setup No.1 of the steel joint for Calibrator Verification ................................96

Figure 5-5 View of Setup No. 2 of the steel joint with DTI washer........................................97

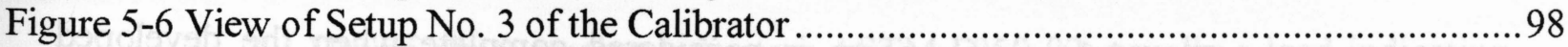

Figure 5-7 View of Setup No. 4 of the Calibrator with the DTI washer in the assembly ............98

Figure 5-8 Comparison between recorded torsion in the calibrator and the achieved tension in steel joint 


\section{CHAPTER-1 \\ INTRODUCTION}

\subsection{General}

Pretensioning bolts are crucial to maintain desired behavior in steel joints used in steel structures at serviceability limit state level. Minimum specified achieved tension in a bolt is required to satisfy the slip critical and pretensioned connections during installation. Experiments on bolted connections showed that the use of bolt pretension improves the behavior of connections subjected to impact or cyclic loading, connections using oversized or slotted holes, shear connections proportioned for seismic requirements and all connections resisting crane loads (CISC, 2009). Connections in steel bridges are examples for bolt pretensioning.

Considering different type of loads and environment conditions affecting the steel structure during its life time, it requires high strength bolt assembly with proper lubrication to be used in joints and connections of this type of structures. In order to achieve desirable tension, the nut or the bolt would be turned against the gripped material, while rotationally restraining the other part of the assembly, which results in bolt elongation. The tightening process is considered complete when the developed pretension of $70 \%$ of the specified minimum tensile strength of the bolt is achieved (CISC, 2009). Many serious damages and undesirable behavior of the structures may result from the failure in achieving the required tension in high tensile bolts used in steel joints. For example, if the defined pretension is not obtained, the effectiveness of 
pretensioned bolts in energy dissipation under cyclic earthquake loading would be reduced. Also, if bolts are not adequately pretensioned, slippage of joint may occur and it could lead to unwanted displacements in the structure or even a fatigue-type failure of the connection.

There are four recognized methods of bolt pretensioning that can be described as follows (RCSC, 2009).

1. Turn-of-nut method: it is a simple and reliable method that relates the turns of the nut relative to the bolt from a snug-tight condition; pretension through bolt elongation to a tension level above the torqued-tension proportional limit of the bolt. The number of turns required varies with the grip length of the bolt. The use of this method requires that a sufficiently small component of torque is applied to the bolt during the installation to permit proper tension development during the combined experience of torque and tension. Generally, the "as-received" condition or that associated with moderate weathering of the assembly provides acceptable behavior.

2. Use of direct tension indicators ASTM F959-02: usually a load-indicating washer with arc-shaped protrusions is used. The deformation of these protrusions when tightening the bolt is correlated to the pretension force that is achieved at the time of tightening. 
3. Tension-control using twist-off ASTM F1852 fasteners: this method for achieving desired pretension uses a bolt/washer/nut assembly with a specifically configured bolt and wrench that later is called Tension Control (TC) Wrench. The fastener has a splined end protruding beyond its threaded portion. The wrench has two coaxial chucks that react against one another during the development of the torque required to twist off the spline. The inner chuck engages the splined end while the outer engages and torques the nut. The bolt is pre-calibrated by the manufacturer so that the splined end shears off at some point after minimum pretension is achieved. Figure 1-1 shows a schematic diagram of the tension-control procedure using twist-off fasteners.

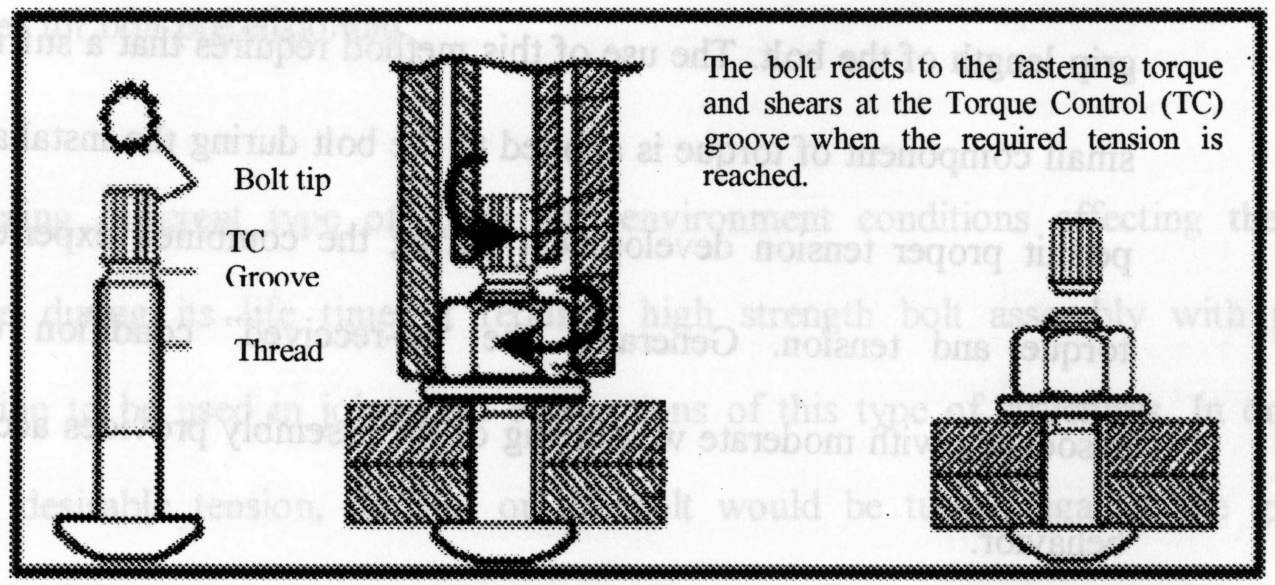

Figure 1-1 Tension-control procedure using twist-off fasteners (www.infasco.com)

4. Calibrated wrench: an additional method that is recognized by RCSC and is similar to the tension control method but can be applied to any bolt assembly after calibration to determine the torque required to achieve 
proper pretension. This torque may be adjusted so that an impact wrench stalls at that value or an electrically or hydraulically powered wrench stops automatically when the torque is reached. Previous research (Kulak and Undershute, 1994) has shown that the pretensions achieved by this method are highly dependent on the friction conditions of the bolt assembly.

\subsection{Advantages of twist-off bolts}

Twist-off bolt assembly is different from that for the conventional bolt. These differences would be defined as differences in geometry, high capacity of tension, installation equipments as well as method of inspection. There are few advantages associated with use of twist-off bolts. That can be described as follows. The TC wrench that is used for installing twist-off bolts is much lighter than the wrench used in other methods. Since the TC wrench holds the nut of the assembly, installation can be performed by one person. Also, visual inspection can easily be achieved since the spline of the assembly shears off when the bolt reaches its desired tension. Other benefit can be added to the use of twistoff bolts is that after the spline breaks off; the assembly still can be tightened up similar to the conventional high strength bolts if there is any concern about achieved tension in the bolt.

Few countries have taken advantage of the benefits that twist-off bolts offer. These bolts have been used in steel construction in Japan, Britain, United States and recently in Canada. Figure 1-2 shows view of the twist-off bolt assembly. 


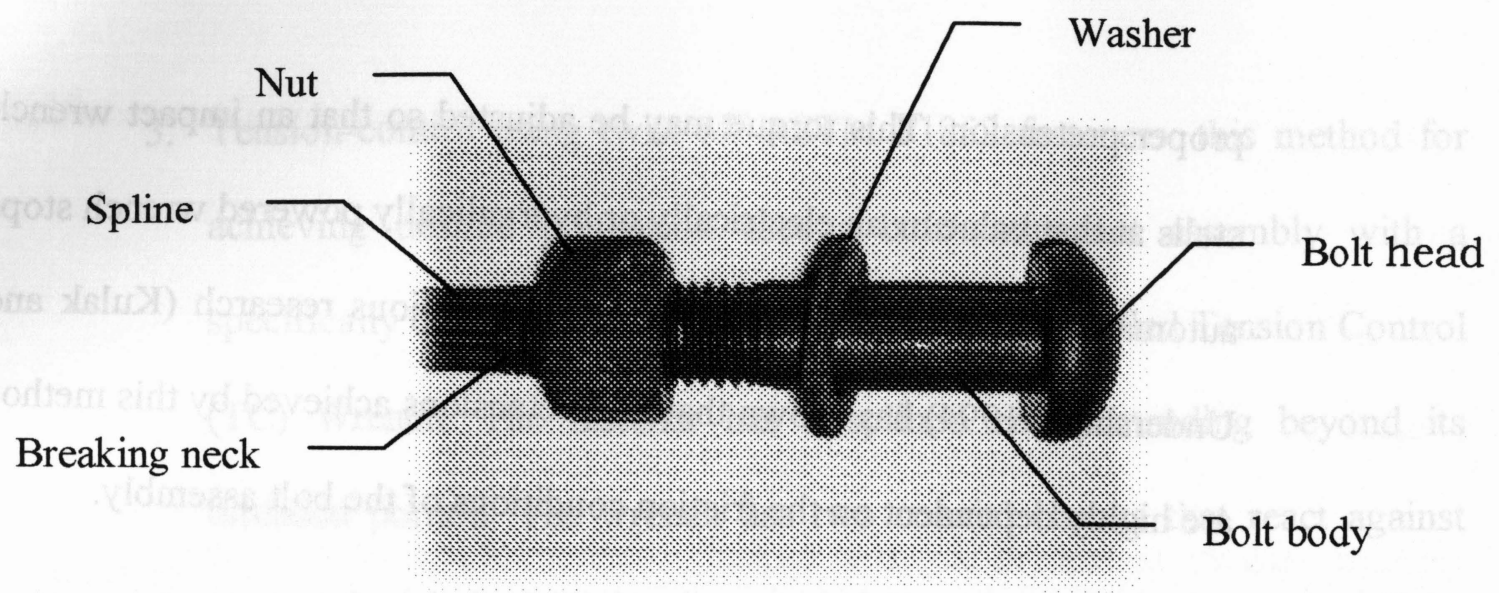

Figure 1-2 View of twist-off bolt assembly

\subsection{The problem}

The effect of delayed installation, wet and moisture were briefly studied at extreme cold temperature (Maleev, 2007). The simulated joint was soaked at $-20^{\circ} \mathrm{C}$ to observe the effect of cold temperature on achieved pretension. The finding of this study suggested to consider other levels of cold temperatures with ultimate goal of finding a level of cold temperature below which the assemblies fail to develop minimum required tension. In addition, further tests were conducted to evaluate the performance of the SkidmoreWilhelm tension calibrator as a provider of adequate verification of assemblies in the field (Tan, 2007).

Based on the specification issued by Research Council on Structural Connections (RCSC, 2004), at least three bolts of each diameter, length, grade and lot must be tested in a tension calibrator to verify that appropriate pretension is developed in the bolt just prior to the installation in steel joint. The principal factor affecting the behavior of these fasteners is the torsional response caused by the total friction appears at the face of the 
nut and between mating threads of the assembly. As a result, any condition that would affect this total friction may influence the achieved pretension. Therefore, questions have been raised about the performance of these fasteners in the field where there may be a significant variability of moisture, temperature, etc., at the time of installation. When a steel structure is erected, the bolts are usually loosely put in place until all the elements are aligned properly. This assembly may be snug tightened, usually at time of erection, but it could be days or weeks before the bolt crew actually completes the installation with the final "twist-off" pretensioning. The resulting delay during the time that assemblies are exposed to the weather and construction site conditions may change bolt installation characteristics. For example, the exposure to weather could lead to deterioration of the thread and nut lubricant conditions and affect the frictional performance of the assembly. In addition, questions have also been raised about the variability in the performance of the tension calibrators that are used in the field to do the required pre-installation verification. Figure 1-3 shows a typical rusting of twist-off bolt assembly after exposure to weather.

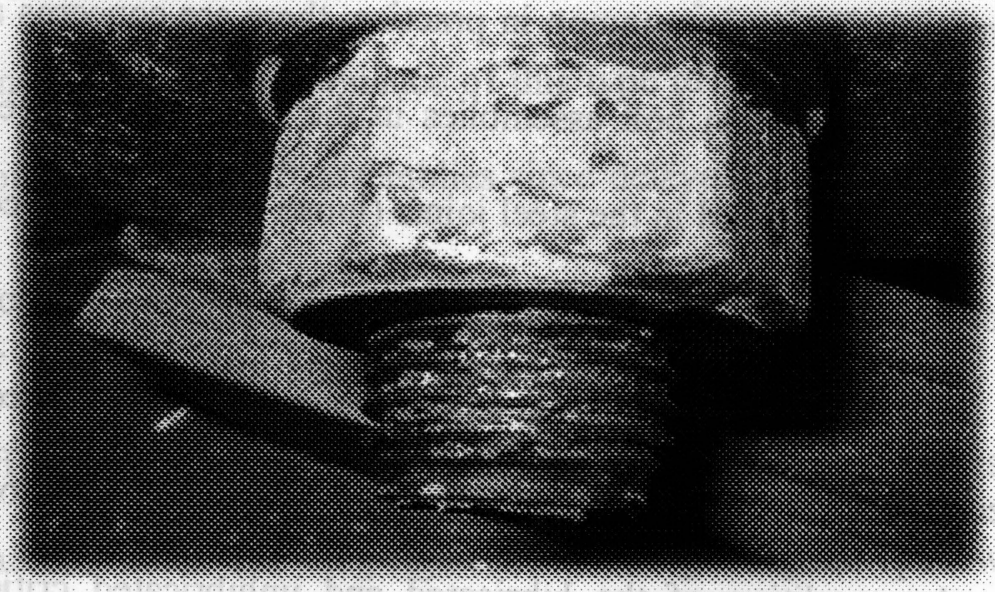

Figure 1-3 View of weathered bolt assembly 
Based on the laboratory tests, achieved pretensioning in bolts is different upon the method that has been implemented for installation of the bolt assembly. When the turnof-nut method is used to install ASTM A325 bolts, the mean pretension is about 1.35 times the specified minimum pretension and when the calibrated wrench method is used, the mean pretension is only about 1.13 times the specified minimum pretension (RCSC, 2004). In case of the twist off tension-control bolt assemblies, the achieved pretension varies with the bolt manufacturer, the time delay at installation and environmental conditions of storage and exposure. Field test data on achieved bolt tensions are only available for turn-of-nut pretensioning, and Direct-Tension-Indicator pretensioning (Kulak and Birkemoe, 1993). They stated that the mean value of pretension was about 1.27 times the specified minimum pretension. It was confirmed that the field practice achieved bolt tensions comparable to the extensive laboratory studies that had been conducted to examin the installation methods. The ultrasonic bolt length measurement device was featured in the field study and this technique presented a convenient and reliable way to determine bolt pretension in the field.

Since delayed installation is common in practice, there are concerns about the adequacy of the developed tension in bolt assemblies in the field. In practice, it is common for twist-off bolts to be inserted in the steel joints (loose condition) for considerable amount of time prior to final installation. The final installation for twist-off bolts will be achieved by turning the nut of the assembly against the bolt with use of special electric wrench until the end sline of the bolt shears off. The delay in installation may cause some changes in the condition of the lubricated and unlubricated critical surfaces of the 
assembly. To investigate the effects of delayed installation, a group of tests were conducted on 3-plate joints placed on the roof of Galbraith building at the University of Toronto (Maleev, 2007). The requirement for field verification of the performance of fasteners that had experienced a delay in final tightening after initial placement in the steel work suggested that scrutiny of the verification technique should be included as a significant objective. In this thesis, further investigation on F1852 twist-off bolt assemblies has been conducted to have better understanding of their behavior when exposed to various environmental conditions. The installation methods and test procedures developed for such assembly in earlier studies were followed in this research to assist in providing data base for test results with ultimate goal of developing guide lines for estimation of actual bolt pretension force for different installation procedure and temperature levels.

\subsection{Objectives and scope}

The main objective of the current research is to evaluate the preload developed in twistoff tension-control assemblies and to study the effect of temperature related to the impact of the field environment on the performance of this type of bolt. Questions arose about the achieved tension in the twist-off assemblies since delayed installation is common in steel construction.

Normally twist-off tension-control assemblies are tightened with the special installation wrench to shear off the end spline. This procedure is performed a few weeks after bolts are inserted into the bolt holes and snug tightened utilizing a regular spud wrench. The lubricated and unlubricated condition of the critical surfaces of the bolt, nut and washer 
may change as they are exposed to various temperature levels. To investigate the effect of various temperature levels, a group of tests were conducted on simulated 3-plate joints exposed to various temperature levels and the results for pre load observed. The field verification requirement for the performance of assemblies that had been subjected to delay installation in final tightening after initial placement in the steel joint, suggested that scrutiny of the verification of the technique should be included as a major concern. Furthermore, this research utilized the ultrasonic measurement technique to determine the elongation and consequently the pretension in the twist-off tension control assemblies. The ultrasonic Bolt Gage was used to measure the bolt elongation in loading and unloading condition and thus determine the bolt preload based on the knowledge of the bolt stiffness.

\subsection{Synopsis of the thesis}

Chapter II reviews the literature on pretensioning and various methods to effectively control the bolt pretension as well as the results from previous studies regarding the behavior of twist-off tension control assemblies. In chapter III, the Bolt Gage is introduced and the technique of utilizing it to measure the elongation of a bolt is reviewed in detail. Also the basic concept of stretch control and theoretical estimate of bolt stiffness are explained. Moreover, laboratory testing method to determine bolt stiffness is introduced. Chapter IV presents the experimental program conducted in this thesis to investigate the behavior of twist-off tension-control bolt assembly under different environmental conditions. The discussion of results is presented in Chapter V while Chapter VI presents the conclusions and the recommendations for further research. 


\section{CHAPTER-2}

\section{LITERATURE REVIEW}

\subsection{General}

Main idea of presenting this section is to provide a brief review of three research projects that were completed on twist off type tension control bolt assemblies as well as an overview of the theoretical consideration supporting the objectives of this research. This study is based on the results from the studies of 2004 and 2007 University of Toronto and the testing parameter is derived from the outlined recommendations of these researches. Most of literature review was quoted from Bickford (2008).

\subsection{Types of bolted joints}

Depending on the direction of force or load we may have two type of joints; one is tension joint and it is when the direction of the force or load is parallel to the axes of the load and perpendicular to the joint and the other type is when the joint is under shear load and is called shear joint. The purpose of all tension bolting and most of the shear bolting is to develop a clamping force between two or more joint members.

In tension joints the bolts are to provide enough clamping force to prevent joint from separating and in case of existence of shear force, the clamping force should prevent the joint from slipping. Also there should be enough tensile force in the bolt to stop bolt from self loosening and make it less susceptible to fatigue. 
There are two important issues to be considered;

- First, the bolts are to create and maintaining the clamping force between joint members.

- Second, the life and behavior of the bolted joint is depended on the magnetite and stability of the clamping force.

In shear joint we are concern about slipping the joins or tearing apart in slip direction and bolts are to prevent these phenomena's as well as resisting the tensile load if exists. Slip is prevented by either friction restrain between joint members by tensioning the bolts to create the clamping load or in some other cases the bolt resist slip by acting as shear pins. In recent case the integrity of the joint is determined by the shear strength of the bolt and joint members.

A joint designer needs to design the members and bolts in a way that they do not fail during the time that they are in service. To do so the designer needs to consider two issues;

- The designer to choose bolt and joint sizes, shapes and materials that support enough clamping forces to avoid bolt self loosening, joint slip, separation, fatigue and in some cases leakage.

- The designer also needs to choose bolts that can secure a combination of maximum assembly stress plus the maximum increased in stress by service condition and thermal effect. 


\subsection{Materials}

The materials that are used in the bolted joints are required to be strong enough to stand different loads and forces as well as combination of them. The type of materials that joint members are made of is crucial for the designer to pick right bolt and right joint members. In this section material strength of the bolt and joint members will be discussed.

The clamping force to clamp the joint members is the most important purpose of using the bolt and therefore we need to know what physical, chemical and other possible issues may affect the magnitude of the clamping force.

\subsection{Magnitude of clamping force}

The magnitude of the clamping force will depend on the tensile and shear strength of the material. For example for a given diameter and thread configuration, stronger material means stronger bolt and stronger bolt is able to create greater clamping force.

\subsubsection{Thermal expansion or contraction}

Temperature and change in temperature will have direct impact in length and thickness of bolt and joint members and these changes can be calculated by knowing the thermal coefficients of linear expansion. The clamping force can be increased or decreased if the bolts and joint members are made from different materials. In extreme cases these differences can break or eliminate the tension in bolt. Temperature can create problems 
also if the bolts and member have same thermal coefficients. Rising the temperature can create the stress relaxation and lead to reduction or even elimination of the clamping force. Normally the room temperature strength of fastener is given in different tables under static tensile load. Sometimes it is necessary to determine what material an unmarked bolt is made of to estimate its strength. For shear strength since practically most of the bolts are used as clamps not shear pins, most of the bolting specifications list tensile strength not shear strength of bolt which would be proof, yield and ultimate tensile strength of the bolts.

\subsubsection{Change in stiffness with temperature}

The stiffness of bolt and joint members can be also affected by the temperature changes as the modulus of elasticity will change by temperature changes. As an example, $10 \%$ reduction in modulus of elasticity means $10 \%$ reduction in achieved tension in the bolt. Changes in stiffness may also reflect changes in the bolt to joint stiffness ratio.

\subsubsection{Proof strength and yield strength of bolting materials}

The proof strength of a bolt is the highest stress that it can support without going under permanent deformation and yield strength is defined as the maximum useful stress that a bolt can tolerate and most likely will experience small permanent deformation. 


\subsubsection{Effect of temperature on material properties}

As mentioned earlier, change in temperature has effect on the clamping force. Bolts will have less strength if they are tightened in temperature higher than room temperature and as a result if the operating temperature is too high then bolts will fail especially if they are heavily loaded. If different materials are used in joint system the thermal expansion and contraction will cause instability in the joint system, therefore even though this situation generally happens when the temperature is too high, but it is recommended too use same or similar material in joint system to avoid undesirable situations.

Creep in joints system involves slow changes in dimension of joint members under heavy loads, or basically strain under stress. On the other hand stress relaxation involves the slow shredding of load (stress) by a joint member under constant deflection (strain).

As defined, it can be observed that under stress relaxation the bolt will lose its preload and the joint cannot perform as it is expected and high temperature can favor the phenomenon.

\subsubsection{Fatigue properties}

Fatigue is a phenomenon that bolt fails under repeated loading and consequently the joint system will fail as the clamping force diminishes. The endurance limit is the maximum tensile stress the bolt can tolerate for an infinite number of cycles, infinite life and fatigue strength is the maximum stress the bolt can stand for an average life of given number of load cycle. 


\subsubsection{Corrosion}

Temperature, geometry, stress level, stress concentration, properties of mating parts, surface flaws and many other factors can have impact in corrosion and corrosion can affect the life time of the fastener and cause the stress loss in the bolt. This can ultimately lead the joint to fail.

\subsubsection{Type of strength}

As previously mentioned the function of a bolt is to provide enough clamping force in the joint to prevent slip, separation and etc. and be strong enough to handle the preload stress and extra stresses that may act on the bolt during the life span of the joint in structure. At this point the strength of bolt will be discussed. The factors that have effect in any material part are related to size and the shape of the part, what material it's made of, material and operation temperature and few other factors. In bolt design we deal with many different type of strength such as; tensile strength, thread stripping strength, shear strength, brittle fracture strength, strength at high and low temperature, fatigue strength and stress corrosion cracking strength. Tensile and stripping strength are a measure for resistance of the bolt to static or slowly change loads, whoever repeated loading will cause the bolt to fail under fatigue and this should be handled by the fatigue strength of bolt. If the bolt is loaded under a force perpendicular to its axis, then should be strong enough under this type of loading. Extreme temperature levels will alter the tensile and stripping strength of bolt because it changes in strength of bolt materials. 


\subsubsection{Bolt in tension}

For ductile bolts such as ASTM A325 if pure tension is applied, a tension versus change in length curve will be generated. In this curve initially we have elastic portion which loading and unloading of the bolt in this region will not cause any permanent deflection. This part of the curve will be called "Elastic region". After the straight line, the "Proportional limit" will develop where the line is no longer straight. It is followed by the "Elastic limit" where any tension loads will form permanent deflection beyond this pint. "Ultimate strength" is the point that the maximum tension can be created by tension load on any bolt. This point often called "Tensile strength".

\subsection{Torque control of preload}

Torque applied to the nut is to control the tension or preload build up in the bolt and it is the best known, most common and least expensive way to control preload. As mentioned earlier the main purpose of most of the bolting is to create clamping force by tensioning the bolt and it is achieved by turning the bolt and the nut against each other. Tension in the bolt is important at three different times;

- Initial preload, which is the tension created in the bolt when it is initially tightened.

- Residual preload, which is the tension remaining in a bolt after all bolts have been tightened. 
- The tension in a bolt in service, this is the time that we are interested the most and is the tension in the bolt while the joint members including the bolts are in service.

Initial preload is the most controllable tightening and it usually determines and often dominates the residual and in service condition. If the initial preloading is properly done, vibration, thermal loads, and other issues will not affect the initial preload and won't cause the joint any problems. There is a direct relation between initial preload and ultimate behavior of the joint.

\subsection{Problems created by incorrect preload}

The followings are the problems that a bolted joint may face if the bolt is not properly loaded;

- Static failure of the fastener: Body of bolt will break under excessive preload.

- Static failure of joint members: excessive preload can harmfully affect the joint members.

- Vibration loosing of the nut: The nut may loosen under vibration if enough preload is not provided.

- Fatigue failure of the bolt: If enough preload is not provided, mean stress in bolt will be low and make the bolt week under repeated loads.

- Joint separation: Proper preload prevents the joint from separation. 
- Joint slip: Enough clamping force prevents the joint from slipping under shear forces.

- Excessive weight: Fewer and smaller joint members can be used if correct preload is applied.

- Excessive coast: Fewer and smaller joint member means lower cost.

Now the question would be how much preload would be appropriate? The answer is that we always want the maximum possible preload. However the followings should be considered;

- Strength of joint members under static and dynamic loading.

- Accuracy with which we expect to tighten the bolts.

- The factor of safety and joint importance.

- Environmental effects on the joint such as; temperature, corrosion, seismic shock, etc.

\subsection{Factors that affect the working loads on bolt}

When a bolt is under working load there are many factors that can affect the tension developed in it. Now briefly the main factors that affect the working loads on the bolts will be mentioned.

- Initial preload: this load is created when we initially tighten the bolt.

- Sequence and procedure: The procedure that the bolts are tightened. 
- Residual preload: The preload left in the bolt after embedment and elastic interaction.

- External loads: External loads can increase or decrease the existing pre load in the bolt.

- Service condition: Extreme weather and temperature can affect the preload condition.

- Long-term relaxation: Corrosion, stress relaxation, creep or vibration can cause relaxation.

- The quality of part: Right size, hardness and quality of the parts will affect the preload.

\subsection{Torque versus preload}

By tightening a bolt two actions will be performed. First, bolt is tightened and second, bolt is tightened to a certain point. When we tighten the bolt, we apply the torque to the nut and it turns against the bolt and stretches the bolt and creates preload (tension) in the bolt. Preload is the most interested issue to control. The easiest and least expensive way to control the preload is with torque or turns, because these are the inputs to the system and there are two equations to predict results. The first one is the simplification of workenergy equation. Theoretical analysis and experimental experiences have shown there is a linear relationship between the torque applied to a bolt and preload developed in it. 


$$
T_{\text {in }}=F_{p} \times C
$$

$$
\text { Torque }=\text { Preload } \times \text { Constant }
$$

This equation will be transformed to the following equation by definition of $\mathrm{C}$

$$
T_{\text {in }}=F_{p}\left(\frac{P}{2 \pi}+\frac{\mu_{t}}{\cos \beta}+\mu_{n} r_{n}\right)
$$

Where:

$T_{n}$ : Torque applied to the fastener (in.-lb, mm-N),

$F_{p}$ : Preload created in fastener $(\mathrm{lb}, \mathrm{N})$,

$P$ : The pitch of the threads (in, $\mathrm{mm}$ ),

$\mu_{t}$ : The coefficient of friction between nut and bolt threads,

$n$ : The effective contact radius of the threads (in., $\mathrm{mm}$ ),

$\beta$ : The half angle of the threads ( 30 for UN or ISO threads),

$\mu_{n}$ : The coefficient of friction between the face of the nut and upper surface of the joint,

$r_{n}$ : The effective radius of contact between the nut and joint surface (in., $\mathrm{mm}$ ),

As mentioned this is a simplification and may contain small error. Whoever it provides the most reliable answer. 
This equation shows that the applied torque will be resisted by following three reactions; $F_{p} \frac{P}{2 \pi}$, this part of the equation is produced by the inclined plane of nut threads on bolt threads and called "bolt stretch component". This will produce the force to compresses the joint and the nut and it is part of the torque. $F_{p} \frac{\mu}{\cos \beta}$, next part is a reaction torque created by friction resistance between nut and the bolt threads. $\mu_{n} r_{n}$, the last part is a reaction torque created by friction resistant between the face of the nut and the washer or joint.

By using the above equation for a typical fastener and assuming a coefficient of friction and input torque, it would be observed that the nut friction torque is about $50 \%$ of the total reaction, thread friction torque is about $40 \%$ and the rest $(10 \%)$ would be so-called bolt stretch component. When the torque equation is used the amount of input that goes to the pre load is not important but the degree of control that is maintained is our concern.

\subsection{Factors affecting the torque-preload relationship}

Obviously there are some factors that affect the relationship between the torque and preload and here they are:

\subsubsection{Variables that affect friction}

There are 30 to 40 variables that affect friction and these make the calculation of coefficient of friction very difficult. The followings are some of these factors;

- Hardness of all parts 
- Surface of finishes

- Type of material

- Thickness, condition and type of plating (if present)

- The type, amount, condition, method of application, contamination and temperature of any lubricant used

- The speed of tightening the nut

- Fit between the threads

- Hole clearance surface pressures

- Presence or absence of washer

- Cut versus rolled threads

\subsubsection{Geometric variables}

The bolt is a high stressed component with a very complex shape which goes under severe stress concentration. It is not a rigid body and the basic deformation is normally elastic. However there are always some plastic deformations in bolt for example in thread roots which altering geometric factors and pitch. The fact is the nut rarely is perpendicular to the axis of thread, holes are seldom drilled perpendicular to the surface of the joint and the contact radius is normally unknown and experiments shown that these factors can introduce even more uncertainty compare to friction. 


\subsubsection{Strain energy losses}

When a nut is tightened, the work is done on the entire nut, bolt and joint system. Part of the input work is used to stretch the bolt or friction loss, but the other portions of the input work end up as bolt twist, a bent shank, nut deformation and joint deformation. Therefore to develop the true relationship between the input torque and bolt preload these factors must be taken into account. Revealing

\subsubsection{Torque}

The torque required to run down a lock nut which has a plastic insert in the threads is called "Prevailing torque". The insert creates interference between nut and threads and helps the bolt to resist vibration. The torque required to overcome this interference doesn't contribute to bolt stretch and needs to be handled as a separate term.

\subsubsection{Weight effect}

In joint members if the bolts are heavy and members are not aligned properly, the members resist being pulled together and this fact reduces the amount of applied torque and ultimately reduces the clamping force between joint members.

\subsubsection{Hole interference}

The amount of torque used to create preload is reduced if the hole is undersize or if the members are misaligned. 


\subsubsection{Interference fit threads}

Some torque will be taken to run the nut down on the loose bolt if threads are damaged or designed to have zero clearance.

\subsubsection{The mechanic}

Human is involved in the bolting procedure and therefore the operator can be a more important factor than all of the other factors.

\subsubsection{Tool accuracy}

Tools also create some errors in order to achieve requested torque depending on their construction, how recently the tools have been calibrated and the accuracy with which the gage reports their output.

\subsubsection{Miscellaneous factors}

There are some other factors that are not mentioned and over the years and through the experiments have been found which have influence in torque-preload relationship.

\subsection{Torque versus preload (the short form equation)}

The other equation which is more useful than the long one is the equation so called the short-form torque-preload.

$$
T_{\text {in }}=F_{p} \times K D
$$


Where,

$$
\begin{aligned}
& \left.T_{\text {in }}: \text { Input torque (lb-in., } \mathrm{N}-\mathrm{mm}\right), \\
& F_{p}: \text { Achieved preload }(\mathrm{lb}, \mathrm{N}), \\
& D: \text { Nominal diameter (in., } \mathrm{mm} \text { ) and } \\
& K: \text { Nut factor }
\end{aligned}
$$

And if a prevailing torque fastener is used, the equation would be:

$$
T_{\text {in }}=F_{p} \times K D+T_{p}
$$

As it can be seen $K$ is not a friction coefficient, it is actually a general purpose experimental constant.

The nut factor as defined in short-term torque-preload equation adds all the factors affect the torque-tension relationship and constitutes the proper way to report or analyze the results of torque control procedures. It has been found that nut factors determined on joints in a laboratory often differ from nut factors determined on the actual joint in the field.

\subsection{Torque calibrator}

The simple way to monitor the torque is torque calibration. The calibrator is used in construction sites to monitor the achieved preload in bolts. The main part of this device is a short hydraulic cylinder with a hole through the middle. A bolt is run through the hole 
and a washer and nuts are added to the bolt from the other side and the bolt will be tightened. By doing so the pressure in the cylinder will increase and a calibrated pressure gage interprets the increased pressure to clamping force. This is a simple and popular tool and accurate for many purposes, however the torque versus preload relationship is affected somewhat by the stiffness of the joint in which the fastener is used. The stiffness of the hydraulic cylinder is much less than the stiffness of most joints and this issue can create undesirable situation in critical applications and may over estimate the achieved preload in the steel joint. The torque produced by some tools can be affected by the characteristics of the joint and this can create a problem with calibration. This can happen by using all tools specially impacting tools. Measuring the output of the tool as it tightens the bolt is reasonable way to monitor the torque applied to the bolt in the joint system. DC-powered tools can be equipped with transducers to measure both output torque and drive angle information. Torque-monitoring equipment can be used to get a digital or control signal readout as the fastener is being tightened. If the tools are not working properly, acceptable result will not be achieved at bolt even though all other factors are working properly. Accuracy test for the tools must be based on test joints with similar hardness to that of the joints on which the tools are to be used, to verify the accuracy of the tools under the factors that affecting the accuracy.

\subsection{Theoretical considerations}

As discussed in the previous section, earlier studies have shown that there is a progressive decline in pretension achieved for the twist-off bolts exposed to the environmental effects resulting from delayed installation. The results from the studies 
have led to changes in the RCSC specification and additional requirements for the use of these assemblies. However, steel fabricators and erectors found these added requirements costly and unnecessary; bolt producers claimed that this negative behavior has improved in subsequent manufacturing modifications. These issues on the installation behavior of twist-off fasteners lead to a call for re-examination of their behavior.

The RCSC specification (RCSC, 2004) requires that a minimum of three fasteners need to be tested in a tension calibrator prior to use of the assemblies in the steel joint. The bolts must achieve a pretension greater than 1.05 times the minimum specified tension. Previous experiments (Tan, 2004) have shown that pretensions achieved in a SkidmoreWilhelm tension calibrator are consistently higher than those obtained in steelwork. As a result, this verification tool could give an unrealistic and misleading value for the performance of the assembly. It is theorized that because of the greater rigidity of the steel plates, less rotation of the nut will be observed during twist-off installation. This lower stiffness of the Skidmore-Wilhelm calibrator is well known and recognized by the RCSC specification for the turn-of-nut method where it is noted "the reading of a hydraulic tension calibrator tends to underestimate the pretension that a given rotation of the turned element would induce in a bolt in a pretensioned joint". However, since twist off installation is governed by the torsional response caused by friction, fasteners do not undergo the same amount of nut rotation in the Skidmore-Wilhelm and in steelwork. Stated differently, the turn-of-nut method prescribes certain number of nut rotations that will be performed both in the steelwork and in the Skidmore resulting in a conservative reading in the tension calibrator while the twist-off installation will result in lower nut 
rotations in more rigid joint and higher nut rotations in the Skidmore-Wilhelm calibrator. The results from this study will be used to provide additional information about the phenomenon.

Finally, the individual effects of cold weather and moisture on the achieved preload have not been examined in detail and need to be investigated further. The Skidmore stiffness effect described above could contribute to a misleading notion regarding the performance of twist-off fasteners in these conditions. Although the RCSC specifies that fasteners be protected from dirt and moisture during storage, there are no guidelines regarding installation that relates directly to these two apparent field parameters.

\subsection{University of Toronto (2007)}

Maleev (2007) performed experiments and did study on the installation behavior of twistoff tension control bolts. His study was based on the results and recommendations of earlier study conducted in 2004 in University of Toronto. The main objectives of this research program were to do further investigation regarding the effects of delayed installation after exposure to the environment. Other experiments also were performed to the behavior of twist off bolts under the effect of extreme cold weather and influence of moisture.

Fasteners from four manufacturers were tested to examine the installation characteristics of the fasteners. The primary factors studied were: 
- Delayed installation in simulated steel joints and Skidmore-Wilhelm tension calibrator,

- Extreme cold temperature effect $\left(-20^{\circ} \mathrm{C}\right)$,

- Moisture Effect, and

- Reinstallation of removed bolts.

This study showed the average preload in the "as-received" condition between all of the manufacturers passed the minimum specified tension, however, individually, two of the manufactures failed to pass the minimum requirement specified in RCSC Specification. The results also showed that the tension calibrator tends to give higher achieved tensions in bolts mainly because of the lower stiffness of the tool and the absence of relaxation effects in the tension calibrator. The other observation was that all of the delayed installation series experienced progressive decline in the achieved load with increasing exposure period (both in steel joint and Skidmore) similar to that observed by Kulak and Undershute (1994), and Tan (2004). However two of the manufactures still maintained the minimum specified tension while other two failed. Another similarity with previous studies was the $5 \%$ to $10 \%$ difference between the as delivered pretensions in the Skidmore and in the steel joints. This difference was believed to be influenced by the different stiffness of the Skidmore parts versus the steel joints. For turn of nut reinstallation, the average pretension in the twist-off assemblies from all manufacturers after reinstallation with the turn-of-nut method was 1.28 with standard deviation of 0.04 . 
So it was confirmed that the twist off bolts can be re-used as ordinary high tension bolt with turn of nut method and could achieve the minimum specified tension.

For the effect of moisture, three out of four manufactures failed to achieve minimum tension specified by RCSC and regarding the experiments for the extreme cold $\left(-20^{\circ} \mathrm{C}\right)$ results shows that cold temperature had an extremely negative effect on the achieved pretension for all manufacturers. None of the installed assemblies exceeded the minimum specified pretension of $39 \mathrm{kips}$. This shows that the achieved pretension in tension control assemblies is largely dependent on the temperature value and despite the fact that $-20^{\circ} \mathrm{C}$ can be considered as extreme case, extra care should be taken when cold weather twistoff installations are performed. This consideration formed the bases of current study.

\subsection{University of Toronto (2004)}

Tan (2004) performed an extensive study for the RCSC on the installation behavior of twist-off tension control bolts. The main objectives of this research program were to investigate the effects of delayed installation after exposure to the environment and to demonstrate the effectiveness of the bolt gage technique as a method for accurately measuring pretension. Over 400 fasteners from four manufacturers were tested to examine the installation characteristics of the fasteners. The primary factors studied were:

- Variable bolt thread and washer conditions,

- Delayed installation in simulated steel joints,

- Reinstallation of removed bolts, and

- Delayed installation in Skidmore-Wilhelm tension calibrator 
In addition, the effect of installation under selected moisture and temperature conditions was also observed.

The study concluded that all the assemblies tested in the "as-received" condition met the minimum specified pretension. The results showed that higher pretensions are achieved in the tension calibrator mainly because of the lower stiffness of the tool and the absence of relaxation effects in the Skidmore. From the delayed installation tests, it was shown that not only did the bolts tested in the tension calibrator generally achieved higher pretension but also the decrease in pretension obtained as a function of exposure period before installation was different between assemblies tested in the Skidmore and in the simulated steel joints. This is a different problem from the one described above since if fasteners experienced the same degree of deterioration with delayed installation, the slope of the decrease in pretension should be the same between the two although the preloads in the Skidmore are usually higher. The reasons for this difference are investigated as part of this research program.

For the temperature effects, Tan concluded that lower temperatures generally led to a decrease in the pretension obtained. On the other hand, when the installation temperature was higher, the fasteners achieved higher pretensions than the as-received assemblies. The presence of moisture did not have a consistent positive or negative effect on all manufacturers. When the assemblies were wetted prior to installation, an increase in the achieved preload was observed for two manufacturers, no effect on the pretension for one manufacturer and a decrease in the obtained preload for one manufacturer. These 
variations were attributed to the variable lubrication employed by the companies in their production of the assemblies.

Tan's study also showed that the bolt gage technique was an accurate method for measuring bolt pretension. Removing small amounts of material from the head of the bolt to attach the transducer from the ultrasonic device did not have an influence on the pretension. She also proposed that rather than calibrating stiffness and an intercept terms to determine the tension in the bolts according the method described by Bickford (1995), the regression analysis can be forced through the origin and only a modified stiffness term is required to determine the preload accurately. The accuracy of this method is also examined further as part of this study.

\subsection{University of Alberta Report (1994)}

This study was sponsored by the Research council on Structural Connections (RCSC) to investigate the pretension of tension-control bolts. Kulak and Undershute (1994), tested over 600 twist-off fasteners to examine the effects of variable bolt thread and washer conditions and variable conditions of exposure on the achieved preload. Variable thread and washer conditions were studied to determine to what degree the lubricant of a bolt governs the pretension. Furthermore, variable exposure conditions, such as exposure to humidity and weather of loose assemblies and exposure of bolts in simulated steel joints were believed to mimic real on-site environments. Thus, two weathering periods considered appropriate were chosen: 2 weeks and 4 weeks. Results were compared 
against the pretension attained by as delivered bolt assemblies, which were installed as supplied by the manufacturer.

Bolts from seven manufacturers were tested. The bolts that were tested for this study were $3 / 4$ in. diameter bolts with different lengths of $21 / 4$ in., $21 / 2$ in., $23 / 4$ in., 3 in., and $31 / 4$ in. and $7 / 8$ in. diameter bolts with a length of 4 in. The bolts were tested in two series: 1 . bolts subjected to various conditions of exposure; 2 . bolts with different kinds of friction conditions. The bolt pretensions were determined either by a hollow load cell for bolts installed in a solid piece of steel or in a simulated joint, or by using a SkidmoreWilhelm hydraulic bolt calibrator.

The pretension in the bolts is reported as the ratio of the achieved preload to the minimum specified preload. The study concluded that both conditions investigated had a negative impact on pretension. For the variable thread and washer conditions, which included bolts cleaned with mineral spirits to remove the lubricant, the average pretension ratio achieved decreased from 1.17 for the as-delivered fasteners to 1.12 . The study also concluded that from the different exposure conditions, the lowest pretensions were obtained in the simulated steel joints. For this case, almost one-third of the bolt lots tested did not meet the minimum specified pretension. The results of the friction tests showed that the lubrication condition of the bolt and nut threads as well as the washer played an important role on the attainment of bolt pretension. If the bolt assembly was intentionally cleaned of lubricant with mineral spirits, the average normalized pretension was only 0.81 . This was significantly less than the "as-received" pretension value of 1.31 
of the bolts from the same lot. Re-lubricating the bolt threads and washer with lithium grease and thread compound produced different pretension results of 1.14 and 1.52, respectively. If the "as received" bolt assemblies were contaminated with dirt, the average pretension dropped to 1.17 . If only the threads of the bolts were contaminated, the pretension was 1.27 , which is very close to the "as received" pretension. Further analysis of the data showed that the torsional friction at the nut-washer interface is about $90 \%$ of the total torsional friction. Proper lubrication at the nut/washer interface is a very important requirement for achieving the desired preload in tension control bolts. Thus, the University of Alberta study confirmed that the pretension obtained in tension control bolts strongly depends both on the friction conditions of the bolt/nut threads and the nut/washer interfaces. Both the lubricant quality and lubricant quantity are key factors in obtaining a well-lubricated bolt assembly. The authors also concluded that quality controlled manufacturing of all the parts of the bolt assembly as well as proper bolt installation methods are required to obtain the expected performance of tension control bolts.

\subsection{Virginia Polytechnic Institute and State University Report (2003)}

Murray and Schnupp performed series of tests to study the effects of head size on the performance of twist-off bolts. RCSC specification states that an ASTM F436 washer is required when there is oversized or slotted hole in an outer ply, however the washer can be excluded, if the heads of tension-control bolts provide a bearing circle with a diameter equal or greater than the diameter of the corresponding ASTM F436 washer. The minimum bearing surface diameter permitted in ASTM F1852 is smaller than the 
nominal outside diameter of ASTM F436 washer. The goal of this research was to test the ASTM F436 washer requirement for oversized or short-slotted hole and determine whether or not it can be omitted for tension-control bolts with smaller bearing surface diameter.

Total of 24 Tests were conducted on tension-control bolts of A325 and A490 strength with diameters ranging from $5 / 8$ in. to $11 / 8$ in. The head bearing surface diameters of the tested bolts included both the minimum required diameter allowed by ASTM F1852 and the larger manufacturer's standard head diameter. A Skidmore-Wilhelm bolt tension calibrator (Model ML) was implemented to measure the bolt pretension.

Additional plates with different hole sizes, including standard, oversized, excessively oversized and slotted ones, were placed under the bolt head. Test data indicated that bolts with the minimum bearing surface diameter on head achieved the same pretension similar to those with the larger manufacturer's standard diameter, and the size of the hole in the plate did not have any impact on the bolt pretension. Since the amount of the bearing surface under the bolt head did not appear to affect the developed bolt pretension, the authors concluded that if the size of the hole is within the RCSC Specification limits on hole size, the pretension expected to be achieved in a bolt with the minimum head bearing surface diameter is the same as that in bolt with a larger diameter equal to that of a F436 washer. 


\subsection{Reports on field studies of bolt pretension}

To investigations on the pretension of high strength bolts in the field two teams were formed were: Team 1 (Birkemoe and Grags, 1990) in University of Toronto and Team 2 (Kulak and Obaia, 1992) in University of Alberta. Bothe group used Ultrasonic Bolt Gage to measurement bolt elongation and evaluate the pretension in bolts installed in the field. Previously installed ASTM A325 and A490 bolts by the structure erector using turn-of-nut method were tested. The use of the Bolt Gage was a reliable and convenient way to measure bolt pretension in the field. Proper setting and calibration for electrical compensation of the Bolt Gage, can limit the error of the established bolt pretension within $5 \%$. First step is to measure the stretched length of bolts that had previously been installed in the field by the Bolt Gage. Then length was measured from the Bolt Gage after the bolt was loosened by turning the nut. The bolt pretension was calculated with the change in length measured in the field and the bolt stiffness calibrated in the laboratory. To determine the stiffness of bolt, data from direct tension test in the unloading process were used. To determine the bolt stiffness, in University of Alberta report, the mean value of measured stiffness's of three individual bolts in a group were used. In the University of Toronto report, the slope of the tension elongation relationship was considered as well as the intercept and a method of establishing the bolt stiffness from the combined data of all three calibrated bolts was proposed. The unloading curves were represented by linear regression accurately. Since the measured stiffness is nonlinear, the Y-intercept values were not zero, and vary from bolt to bolt. After data analysis, it was concluded that when the unloading data for all the calibrated bolts in a group was combined for regression analysis, the $\mathrm{Y}$ intercepts obtained were closer to zero compare 
to those calculated for the individual bolts. In this report the stiffness and Y-intercepts, obtained from linear regressions of the combined data were used to establish pretensions of bolts installed in the field. The test results showed that the mean pretension of ASTM A325 bolts using turn-of-nut method in bridges is about 1.27 times the specified minimum tension. This mean value of pretension was higher compare to those obtained from other building structures, and slightly lower than that yielded from laboratory tests (1.35). Also, the results for installation of ASTM A325 bolts by turn-of-nut method and by the use of direct tension indicators are very similar.

\subsection{Slip performance}

The main concern for engineers is the occurrence of slip, not the obtaining the required pretension. Therefore, it was considered important to also observe the environmental effects on slip resistance of steel plates. This is also a major issue in the field, where the steel is considered to be blast-cleaned, but at the time of inspection or installation it has already begun to rust. Thus, some tests were conducted to comparing the slip behavior of rusted versus blast-cleaned plates.According to the RCSC Bolt Specification, the nominal slip resistance, is defined as;

$$
R_{n}=\mu D_{u} T_{m} N_{b}\left(1-\frac{T_{u}}{D_{u}+T_{m}+N_{b}}\right)
$$

Where $T_{u}$ is the tensile component of applied factored load for combined shear and tension loading. It is assumed that the connection is loaded only in shear for simplicity. Then equation 2.4 becomes: 


$$
R_{n}=\mu D_{u} T_{m} N_{b}
$$

Where,

$\mu=$ Mean slip coefficient for class A, B or C, faying surfaces, as applicable, or as established by testing in accordance with Appendix A of the specification $=0.33$ for Class A faying surfaces (uncoated mill scale surfaces or surfaces with Class A coatings on blast-cleaned steel) $=0.50$ for Class B surfaces (uncoated blast-cleaned steel surfaces or surfaces with Class B coatings on blast-cleaned steel) $=0.35$ for Class $\mathrm{C}$ surfaces (roughened hot-dip galvanized surfaces) $D_{u}=1.13$, a multiplier that reflects the ratio of the mean installed bolt pretension to the specified minimum bolt pretension $T_{m}=$ Specified minimum bolt pretension ( 28 kips for $3 / 4$ inch A325, F1852 diameter bolts) $N_{b}=$ Number of bolts in the joint

The mean slip coefficient assumed for blast-cleaned surfaces is the highest specified and is 0.50 . The use of blast cleaned steel is recommended to achieve a high slip resistance but raises a question about the possible deterioration of the slip performance if the blast cleaned surface rusts. Few tests conducted to investigate the effects of rusting on this mean slip coefficient and added to this research by performing laboratory slip tests on weathered and blast cleaned samples used in the delayed tensioning series. 


\section{CHAPTER-3}

\section{MEASUREMENT OF BOLT PRETENSION}

\subsection{General}

In this research, in order to determine the developed tension in bolt, the elongation of bolt needed to be measured. Theoretically, the elongation measured in bolt times the bolt stiffness calculates the developed tension in bolt assembly. Bolt stiffness can be calculated by the direct tension test and the relationship of load vs. elongation. The theoretical estimation of bolt stiffness is derived from simple mechanics as it will be presented later. Bolt Gage 3 from BIDWELL Industrial Group Inc (www.bidwellinc.com) is an ultrasonic instrument used for this method to measure the elongation of a bolt. Ultrasonic measurement provides a very precise method of measuring the elongation of a bolt. It has been designed to cancel the influence of stress on the material transmission of ultrasonic waves. Thus, the elongation is nearly linear with respect to the bolt load if the bolt remains in the elastic range. Some small nonlinearity is observed as the boundary conditions change during the seating in at the ends of the fastener and in the threads. The most important features of this approach include:

a) The realistic material response was uninfluenced by a force measurement that tends to reduce the effective stiffness of the bolted parts,

b) The technique does not require special handling or modification of the bolt that would influence the physical parameters of interest and 
c) The measurement technique is portable and automatically compensated for temperature.

\subsection{Basic concept: Stretch control method}

In stretch control method, the bolt assumed to be a very stiff spring. Hence, the relationship between the change in length of the bolt and the developed load in it can be calculated by following equation:

$$
\Delta L=T\left(1 / K_{b}\right)
$$

Where,

$$
\begin{aligned}
& \Delta L=\text { the change in length of the bolt (in., mm) } \\
& K_{b}=\text { the stiffness of the bolt }(\mathrm{lb} / \mathrm{in} ., \mathrm{N} / \mathrm{mm}) \\
& T=\text { tensile preload in the bolt }(\mathrm{lb}, \mathrm{N})
\end{aligned}
$$

The equation is based on the fundamental concept of stretch control method on which the bolt assembly is modeled as a spring with very high stiffness. The accuracy of developed tension in the assembly is directly related to the precise measurement of the elongation of the bolt. Throughout this research, an ultrasonic Bolt Gage 3 was utilized to accurately measure the change in length of the assembly. 


\subsection{Bolt gage measurement technique}

The Bolt Gage 3 is a very accurate and consistent instrument that uses ultrasonic waves to measure the elongation and stretch in bolt. The Bolt Gage has an accuracy of one in hundred thousand of an inch (0.00001") with stable repeatability of one in ten thousand of an inch (0.0001"). This, results in a preload resolution in the order of one thousandth of a kip for typical bolt sizes can be achieved. Series of ultrasonic pulses are sent into one end of a bolt and effectively measures the time for the echoes to return. This device contains a microprocessor and software that analyze the returning echo duration and compare the information to a reference value for the bolt. The Bolt Gage (Model 3) analyzes this data and provides the new bolt length and the bolt stretch, stress and load calculated based on the input parameters. Figure 3-1 shows a view of Bolt Gage (Model 3) including a 3 inch calibration reference cylinder. As it can be seen in Figure 3-1, the bolt gage has a transducer connected to the Bolt Gage. This transducer would be mounted on the head of the bolt assembly. The head of the assembly must be machined to a very smooth surface before the transducer is mounted on the head of the bolt. Non-parallel, uneven or rough surfaces will not properly transfer the ultrasonic waves to measure the length or elongation of the bolt. The transducer contact area determines the amount of signal that can be coupled from the transducer to the bolt. It is ideal to have a very flat area on the head of the bolt that is large enough for the transducer area to be in flat contact. 


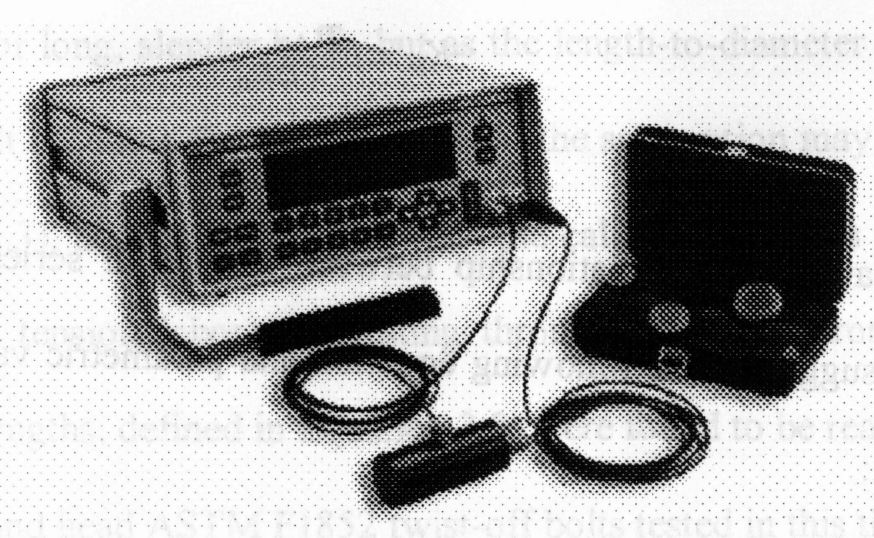

Figure 3-1 View of Bolt Gage 3

The tip of the bolt also needs to be reasonably flat, smooth and parallel to the head surface to provide proper reflection of the sound waves. It is necessary to measure the stretched length of the bolt first with the splined end removed. The stretched length is recorded on the Bolt Gage before the tension is released. The transducer must remain on the bolt head to minimize remounting effects. Then, the bolt is loosened with a manual, dial-indicating torque wrench and the unloaded length is similarly measured. An electric non impacting wrench may be required for larger diameters and in restricted areas to release the nut. The display of the Bolt Gage shows the change in bolt length as nut loosening. Removal torque higher than expected may result in inelastic behavior and it may lead to rejection and invalid conclusions.

\subsection{Theoretical estimate of bolt stiffness}

As mentioned earlier, the bolt assembly considered to be a very stiff spring. Recalling the equation (3.1), the spring constant or bolt stiffness can be defined as: 


$$
K_{b}=T / \Delta L_{c}
$$

Using Hooke's law and the relationship between springs in series to equation (3.2), Bickford (2008) suggested the following equation and parametric values to compute the stiffness of a bolt:

$$
\frac{1}{K_{b}}=\frac{L_{b e}}{E A_{b}}+\frac{L_{s e}}{E A_{S}}
$$

Where,

$L_{b e}=$ effective body length (approximated as the true body length plus one-half the thickness of the head of the bolt) (in., mm)

$A_{b}=$ body cross-sectional area $\left(\right.$ in. $^{2}, \mathrm{~mm}^{2}$ )

$E=$ Modulus of elasticity (ksi, MPa)

$L_{s e}=$ effective thread length (approximated as length of exposed threads plus one-half the thickness of the nut) (in., mm)

$\mathrm{A}_{\mathrm{s}}=$ effective cross-sectional area of threads (in. ${ }^{2}, \mathrm{~mm}^{2}$ )

Bickford calculated the effective length with the assumptions that the average stress level in the head of the bolt is one-half the body stress, and one-half of the threads engaged by the nut are loaded at the "exposed thread" stress level. Since the stress distribution depends on the geometry of the particular bolt and the fit with the nut, there is no simple way to study the actual stress distribution. It was also mentioned that the above 
assumption is good for long, slender bolts, but as the length-to-diameter ratio of the bolt decreases, and the bolt becomes shorter and stubbier, the assumption may not be valid. Based on equation (3.3), and the correlation with the calibration results of bolt stiffness obtained from direct tension laboratory testing through trial and error, the following calculated effective lengths, defined in Equation 3.3, were found to be reasonable and can be used for all the round head ASTM F1852 twist-off bolts tested in this thesis:

$$
\begin{aligned}
& L_{s e}=L_{s}+0.45 \times H_{n} \\
& L_{b e}=L_{b}+0.40 \times H_{h}
\end{aligned}
$$

Where,

$$
\begin{aligned}
& L_{s}=\text { length of exposed threads } \\
& H_{n}=\text { thickness of the nut } \\
& L_{b}=\text { body length } \\
& H_{h}=\text { thickness of the head of the bolt measured from the bottom }
\end{aligned}
$$

In equation (3.3), Bickford suggested to use one half of the head height to compute the effective body length for hex head bolt. Prior to determination of the parameters 0.45 and 0.40 in equation (3.4) and (3.5), respecting, several combinations of such coefficients as $0.5,0.45,0.40$, and 0.35 were verified in equations (3.4) and (3.5) to reach a better interpretation of the bolt stiffness. 
The result for stiffness calculation of 3/4 inch diameter button head ASTM F1852 twistoff bolts of three different lengths and with varying grip lengths when parameters of 0.45 and 0.40 was used in equation (3.4) and equation (3.5), separately are shown in Table 31. The detailed comparisons between the various combinations of those coefficients listed above are shown in Table 3-2.

The difference between the theoretical calculated bolt stiffness $K_{t}$ and the measured and calibrated bolt stiffness in direct tension $K_{c}$ ranges from $-2 \%$ to $1 \%$, and average variation was around $-1 \%$. For other combinations of parameters of $0.5,0.45,0.4$, and 0.35 as presented in Table 3-2, the average variations are about $-5 \%,-4 \%,-1 \%$ and $0 \%$, for five bolts considered herein. It should be noted that the combination of 0.45 and 0.35 was ignored because it would possibly overestimate the bolt stiffness for some bolts. Maleev suggested that the assumptions of the effective lengths shown in equation (3.4) and equation (3.5) are proved suitable for ASTM F1852 round head bolts with length-todiameter ratio of 3 through 4.5. In the field, when using the Bolt Gage measurement method and when the direct bolt calibration is not possible, the theoretical calculated bolt stiffness with mentioned assumptions can be used for the estimation of the bolt preload. Based on these observations, Bickford developed more empirical equations for the effective body and thread lengths in order to calculate an estimate of the stiffness of the bolt. Detailed investigation and evaluation of this technique was performed and confirmed in previous studies. (Maleev, 2007) 
Table 3-1 Bolt stiffness theoretical calculation and its correlation with the assumed bolt stiffness (Maleev, 2007)

\begin{tabular}{|c|c|c|c|c|c|c|c|c|c|c|c|c|}
\hline Bolt Size & $\begin{array}{l}\mathrm{H}_{\mathrm{h}} \\
\text { (in) }\end{array}$ & $\begin{array}{l}\mathrm{L}_{\mathrm{b}} \\
\text { (in) }\end{array}$ & $\begin{array}{l}\mathrm{L}_{\mathrm{be}} \\
\text { (in) }\end{array}$ & $\begin{array}{l}. A_{b} \\
\text { (in) }\end{array}$ & $\begin{array}{l}\mathrm{L}_{\mathrm{G}} \\
\text { (in) }\end{array}$ & $\begin{array}{l}\mathrm{L}_{\mathrm{s}} \\
\text { (in) }\end{array}$ & $\begin{array}{l}\mathrm{H}_{\mathrm{n}} \\
\text { (in) }\end{array}$ & $\begin{array}{l}\mathrm{L}_{\mathrm{se}} \\
\text { (in) }\end{array}$ & $\begin{array}{c}\mathrm{A}_{\mathrm{s}} \\
\left(\mathrm{in}^{2}\right)\end{array}$ & $\begin{array}{l}\mathrm{K}_{\mathrm{t}} \\
\text { (kip/ } \\
\text { in) }\end{array}$ & $\begin{array}{l}\mathrm{K}_{\mathrm{c}} \\
\text { (kip/ } \\
\text { in) }\end{array}$ & $\begin{array}{c}\Delta \mathrm{K} / \mathrm{K}_{\mathrm{c}} \\
\%\end{array}$ \\
\hline $3 / 4 \times 21 / 2$ & 0.48 & 0.88 & 1.07 & 0.442 & 1.250 & 0.380 & 0.73 & 0.71 & 0.334 & 6634 & 6729 & -1 \\
\hline $3 / 4 \times 21 / 2$ & 0.49 & 1.16 & 1.36 & 0.442 & 1.625 & 0.465 & 0.73 & 0.79 & 0.334 & 5513 & 5651 & -2 \\
\hline $33 / 4 \times 21 / 2$ & 0.48 & 1.44 & 1.63 & 0.442 & 1.875 & 0.435 & 0.73 & 0.76 & 0.334 & 5019 & 5061 & -1 \\
\hline $3 / 4 \times 21 / 2$ & 0.48 & 1.63 & 1.82 & 0.442 & 2.00 & 0.370 & 0.73 & 0.70 & 0.334 & 4829 & 4862 & -1 \\
\hline $3 / 4 \times 21 / 2$ & 0.48 & 1.63 & 1.82 & 0.442 & 2.250 & 0.620 & 0.73 & 0.95 & 0.334 & 4310 & 4292 & 0 \\
\hline
\end{tabular}

Note: $L_{b}=$ measured unthreaded bolt body length; $\mathrm{L}_{\mathrm{be}}=L_{b}+0.4 H_{h} ; H_{h}=$ measured bolt head height; $L_{s}=$ length of exposed threads; $L_{s e}=L_{s}+.45 H_{n} ; H_{n}=$ measured nut height; $L_{G}=$ grip length; $K_{c}=$ average calibrated bolt stiffness in direct tension; $\Delta K / K_{c}=$ the variation of $K_{t}$ expressed as a percentage of $K_{c} ; K_{t}=$ Calculated theoretical bolt stiffness. 
Table 3-2 Determination of parameters in bolt stiffness calculation (Maleev, 2007)

\begin{tabular}{|c|c|c|c|c|c|c|c|c|c|c|}
\hline \multirow[b]{2}{*}{ Bolt Size } & \multirow[b]{2}{*}{$\begin{array}{l}\mathrm{L}_{G} \\
\text { (in) }\end{array}$} & \multirow[b]{2}{*}{$\begin{array}{c}\mathrm{K}_{\mathrm{c}} \\
\text { (kip/in) }\end{array}$} & \multicolumn{2}{|c|}{$\begin{array}{l}L_{s e}=L_{s}+.5 H_{n} \\
L_{b e}=L_{b}+.5 H_{h}\end{array}$} & \multicolumn{2}{|c|}{$\begin{array}{c}L_{s e}=L_{s}+.5 H_{n} \\
L_{b e}=L_{b}+.45 H_{h}\end{array}$} & \multicolumn{2}{|c|}{$\begin{array}{c}L_{s e}=L_{s}+.45 H_{n} \\
L_{b e}=L_{b}+.4 H_{h}\end{array}$} & \multicolumn{2}{|c|}{$\begin{array}{l}L_{s e}=L_{s}+.45 H_{n} \\
L_{b e}=L_{b}+.35 H_{h}\end{array}$} \\
\hline & & & $\begin{array}{c}K_{t} \\
\text { (kip/in) }\end{array}$ & $\begin{array}{c}\Delta \mathrm{K} / K_{c} \\
(\%)\end{array}$ & $\begin{array}{c}\mathrm{K}_{\mathrm{t}} \\
\text { (kip/in) }\end{array}$ & $\begin{array}{c}\Delta \mathrm{K} / K_{c} \\
(\%)\end{array}$ & $\begin{array}{c}K_{t} \\
\text { (kip/in) }\end{array}$ & $\begin{array}{c}\Delta \mathrm{K} / K_{c} \\
(\%)\end{array}$ & $\begin{array}{c}K_{t} \\
\text { (kip/in) }\end{array}$ & $\begin{array}{c}\Delta \mathrm{K} / K_{c} \\
(\%)\end{array}$ \\
\hline$\$ 3 / 4 \times 21 / 2$ & 1.250 & 6729 & 6329 & -6 & 6402 & -5 & 6634 & -1 & 6715 & 0 \\
\hline$\Phi 3 / 4 \times 21 / 2$ & 1.625 & 5651 & 5299 & -6 & 5351 & -5 & 5513 & -2 & 5570 & -1 \\
\hline $3 / 4 \times 21 / 2$ & 1.875 & 5061 & 4843 & -4 & 4886 & -3 & 5019 & -1 & 5065 & 0 \\
\hline$\phi 3 / 4 \times 21 / 2$ & 2.00 & 4862 & 4665 & -4 & 4705 & -3 & 4829 & -1 & 4871 & 0 \\
\hline $3 / 4 \times 21 / 2$ & 2.250 & 4292 & 4180 & -3 & 4211 & -2 & 4310 & 0 & 4344 & 1 \\
\hline Average & & & & -5 & & -4 & & -1 & & 0 \\
\hline
\end{tabular}

Note: $K_{c}=$ average calibrated bolt stiffness in direct tension; $K_{t}=$ calculated theoretical bolt stiffness; $\Delta K / K_{c}=$ the variation of $K_{t}$ expressed as a percentage of $K_{c}$

\subsection{Laboratory calibration of bolt stiffness}

Bolt stiffness is one of the parameters that need to be calculated in order to calculate the developed tension in bolt. To calibrate bolt stiffness in the laboratory, the Bolt Gage is used for an accurate length measurement. In order to install the transducer of the Bolt Gage on the bolt head, a reasonably flat surface on bolt head is provided. The tip of the bolt also has to be smooth and flat after the spline is removed to provide proper and efficient area to reflect the sound waves. Previous studies showed that the quantity of removed material on both ends is minimal and also tests confirmed that this has no considerable effect on the behavior of the assembly for the purposes of this study. After the bolt was machined on both head and end, it was installed in a tensile loading adapter. 
Then the assembly was placed in the MTS universal frame located in structural lab in engineering building of Ryerson University. Three 7/8" diameter bolts from each manufacturer were tested for the stiffness calibration procedure. Calibration was performed by unloading slope of the load vs. elongation plot. It should be noted that at each applied load the elongation of the bolt was measured using the Bolt Gage. However, for the accuracy assurance of procedure and to make sure that bolt is in elastic linear region, three points on loading and unloading slope were chosen for comparison. The bolt elongation for chosen points was measured and compared to make sure that elongations were reasonably close. It should be noted that the unloading slope was chosen because it is considered to reflect the loosening of the assembly in the test specimens, which is the usual order of measurements.

The grip length in the tensile adapter was adjusted to be identical to that of the test specimens and the Skidmore-Wilhelm tension calibrator. Previous studies showed that in this method the stiffness of the assembly varies considerably with the grip length and therefore it is important to obtain the correct grip. Hence, in this study, it was decided that two other grip length to be added to exact grip to make sure that correct grip is covered. These two grips were (i) Half of Turn Loose (longer grip) and (ii) Half of Turn Tight (shorter grip). As expected, for the same bolt, the bolt stiffness decreased as the grip length of the bolt increased. The bolt was loaded up to a load of 50 kips and then unloaded. Although this load is well above the required 39 kip proof load for $7 / 8$ " diameter bolts, preliminary tests in the Skidmore-Wilhelm tension calibrator had shown 
that it is not unusual for bolts in the as received condition to reach pretensions of 50 kips and even higher.

Considering these bolts were loaded up to $50 \mathrm{kips}$, an elastic behavior was expected since these steel assemblies were only loaded to approximately $70 \%$ of their ultimate tensile strength which is well below the yield threshold of the material. That is the reason why linear regression analysis was used for each set of bolts to obtain a stiffness constant for each manufacturer.

The final pretension in an assembly can be calculated using the following equation: (Bickford, 2008)

$$
T=K_{u} \times \Delta L+Y
$$

Where,

$$
\begin{aligned}
& K_{u}=\text { bolt stiffness obtained from linear regression analysis of unloading data, } \\
& Y=\text { intercept obtained from the linear regression analysis of unloading data, } \\
& \Delta L=\text { the change in bolt length }
\end{aligned}
$$

Earlier studies showed that during stiffness calibration, even the slightest nonlinearity in the behavior of a fastener affected significantly the Y-intercept for that assembly. Also, it was noticed that the slope (or the stiffness) remained relatively constant from bolt to bolt. As result, Tan (2004) suggested that the calibrations are forced through the origin so that 
a single stiffness constant can be determined for each manufacturer and pretensions calculated without the Y-intercept according to the equation:

$$
T=K_{u}^{0} \times \Delta L
$$

Where,

$K_{u}^{0}=$ average bolt stiffness obtained from linear regression analysis of combined unloading data with the best fit line being forced through the origin $\Delta L=$ the change in bolt length.

In previous studies, one of the objectives was to investigate this approach, so bolts from each manufacturer were calibrated using both Equations 3.1 and 3.2. The results showed that the two methods give almost identical pretension values. Therefore, since the modified stiffness constant approach facilitates the calibration process, it will be used in this study.

\subsection{Stiffness calibration procedure}

The procedure of stiffness calibration started with marking the exact grip on the bolt. To do so, the heads of the bolts were machined to smooth and flat surface for transducer mounting. Then, they were installed in steel joint and tightened with regular wrench. TC wrench was used to reach final preload and shear off the end spline. As the end when spline shears off, the exact grip was achieved. To record the exact grip length, bolts and the nuts were marked against each other. As mentioned earlier the grip length had major 
impact in stiffness calibration. The end of the bolt also needed to be machined to a smooth surface as shown on Figure 3-2.

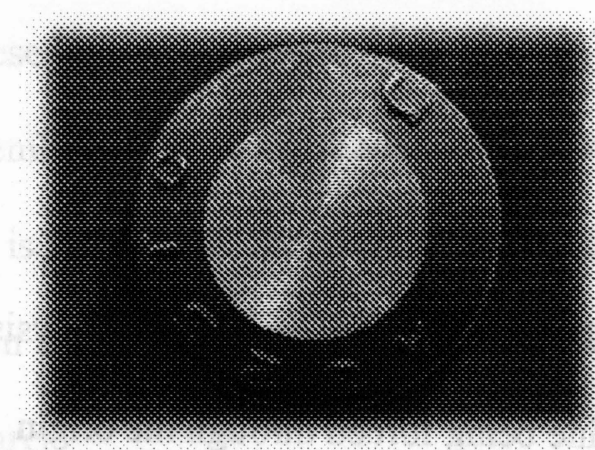

a) View of Bolt head

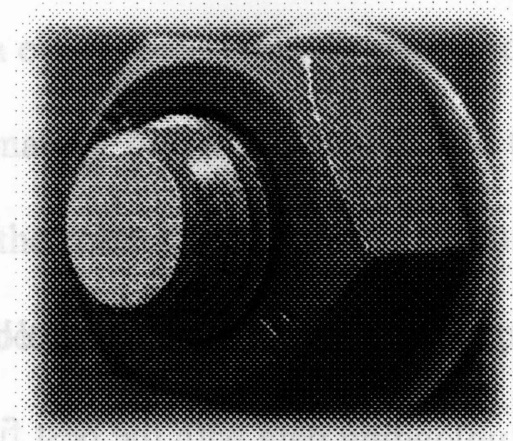

b) View of Bolt end

Figure 3-2 Views of head and end of assembly after machining

Next step was to install the bolt in the Tensile Bolt Testing Adaptor. This apparatus shown in Figure 3-3, consists of two flat plates with six holes in them as well as on hole in the middle to pass through the bolt and two other plates with six vertical legs attached to them. The target bolt assembly was installed in two flat plates with proper grip length. Then, they were mounted in the adaptor in a way that the system laid the bolt in tension. 


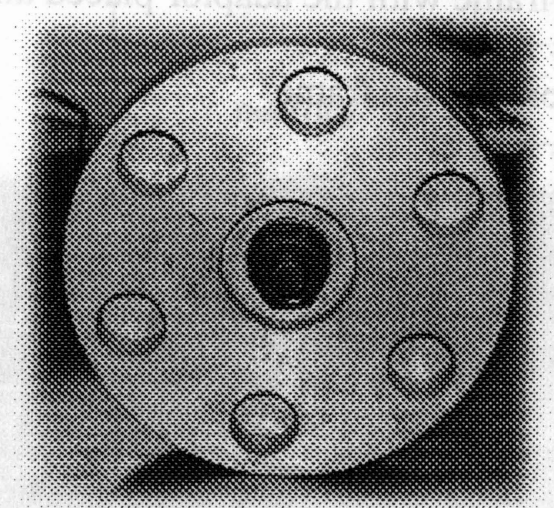

a) Bottom view

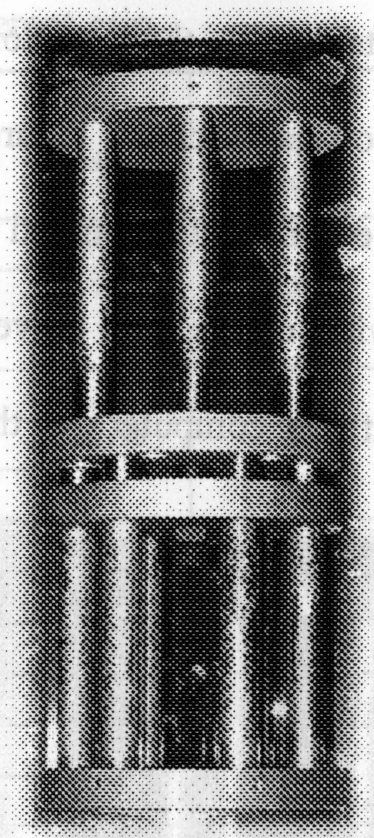

b) Elevation view

Figure 3-3 View of the tensile bolt testing adaptor for stiffness calculation

The Tensile Bolt Testing Adaptor, with the installed bolt was placed and centered inside the MTS universal frame. The MTS frame is used to apply compression force to the adaptor ends that was transferred to tensile force acting on the bolt assembly. Before test, the Bolt Gage was attached on top of the assembly. Since existence of any gap or air between the bolt head and transducer prevents ultrasonic waves to be transmitted to the bolt, special type of lubricant (recommended by the Bolt Gage manufacturer) was applied on the bolt head to eliminate any possible gap between the transducer and the bolt head. The MTS universal frame was fully automated and it was controlled by a programmable computer attached to it. This equipment can be programmed according to the needs of the operator. For the purpose of this study, it was programmed to load the adaptor to 20,40 and 50 kips. On the unloading step, the machine was programmed to unload by 5 kips interval. It was also programmed to slowdown as the applied load reaches the specified 
loading points to give the operator enough time to read and record the bolt elongation showed in Bolt gage screen. Figure 3-4(a) shows the Tensile Bolt Testing Adaptor with the Bolt Gage transducer mounted on the head of the bolt and the picture, while Figure 34(b) shows view of the MTS universal frame with the adaptor placed and centered inside the frame with the computer unit that controls the frame.

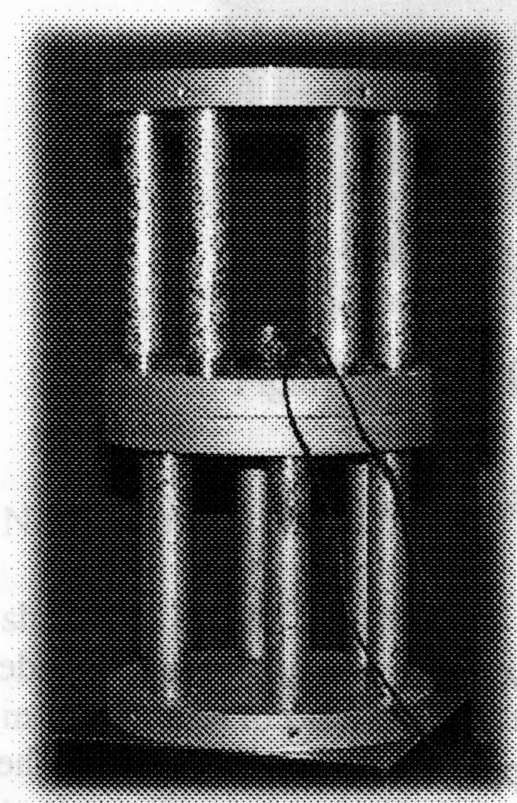

a) View of the adaptor

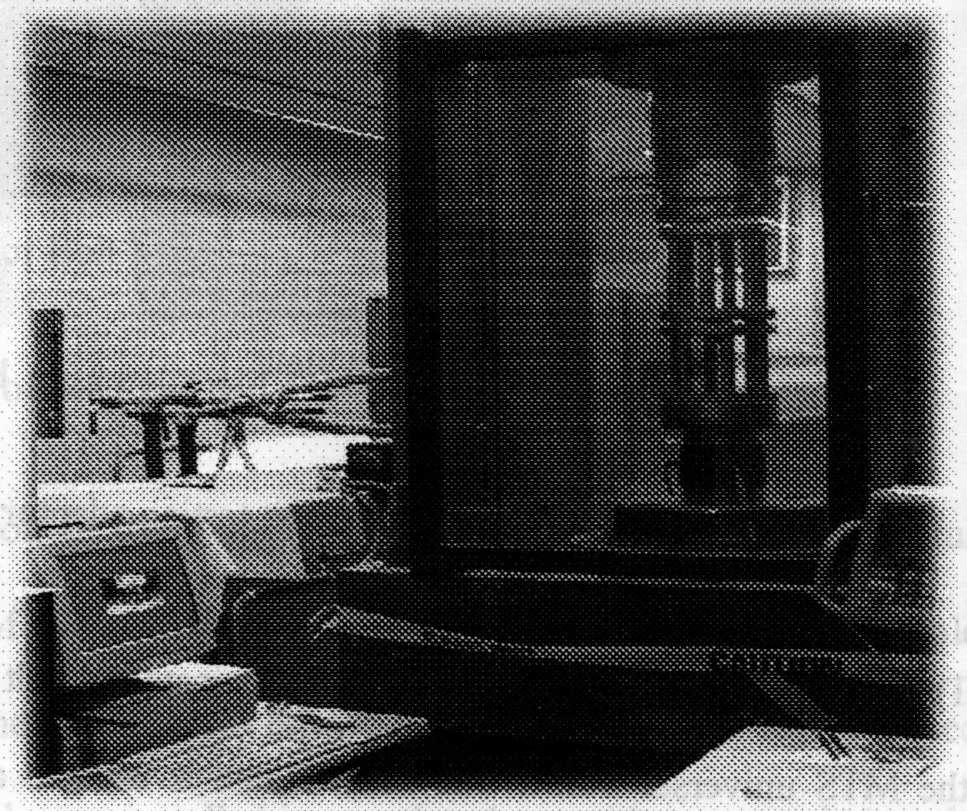

b) View of the MTS universal frame

Figure 3-4 Views of the tensile bolt testing adaptor and the MTS Machine

Table 3-3 presents a summary of the bolt stiffness as obtained experimentally for different grip length. It should be noted that three bolts were tested for each bolt manufacturer. While, Figure 3-5 to 3-8 present the same finding in graphical format as a relation between the achieved axial tensile force and the corresponding bolt elongation. It can be observed that the grip length affects the bolt stiffness by maximum of $4.9 \%$. Results vary from one manufacturer to the other. 
Table 3-3 Bolt stiffness for different grip

\begin{tabular}{|c|c|c|c|c|}
\hline Bolt Manufacturer & Grip length & $\begin{array}{c}\mathrm{K} \\
\text { (kips/in) }\end{array}$ & $\begin{array}{l}\text { K Ave. } \\
\text { (kips/in) }\end{array}$ & $\begin{array}{c}\text { Difference to } \\
\text { the average } \\
\text { (\%) }\end{array}$ \\
\hline \multirow{9}{*}{$\mathbf{A}$} & \multirow{3}{*}{ Half of Turn Tight } & 7324 & \multirow{3}{*}{7313} & \multirow{3}{*}{1.6} \\
\hline & & 7212 & & \\
\hline & & 7404 & & \\
\hline & \multirow{3}{*}{ Exact Grip } & 7335 & \multirow{3}{*}{7196} & \multirow{3}{*}{0} \\
\hline & & 7225 & & \\
\hline & & 7027 & & \\
\hline & \multirow{3}{*}{ Half of Turn Loose } & 7046 & \multirow{3}{*}{7091} & \multirow{3}{*}{-1.5} \\
\hline & & 7102 & & \\
\hline & & 7125 & & \\
\hline \multirow{9}{*}{ B } & \multirow{3}{*}{ Half of Turn Tight } & 7161 & \multirow{3}{*}{7084} & \multirow{3}{*}{2.9} \\
\hline & & 7049 & & \\
\hline & & 7042 & & \\
\hline & \multirow{3}{*}{ Exact Grip } & 7005 & \multirow{3}{*}{7029} & \multirow{3}{*}{2} \\
\hline & & 6986 & & \\
\hline & & 7096 & & \\
\hline & \multirow{3}{*}{ Half of Turn Loose } & 6564 & \multirow{3}{*}{6554} & \multirow{3}{*}{-4.9} \\
\hline & & 6538 & & \\
\hline & & 6560 & & \\
\hline \multirow{9}{*}{$\mathbf{C}$} & \multirow{3}{*}{ Half of Turn Tight } & 7627 & \multirow{3}{*}{7539} & \multirow{3}{*}{1.9} \\
\hline & & 7388 & & \\
\hline & & 7602 & & \\
\hline & \multirow{3}{*}{ Exact Grip } & 7589 & \multirow{3}{*}{7508} & \multirow{3}{*}{1.5} \\
\hline & & 7526 & & \\
\hline & & 7409 & & \\
\hline & \multirow{3}{*}{ Half of Turn Loose } & 7155 & 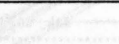 & $a t$ \\
\hline & & 7160 & 7145 & -3.4 \\
\hline & & 7120 & & \\
\hline & & 7495 & & \\
\hline & Half of Turn Tight & 7477 & 7457 & 3.4 \\
\hline & & 7400 & & \\
\hline & & 7335 & & \\
\hline $\mathbf{A h}$ & Exact Grip & 7123 & 7244 & 0 \\
\hline & & 7274 & & \\
\hline & & 6922 & & \\
\hline & Half of Turn Loose & 6941 & 6926 & -3.9 \\
\hline & & 6917 & & \\
\hline
\end{tabular}




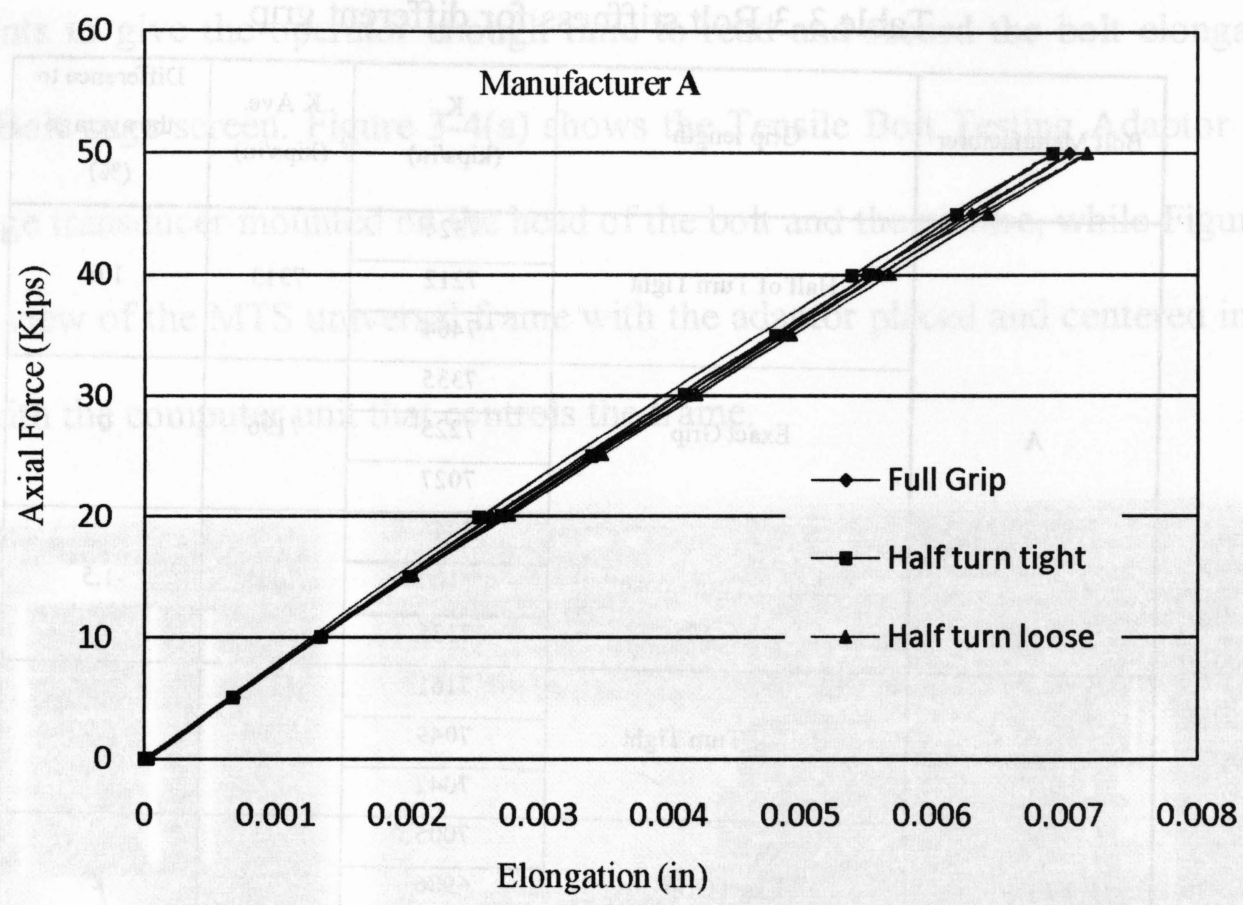

Figure 3-5 Stiffness calibration relationship for bolts supplied by manufacturer A

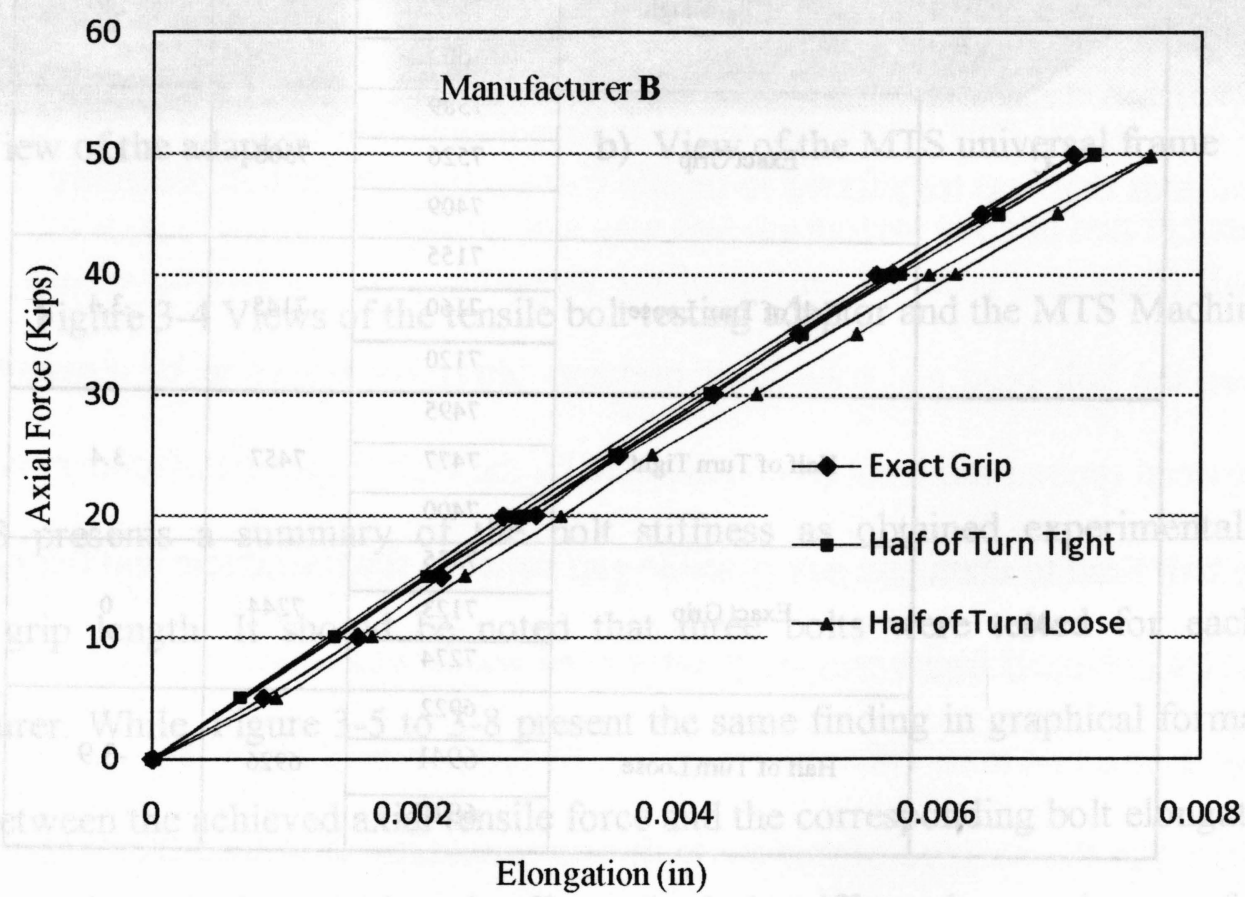

Figure 3-6 Stiffness calibration relationship for bolts supplied by manufacturer B 


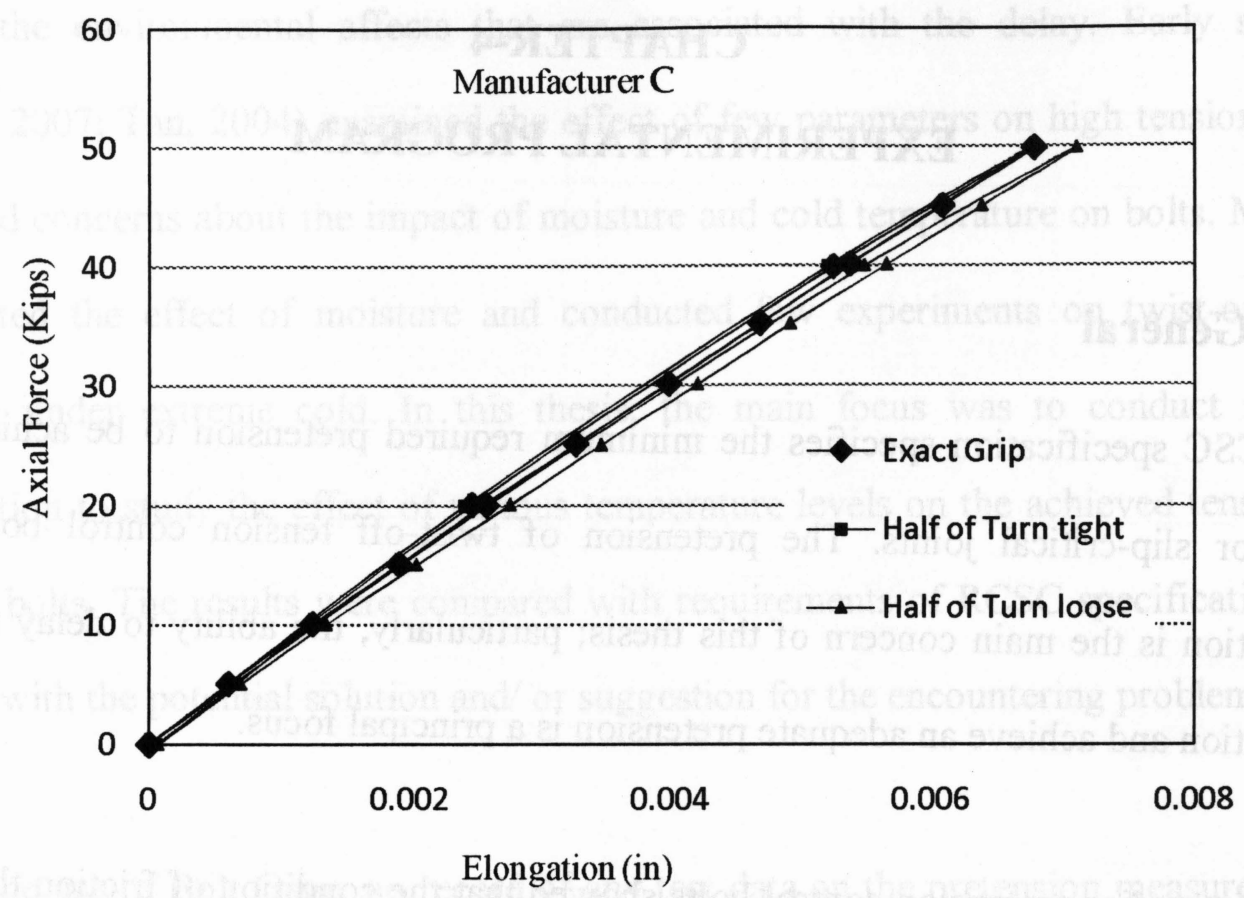

Figure 3-7 Stiffness calibration relationship for bolts supplied by manufacturer C

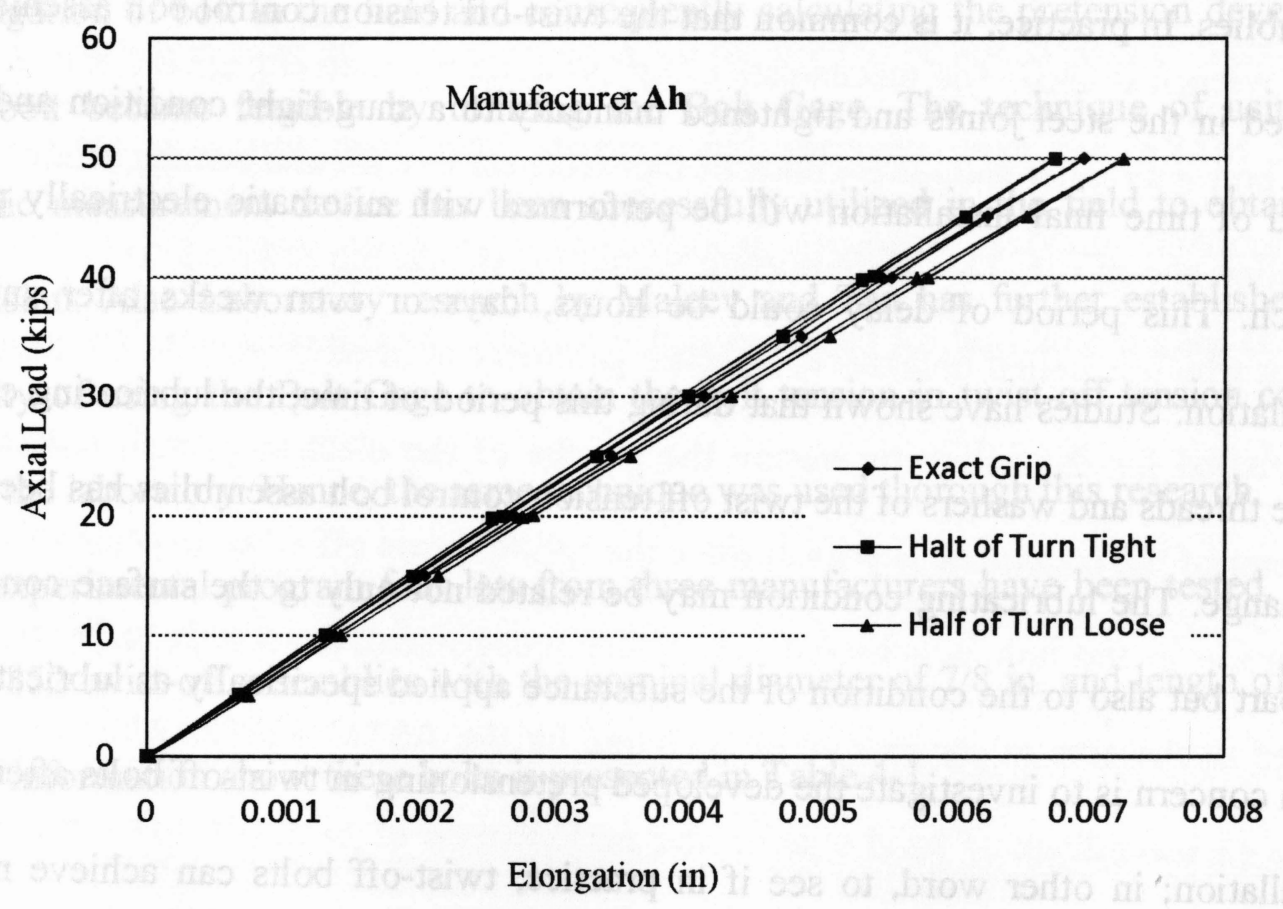

Figure 3-8 Stiffness calibration relationship for bolts supplied by manufacturer Ah 


\section{CHAPTER-4 \\ EXPERIMENTAL PROGRAM}

\subsection{General}

The RCSC specification specifies the minimum required pretension to be achieved by bolts for slip-critical joints. The pretension of twist-off tension control bolts after installation is the main concern of this thesis; particularly, the ability to delay the final installation and achieve an adequate pretension is a principal focus.

Previous studies on tension control bolts showed that the condition of friction that exists on the threads has a considerable effect on the achieved tension. Furthermore, additional effect on pretensioning was observed for the condition of the nut to washer at twist-off assemblies. In practice, it is common that the twist-off tension control bolt assemblies are inserted in the steel joints and tightened manually to a snug-tight condition and after a period of time final installation will be performed with automatic electrically powered wrench. This period of delay could be hours, days or even weeks after snug tight installation. Studies have shown that during this period of time, the lubricating condition of the threads and washers of the twist off tension control bolt assemblies has been shown to change. The lubricating condition may be related not only to the surface condition of the part but also to the condition of the substance applied specifically as lubrication. The main concern is to investigate the developed pretensioning in twist-off bolts after delayed installation; in other word, to see if in practice, twist-off bolts can achieve minimum tension specified by RCSC after delay installation of the bolt in the structure and to 
observe the environmental affects that are associated with the delay. Early studies (Maleev, 2007; Tan, 2004) examined the effect of few parameters on high tension bolts and raised concerns about the impact of moisture and cold temperature on bolts. Maleev investigated the effect of moisture and conducted few experiments on twist-off bolt assembly under extreme cold. In this thesis, the main focus was to conduct further investigation to study the effect of various temperature levels on the achieved tension in twist-off bolts. The results were compared with requirements of RCSC specifications to come up with the potential solution and/ or suggestion for the encountering problems.

Prior to the use of Bolt Gage, no record of any test data on the pretension measurements of twist-off tension control bolts in the field was available. It appears that technical difficulties in measuring the bolt tension have been the main in-situ drawback. Measuring the elongation of bolt in the field and consequently calculating the pretension developed in the bolt became feasible by utilizing the Bolt Gage. The technique of using an ultrasonic measurement device has been successfully utilized in the field to obtain the bolt tension. Also Laboratory research by Maleev and Tan has further established the feasibility of using the Bolt Gage to obtain the bolt tension in twist-off tension control bolts in the laboratory. Hence, the same technique was used thorough this research.

In this experimental program four lots from three manufacturers have been tested. Bolts were F1852 twist-off assemblies with the nominal diameter of 7/8 in. and length of 3 in. General information about these bolts is presented in Table 4-1. 
Table 4-1 Bolt lot information

\begin{tabular}{|c|c|c|}
\hline Manufacturer & Bolt size (in) & Bolt Assembly \\
\hline A & $\phi 7 / 8-10$ UNC x 3 & F1852-1SL + A563-DH + F436-1 \\
\hline B & $\phi 7 / 8-10$ UNC x 3 & F1852-1SL + A563-DH + F436-1 \\
\hline C & $\phi 7 / 8-10$ UNC x 3 & F1852-1SL + A563-DH + F436-1 \\
\hline Ah & $\varnothing 7 / 8-10$ UNC x 3 & F1852-1SL + A563-DH + F436-1 \\
\hline
\end{tabular}

\subsection{Bolt geometrical and mechanical properties}

The F1852 twist-off bolt is a type of assembly with unique geometry. It has an extended spline tip beyond the treads of bolt. The main factors affecting the control of pretension in the twist-off tension control are dimensional and physical properties of the bolt, nut and washer. To apply torque and install twist-off bolt, special electrically powered double chuck wrench is used. The mechanism of applying torque is to engage the spline and nut of the bolt with inner and outer chuck of the electrical wrench and turning relatively until the spline shears off. This phenomenon would happen at the reduced size of bolt cross section which is called breakneck. Specific geometry defined by ASTM F1852 needs to be satisfied for the spline to engage the chucks of the electric wrench properly. The diameter of the breakneck is critical since the spline shears off when expected torque and pretension in the bolt is achieved. The other requirement that needs to be satisfied is related to the size of the bolt head specified by the ASTM F1852. Although a recent study on the effects of head size on the performance of twist-off bolts (Schnupp and Murray, 2003) claimed that as the amount of bearing surface under the twist-off bolt head has no effect on the tension achieved in assembly, the minimum bearing surface diameter 
of the bolt head specified in the ASTM F1852 specification is adequate for reliable bolt performance even in oversized or slotted holes.

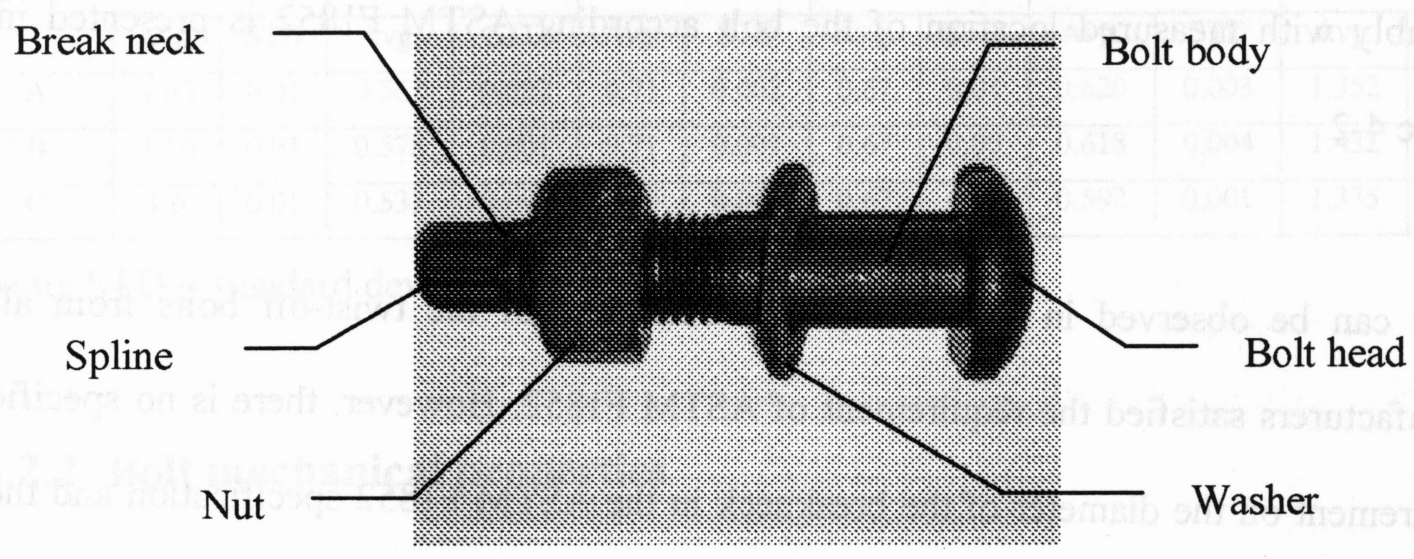

Figure 4-1 View of a Typical Twist-off Tension Control Bolt Assembly

Bolt manufacturers/suppliers are required to provide the mechanical properties of each bolt lot and attach to each lot. However, bolts are required to be tested prior to installation in steel joints to verify that bolts' strength and hardness meet the ASTM F1852 specifications. For twist-off bolts with identical geometry, surface finishing and lubrication, higher achieved tension in the bolt is expected for bolt with higher stiffness and strength.

\subsubsection{Bolt geometrical properties}

Geometrical properties of twist-off bolt assembly tested in this research such (i.e.: height of the head, bearing surface diameter, length of the spline, width across flats of the spline, diameter of the breakneck and the unthreaded body length) were measured by utilizing micrometer calipers to verify the requirements specified by ASTM F1852. The 
dimensions of bolts in this phase of study confirmed the findings and were consistent with previous experiments conducted by Maleev and Tan. New measurements were added for the new and untested twist-off assembly lot .A schematic drawing of twist-off assembly with measured location of the bolt according ASTM F1852 is presented in Figure 4-2.

As it can be observed in Table 4-2, the dimensions of the twist-off bolts from all manufacturers satisfied the requirement of ASTM F1852. However, there is no specific requirement on the diameter of the breakneck in the ASTM F1852 specification and the diameters of the break necks were measured for comparison.

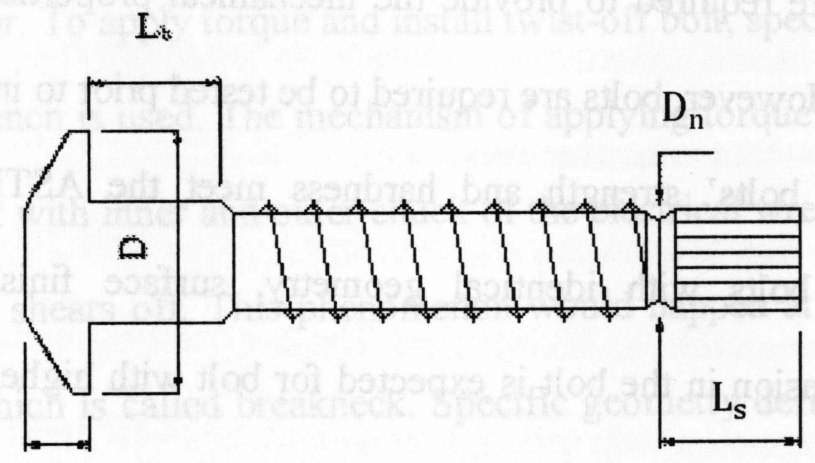

H

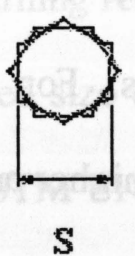

$S$
a) Elevation
b) Cross-section at threaded portion

Figure 4-2 Schematic diagram of the bolt dimensions 
Table 4-2 Dimensions of Twist-off TC assemblies considered in this study

\begin{tabular}{|c|c|c|c|c|c|c|c|c|c|c|c|c|}
\hline \multirow{2}{*}{ 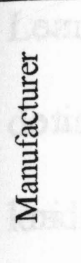 } & \multicolumn{2}{|c|}{$\begin{array}{c}\text { D } \\
\text { Bearing } \\
\text { Surface } \\
\text { Diameter (in) }\end{array}$} & \multicolumn{2}{|c|}{$\begin{array}{c}\text { H } \\
\text { Head } \\
\text { Height (in) }\end{array}$} & \multicolumn{2}{|c|}{$\begin{array}{c}L_{s} \\
\text { Length of } \\
\text { Spline (in) }\end{array}$} & \multicolumn{2}{|c|}{$\begin{array}{c}\text { S } \\
\text { Width across } \\
\text { Flats (in) }\end{array}$} & \multicolumn{2}{|c|}{$\begin{array}{c}\mathrm{D}_{\mathrm{n}} \\
\text { Breakneck } \\
\text { Diameter (in) }\end{array}$} & \multicolumn{2}{|c|}{\begin{tabular}{c}
\multicolumn{1}{c}{$\mathbf{L}_{\mathrm{b}}$} \\
Unthreaded \\
Length (in)
\end{tabular}} \\
\hline & Avg. & STD & Avg. & STD & Avg. & STD & Avg. & STD & Avg. & STD & Avg. & STD \\
\hline A & 1.63 & 0.01 & 0.561 & 0.002 & 0.71 & 0.002 & 0.67 & 0.01 & 0.620 & 0.003 & 1.352 & 0.005 \\
\hline B & 1.56 & 0.01 & 0.578 & 0.001 & 0.71 & 0.001 & 0.67 & 0.00 & 0.618 & 0.004 & 1.432 & 0.003 \\
\hline $\mathrm{C}$ & 1.6 & 0.01 & 0.537 & 0.003 & 0.70 & 0.003 & 0.67 & 0.01 & 0.592 & 0.001 & 1.335 & 0.007 \\
\hline
\end{tabular}

Note: $\mathrm{STD}=$ standard deviation, Avg. = average

\subsubsection{Bolt mechanical properties}

Stiffness and tensile strength are two properties of twist-off assemblies that need to meet the requirements of ASTM F1852. Tensile tests were performed by following the procedure specified in ASTM F606. Axial tension tests of full size bolt assemblies were conducted to measure the ultimate tensile strength of the bolt and indirectly the nuts were also given a proof test. In earlier studies, the ultimate strength of bolts from the three different manufactures were testes and established. However, in the current study a new lot added to previous bolts and needed to be tested for ultimate strength.

The apparatus and equipments that were used in this test were the same as those used for stiffness calibration procedure described in Chapter 3. For the new bolt lot, four bolts were loaded axially up to the failure. To conduct the test, assemblies with machined head were mounted on the tensile bolt testing adaptor with specified grip length. According to ASTM F1852 for the ultimate test, four full threads should be exposed between the nut and the beginning of the threads (toward bolt head). To obtain this grip the nut was 
rotated towards the bolt head until the threads on the bolt ran out. Then, the nut and threads on the bolt were marked against each other. Then, the nut was rotated in reverse direction for four full threads to reach the desired grip length and marked with white marker. As described in stiffness calibration, tensile bolt testing adaptor as shown in Figure 4-3 includes three parts: the upper and lower components with six evenly spaced 1 in. diameter columns, and two identical plates in the centre. One of the middle plates has six corresponding holes to fit in with the other plate with vertical columns. The plates accommodate a hole in center which needs to be appropriate for the bolt size. Two middle plates were put together and the twist-off bolt was inserted through the middle hole and the nut was adjusted to appropriate grip length. The surrounding holes of the two plates were staggered so that the adapters can be assembled vertically on top of the two middle plates.

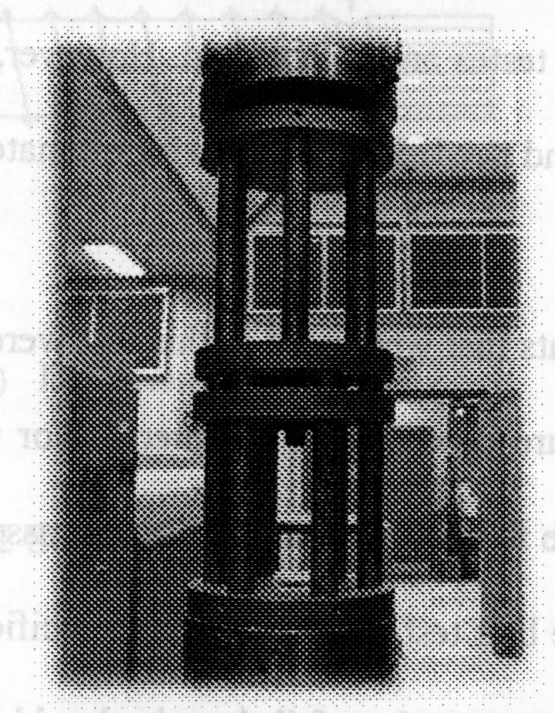

Figure 4-3 View of the tension adaptor 
The adaptor with installed bolt was placed and centered in the MTS universal frame. Loading in MTS was a compressive loading that pushed the adaptor top portion downward while pushing the adaptor bottom plate upward. Thus, this compressive loading was transferred to tensile loading on the twist-off tension control assembly. The tensile load applied to the assembly increased in increments until it reached the ultimate tensile strength of the bolt, leading to bolt fracture as shown in Figure 4-4.

The information of bolt mechanical properties provided by the manufacturer and test results from the laboratory are reported in Table 4-3. The laboratory results showed that bolts from all manufacturers met the ASTM mechanical property requirements.

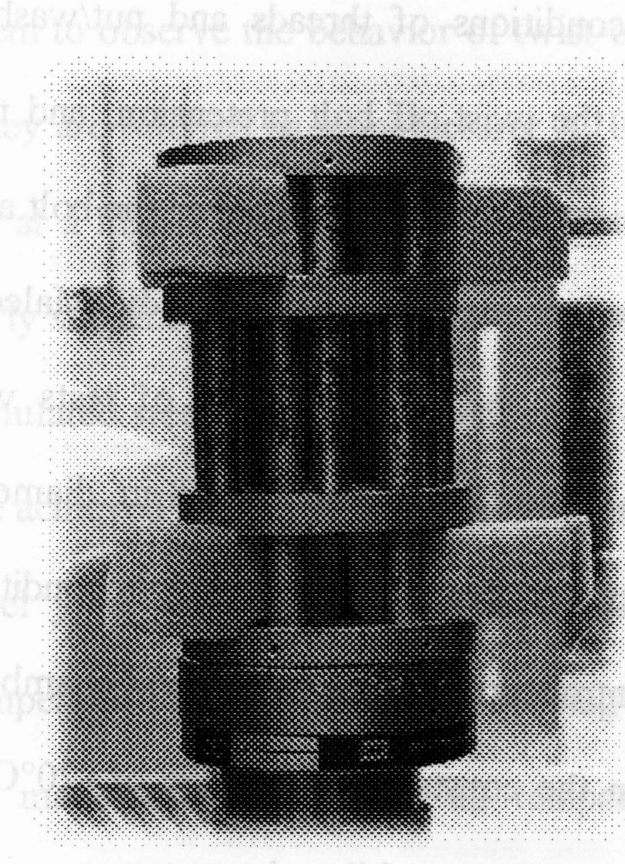

a) View of the adaptor after bolt fracture

Figure 4-4 Views of adaptor assembly and the bolt after failure 
Table 4-3 Tensile Strength

\begin{tabular}{|c|c|c|c|c|c|c|}
\hline \multirow{2}{*}{ Manufacturer } & \multirow{2}{*}{$\begin{array}{c}\text { Bolt Size } \\
\text { (in) }\end{array}$} & \multicolumn{2}{|c|}{$\begin{array}{c}\text { Hardness } \\
(\mathrm{RC} 25-34)\end{array}$} & $\begin{array}{c}\text { Proof Load } \\
(39 \mathrm{kips})\end{array}$ & $\begin{array}{c}\text { Tensile } \\
\text { Strength } \\
(\mathrm{kips})\end{array}$ & \multicolumn{2}{|c|}{ Direct tensile strength } \\
\cline { 5 - 7 } & & & Ave. (kips) & STD \\
\hline $\mathrm{A}$ & $\phi 7 / 8 \times 3$ & 29.1 & All Pass & 68.5 & 69.5 & 0.8 \\
\hline $\mathrm{B}$ & $\phi 7 / 8 \times 3$ & 31.7 & All Pass & 69.5 & 74.5 & 0.3 \\
\hline $\mathrm{C}$ & $\phi 7 / 8 \times 3$ & 27.9 & All Pass & 69.4 & 72.1 & 0.2 \\
\hline
\end{tabular}

\subsection{Cold temperature installation}

In North America the achieved pretension by twist-off bolts is questioned because of the uncertainty of the effect of cold temperature during the installation. According to Kulak and Undershute's report (1994), the frictional conditions of threads and nut/washer interface are the major key issues that influence the twist-off bolt pretension, and the installed pretension tend to decrease as the coefficient of the friction between the bolt and nut threads and/or that at the nut-washer interface increases. In previous study (Maleev, 2007), to simulate the twist-off bolt installation in the field, a series of tests was conducted on a 3-plate simulated steel joint. Similar to that in practice, $7 / 8$ in. diameter twist-off bolts were installed in the joint. The bolts were brought to a snug-tight condition and the joint was placed inside a temperature controlled room (environmental chamber). The environmental chamber was set to maintain the constant temperature of $-20^{\circ} \mathrm{C}$ to simulate the installation environment of twist-off assemblies in extreme winter conditions. The chamber is located in the Sanford Fleming building at the University of Toronto and operated by building science researchers. The bolts were finally tightened with the automatic TC wrench inside the cold chamber. This cold test series was further 
expanded into assemblies installed after 4 hours and after one week at the $-20^{\circ} \mathrm{C}$. These tests were conducted to investigate the immediate and longer term effects of extreme cold. These tests were conducted to have a better understanding of installation behavior of twist-off bolts that are exposed to extreme temperatures during the installation, including $-20{ }^{\circ} \mathrm{C}$. The study showed that extreme cold temperature has a significant negative effect on the installed tension of twist-off assemblies. It was theorized that extreme temperature may have some effects on the lubricant and this causes reduction on achieved pretension in twist-off assemblies. To verify the effect of temperature on twistoff assembly, further experiments were recommended.

In this research, three different manufacturers were chosen to conduct a series of test on them to observe the behavior of twist-off bolts exposed to various levels of temperature. They are referred as manufacturer A, B and C. In some parts of the experiment, second lot at a higher strength level from manufacture A was tested and is referred as Ah. At early stages of the experiments, it was observed that if the bolt was snug-tightened in the simulated steel joint prior to exposure to the cold temperature (referred as "Pre-Snug"), the achieved tension in bolt was different from the condition that bolt was left loose in the steel joint and was snugged after the specimen was adequately soaked at reduced temperature (referred to as "Cold-Snug"). Hence, it was decided to perform all tests for all manufacturers and for all temperature levels, for these (Pre-Snug, Cold-Snug) conditions. Initially, tests for each manufacturer were conducted at three main temperature levels of 24,0 and $-20^{\circ} \mathrm{C}$ to observe the corresponding achieved tension in 
bolts. It should be noted that the minimum specified tension for ASTM A325 and 1872 twist-off bolts was 39 kips.

\subsubsection{Test apparatus: Three plate steel joint}

The three plate joint used in the prototype joint consists of 3 solid steel plates $(20 \times 4 \times$ 0.5 inches) with 4 holes in the plates. All the edges of the plates were saw- or flame-cut. The holes were drilled holes, and the size and placement of the hole satisfied the requirements of CAN/CSA-S16.1 (CISC-2008). All the Individual plates in a joint were identical and fabricated from steel meeting CSA G40.21-M300W (CISC-2008). Figure 45 shows view of this steel joint. All the Specimens were similar to those in previous study and were fabricated by a local fabricator. All plates in the specimens labeled as; Top, Middle and Bottom and the 4 holes in the plates were named as a, b, c and d from right to left. The order of placing plates in simulated prototype joint was kept consistent as well as the order of installing and tightening of the assemblies. (Start from ' $a$ ' and finish with 'd'). Four bolts per joint was selected to provide a suitable sample size for each set of test parameters and to replicate the specimens used in the earlier phase of the study by Maleev.

The Bolt Gage was used to measure the bolt tension and for direct comparison and verification, the Skidmore-Wilhelm model MS bolt tension calibrator was utilized to measure the bolt load. 


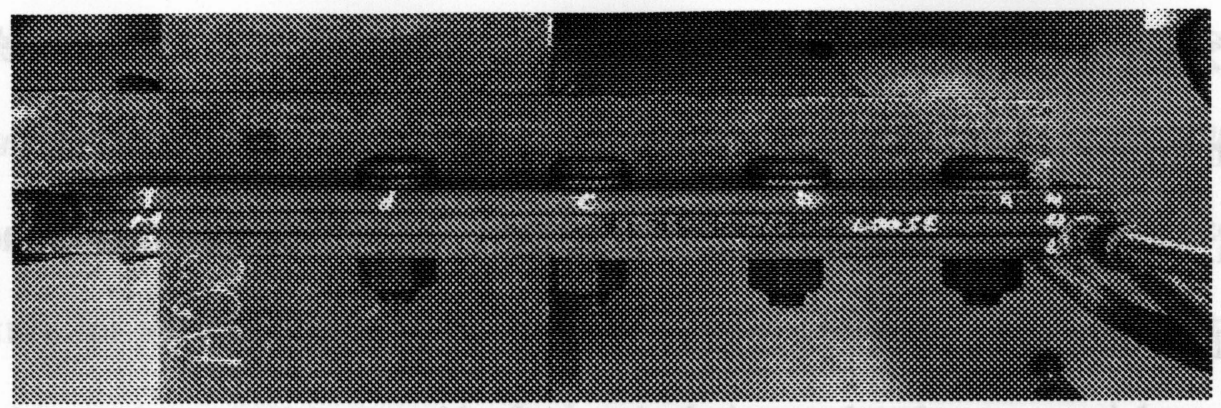

Figure 4-5 View of the simulated steel joint tested in this study

\subsubsection{Cold temperature installation test parameters}

Twist-off bolts were tested in the "as-received" condition at room temperature of $24^{\circ} \mathrm{C}$, $0{ }^{\circ} \mathrm{C}$ and extreme cold temperature of $-20{ }^{\circ} \mathrm{C}$. Subsequently, further tests for various temperatures were conducted as bolts failed to achieve minimum specified tension. As mentioned earlier, since in early studies by Maleev and Tan, bolts demonstrated different behavior for "Pre-Snug" and "Cold-Snug" conditions, all parametric tests, were conducted for both conditions.

\subsubsection{Test specimen description}

Twist-off tension controlled bolt assemblies were supplied by three manufacturers and were tested in this experimental program to compare the performance of the twist-off bolts with different lubricant condition when they are exposed to cold environment. Regarding the grip length, typical required grip length of bolts in the RCSC specification

and CISC Steel Handbook for the 7/8 in. diameter 3 in. long bolts was between $111 / 16$ and $17 / 8$ in.; this grip length was achieved by three 0.5 in. plates and a nominal thickness of two washers in the grip or $3 / 16$ in. total. Thus, the grip length of 3 in. long bolt was 
$3 \times 0.5+2 \times 3 / 16=17 / 8$ in. Furthermore, this setup permitted to use one washer in the grip length for the purpose of the grip variation tests. One washer with nominal thickness of $3 / 16$ in. brought the total grip length to $111 / 16$ in. which was specified as the lower limit for the $3 \mathrm{in}$. long bolts.

\subsubsection{General test procedure}

According to RCSC specification, before the bolts were tested in the steel joint, preinstallation verifications in the Skidmore-Wilhelm bolt tension calibrator needed to be performed. To perform the verification, three bolts from each test category were snugtightened in the Skidmore to about 5 10 kips using a spud wrench and then installed with the special electrically-powered TC bolt installation wrench (automatic TC wrench). The same grip length as in the steel joint was provided. A minimum of eight bolts from each lot for each temperature levels were tested. Based on initial findings, two sets of specimens were formed to be tested, one for Pre-Snug and the other one for Cold-Snug condition. The three plates forming simulated steel joint were marked as Top, Middle and Bottom and holes were marked as; a, b, c and d. the order of placing plates and installation of the bolts in the holes from "a" to " $\mathrm{d}$ " were consistent throughout the experimental program.

As initial findings showed that achieved tension for Pre-Snug and Cold-Snug conditions were different, two sets of specimens were prepared (one for Pre-Snug and one for ColdSnug). For Pre-Snug condition, the bolts were inserted in the holes and were tightened to 
snug-tight condition with the operator's full effort using a spud wrench. For Cold-Snug, similar bolts were inserted in the holes of the joint but they were left in loose condition. Both specimens were placed in environmental chamber which provides consistent temperature for various temperature levels. Inside the chamber, specimens were placed inside a bin and covered to provide further isolation and reduce potential temperature variations. A regular mercury thermometer was placed beside the specimens inside the bin to make sure that the desired temperature was achieved. Specimens were soaked at the set desired temperature for period of 24 hours. Inside the camber room and after a period of 24 hours, the bolts of Cold-Snug specimens were tightened to snug-tight condition similar to Pre-snug specimen with the operator's full effort and use of spud wrench. The automatic TC wrench was then used to complete the tightening procedure.

After 24 hours of exposure to desired temperature and completion of tightening procedure, specimens were removed from the chamber and were exposed to room temperature $\left(24^{\circ} \mathrm{C}\right)$ for next 24 hours. It was assumed that 24 hours of exposure to certain temperature level is adequate to confidently believe that the whole joint system had reached the surrounding environment temperature. The tip of the bolt would have an uneven surface when tightening of the bolts was completed and the end spline was removed. Regular steel grinder was used carefully to provide a relatively flat and smooth surface at the tip of bolt for elongation measurement reference purposes. The final step was to measure the elongation of the bolt by utilizing the Ultrasonic Bolt Gage. The bolt gage was calibrated by measuring the length of a standard piece of solid round bar with specific length. A coupling and agent was applied to the flattened head of the bolt and the 
transducer was carefully placed and centered on top of the bolt head. The bolt gage was zeroed to show 0.00000 to 0.00001 in. of elongation. The temperature transducer was attached to the steel joint to take into account the related temperature changes that may happened in steel joint during unloading procedure. As transducers were attached to the bolt and the steel joint, a loosening torque was manually applied to the nut of the assembly. A manual measuring torque wrench was used to completely loosen the nut of the assembly. As loosening was completed, the shown elongation on the Bolt Gage screen and loosening torque on the manual torque wrench were recorded. By finalizing the above mentioned procedure, the bolt elongation was available as well as the stiffness of the bolt from the procedure described in section 3.5. Thus, the achieved tension was calculated by multiplying the elongation by the calibrated stiffness as described in chapter 3 . The described procedure to measure the elongation in bolts and equipments used during the experiment are shown in Figure 4-6. 


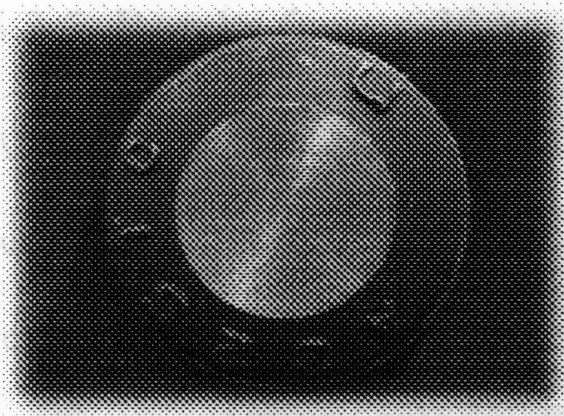

A. Grinded bolt head

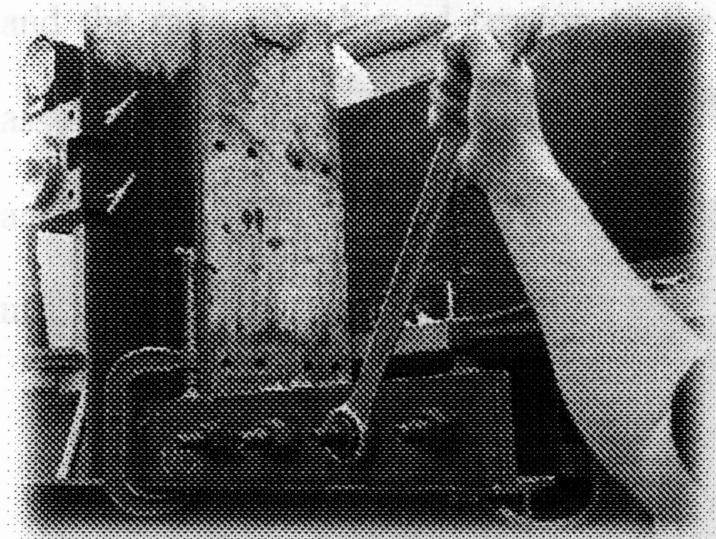

C. Snug-tight of bolts

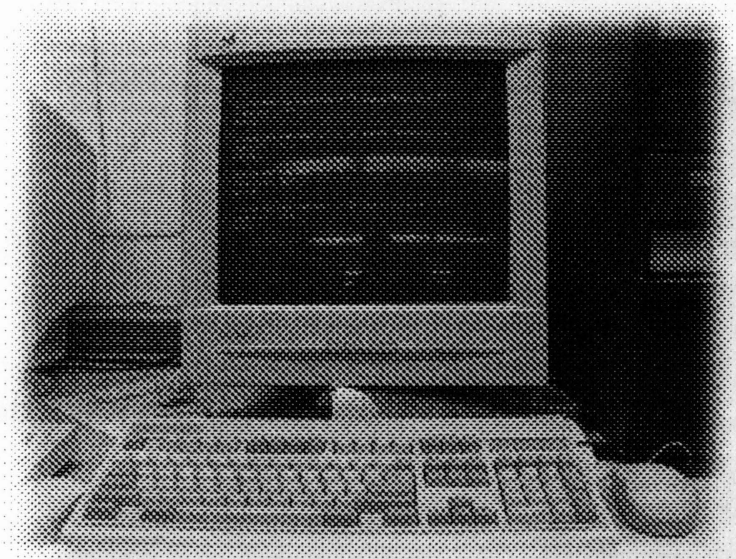

E. Temperature control station

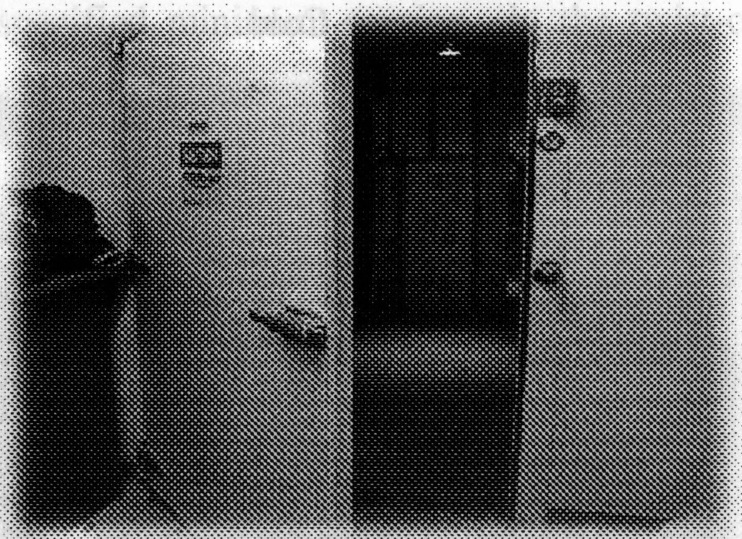

D. Specimens in the environmental chamber room

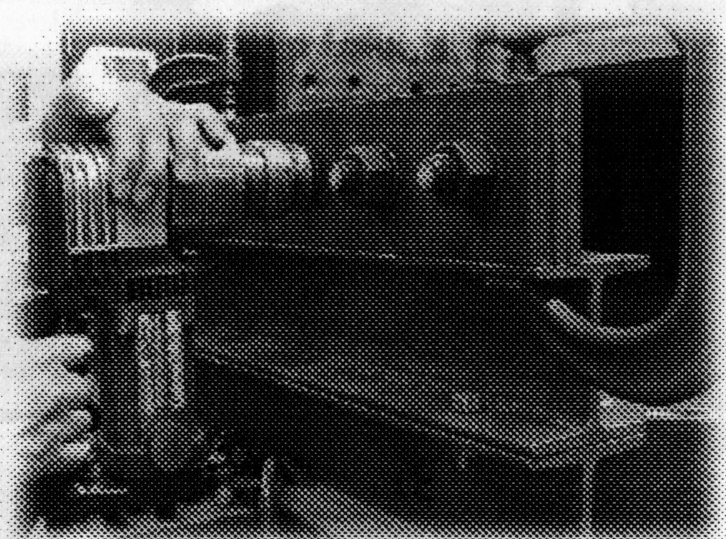

F. TC wrench used in tightening nuts 


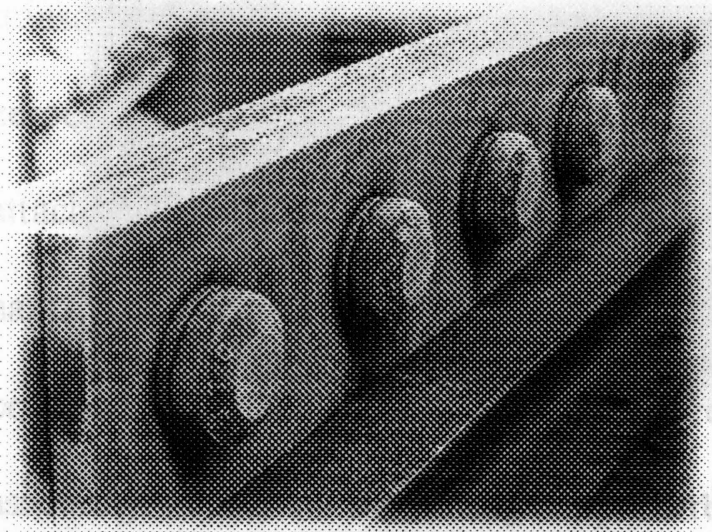

G. Specimens during the exposure to extreme Cold

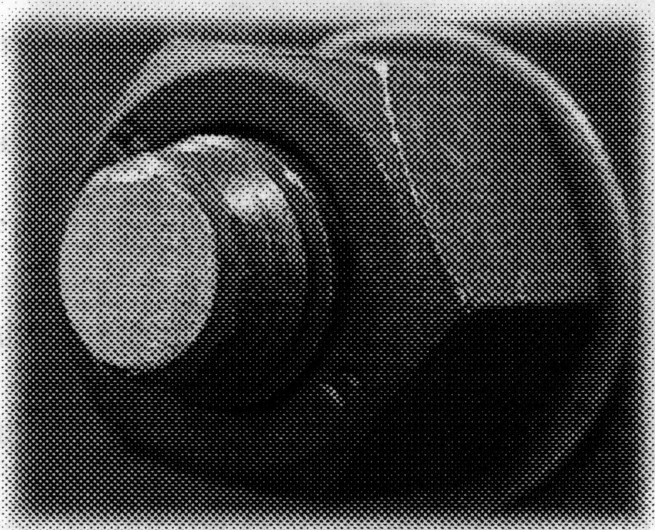

I. Bolt end after grinding

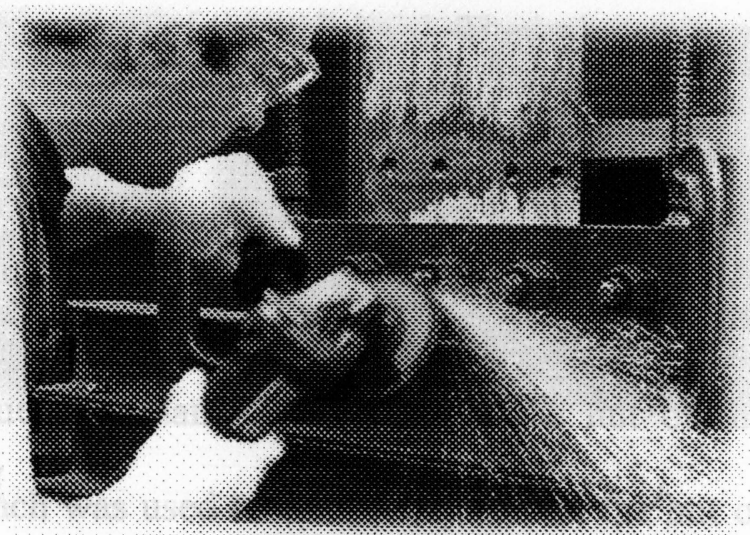

H. Grinding the bolt end

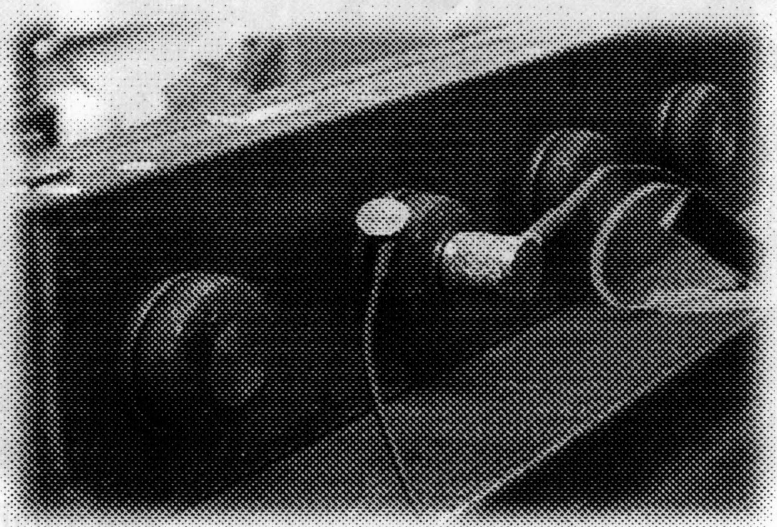

J. Bolt gage attachments on bolt

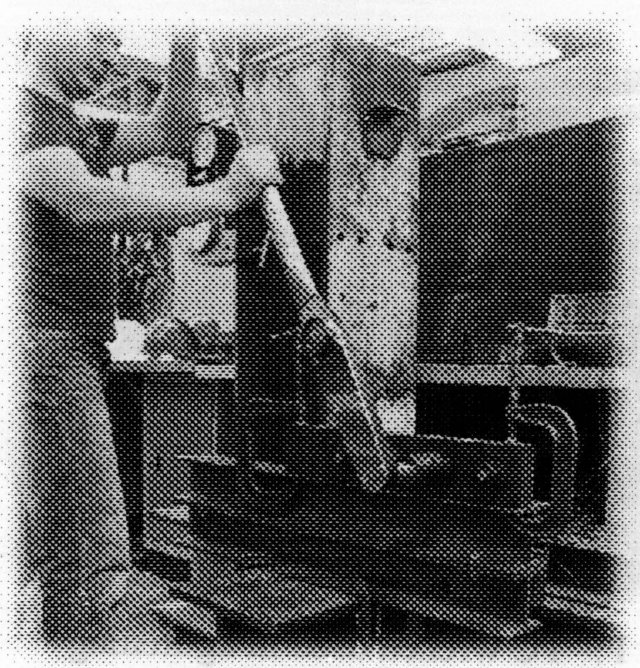

K. Loosening nut

Figure 4-6 Views of elongation test procedure 


\subsubsection{Results from cold temperature installation experiments}

After the above-mentioned procedure was completed for each bolt, series of test data were collected and analyzed. Initially, three main temperature levels were chosen to reflect relatively normal, cold and extreme temperature levels for installation conditions. The results of these tests are presented in following tables and figures for three manufacturers of A, B and C. Table 4-4, 4-5 and 4-6 present the average achieved tension and the ratio of achieved tension to the specified minimum tension in the twist-off assemblies for Pre-Snug condition and Cold-Snug condition as well as the ratio of achieved tension to the ultimate tensile strength of the bolt in direct tension for manufacturer $\mathrm{A}, \mathrm{B}$ and $\mathrm{C}$, respectively. 
Table 4-4 Preload for bolts supplied by manufacturer A

\begin{tabular}{|c|c|c|c|c|c|c|c|}
\hline $\begin{array}{c}\text { Temperature } \\
\left({ }^{\circ} \mathrm{C}\right)\end{array}$ & Condition & $\begin{array}{c}\text { Number } \\
\text { tested }\end{array}$ & $\begin{array}{c}T_{c} \\
\text { (kips) }\end{array}$ & $\begin{array}{c}\text { Average } T_{c} \\
\text { (kips) }\end{array}$ & $T_{c} / T_{m}$ & $\begin{array}{l}\text { Standard } \\
\text { Deviation }\end{array}$ & $T_{c} / T_{u}$ \\
\hline \multirow{8}{*}{$\begin{array}{c}\text { Room Temp. } \\
\qquad\left(24^{\circ} \mathrm{C}\right)\end{array}$} & \multirow{4}{*}{ Pre-Snug } & \multirow{4}{*}{4} & 47.30 & \multirow{4}{*}{47.28} & \multirow{4}{*}{1.21} & \multirow{4}{*}{0.02} & \multirow{4}{*}{0.68} \\
\hline & & & 48.30 & & & & \\
\hline & & & 46.00 & & & & \\
\hline & & & 47.50 & & & & \\
\hline & \multirow{4}{*}{ Cold-Snug } & \multirow{4}{*}{4} & 49.10 & \multirow{4}{*}{48.78} & \multirow{4}{*}{1.25} & \multirow{4}{*}{0.02} & \multirow{4}{*}{0.70} \\
\hline & & & 49.70 & & & & \\
\hline & & & 48.30 & & & & \\
\hline & & & 48.00 & & & & \\
\hline \multirow{8}{*}{0} & \multirow{4}{*}{ Pre-Snug } & \multirow{4}{*}{4} & 38.50 & \multirow{4}{*}{39.63} & \multirow{4}{*}{1.02} & \multirow{4}{*}{0.03} & \multirow{4}{*}{0.57} \\
\hline & & & 40.70 & & & & \\
\hline & & & 40.60 & & & & \\
\hline & & & 38.70 & & & & \\
\hline & \multirow{4}{*}{ Cold-Snug } & \multirow{4}{*}{4} & 42.30 & \multirow{4}{*}{41.85} & \multirow{4}{*}{1.07} & \multirow{4}{*}{0.03} & \multirow{4}{*}{0.60} \\
\hline & & & 40.30 & & & & \\
\hline & & & 43.90 & & & & \\
\hline & & & 40.90 & & & & \\
\hline \multirow{8}{*}{-20} & \multirow{4}{*}{ Pre-Snug } & \multirow{4}{*}{4} & 33.80 & \multirow{4}{*}{34.00} & \multirow{4}{*}{0.87} & \multirow{4}{*}{0.03} & \multirow{4}{*}{0.49} \\
\hline & & & 32.80 & & & & \\
\hline & & & 33.60 & & & & \\
\hline & & & 35.80 & & & & \\
\hline & & & 36.70 & & & & \\
\hline & Cold-Snug & 4 & 37.20 & 36,23 & 0.93 & 0.02 & 0.52 \\
\hline & & & 35.60 & & & & \\
\hline & & & 35.40 & & & & \\
\hline
\end{tabular}

$T_{c}=$ Calibrated tension, $T_{m}=$ Specified minimum pretention $(39 \mathrm{kips}), T_{u}=$ ultimate tensile strength in direct tension (tested average $=69.5 \mathrm{kips}$ )

Figure 4-7, 4-8 and 4-9 present the preload-temperature relationship for bolts supplied by manufacturers A, B and C, respectively. As it can be seen in Figure 4-7, for the manufacturer A, all assemblies achieved minimum pretension as specified in RCSC for 
both conditions of Pre-Snug and Cold-Snug at room temperature of $24{ }^{\circ} \mathrm{C}$ and $0{ }^{\circ} \mathrm{C}$. However, similar bolts failed to achieve minimum specified tension at $-24^{\circ} \mathrm{C}$. It should be noted that both dotted lines in Figure 4-7 present the low-bound value of $T_{c} / T_{m}$ at each installation temperature. Figure 4-8 shows that all assemblies from manufacturer B passed the minimum specified tension at all temperature levels for both Pre-Snug and Cold-Snug conditions expect at $-20{ }^{\circ} \mathrm{C}$ where $T_{c} / T_{m}$ was between 0.95 and 1.0 for some tested bolts. Figure 4-9 shows that for the manufacturer $\mathrm{C}$, at room temperature of $24^{\circ} \mathrm{C}$, bolts passed the minimum specified tension for both Pre-Snug and Cold-Snug conditions, however for $0{ }^{\circ} \mathrm{C}$ and $-20^{\circ} \mathrm{C}$, bolts could not reach the minimum pretension Specified by RCSC.

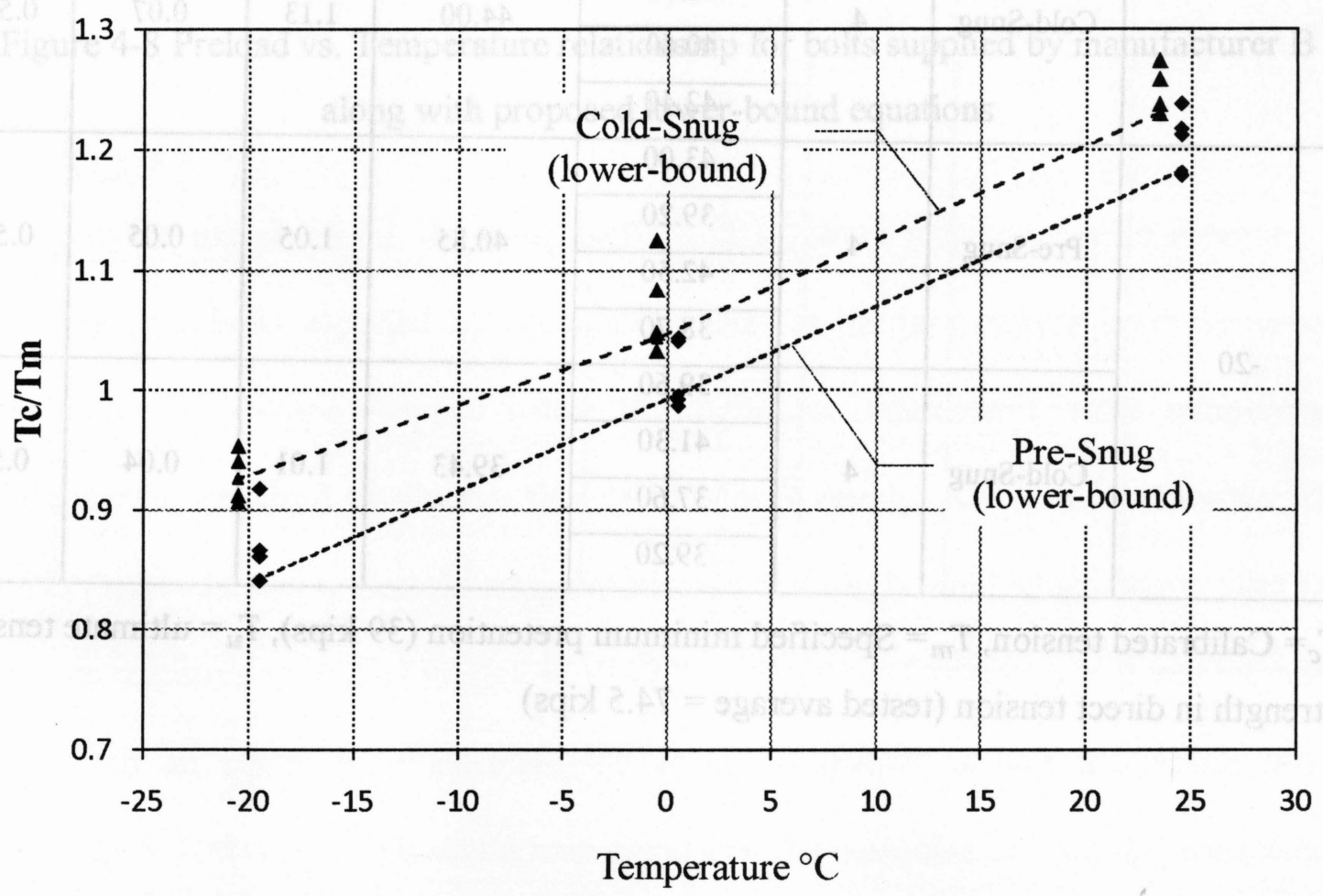

Figure 4-7 Preload vs. Temperature relationship for bolts supplied by manufacturer A along with proposed lower-bound equations 
Table 4-5 Preload for bolts supplied by manufacturer B

\begin{tabular}{|c|c|c|c|c|c|c|c|}
\hline $\begin{array}{c}\text { Temperature } \\
\left({ }^{\circ} \mathrm{C}\right)\end{array}$ & Condition & $\begin{array}{c}\text { Number } \\
\text { tested }\end{array}$ & $\begin{array}{c}T_{c} \\
\text { (kips) }\end{array}$ & $\begin{array}{c}\text { Average } T_{c} \\
\text { (kips) }\end{array}$ & ${ }^{c} / T_{m}$ & $\begin{array}{l}\text { Standard } \\
\text { Deviation }\end{array}$ & $T_{c} / T_{u}$ \\
\hline \multirow{8}{*}{$\begin{array}{l}\text { Room Temp. } \\
\qquad\left(24^{\circ} \mathrm{C}\right)\end{array}$} & \multirow{4}{*}{ Pre-Snug } & \multirow{4}{*}{4} & 44.00 & \multirow{4}{*}{45.33} & \multirow{4}{*}{1.16} & \multirow{4}{*}{.0 .30 .06} & \multirow{4}{*}{0.61} \\
\hline & & & 48.90 & & & & \\
\hline & & & 42.90 & & & & \\
\hline & & & 45.50 & & & & \\
\hline & \multirow{4}{*}{ Cold-Snug } & \multirow{4}{*}{4} & 44.60 & \multirow{4}{*}{45.90} & \multirow{4}{*}{1.18} & \multirow{4}{*}{.060 .03} & \multirow{4}{*}{0.62} \\
\hline & & & 46.70 & & & & \\
\hline & & & 48.20 & & & & \\
\hline & & & 44.10 & & & & \\
\hline \multirow{8}{*}{0} & \multirow{4}{*}{ Pre-Snug } & \multirow{4}{*}{4} & 38.90 & \multirow{4}{*}{40.90} & \multirow{4}{*}{1.05} & \multirow{4}{*}{0.05} & \multirow{4}{*}{0.55} \\
\hline & & & 43.20 & & & & \\
\hline & & & 39.00 & & & & \\
\hline & & & 42.50 & & & & \\
\hline & \multirow{4}{*}{ Cold-Snug } & \multirow{4}{*}{4} & 44.30 & \multirow{4}{*}{44.00} & \multirow{4}{*}{1.13} & \multirow{4}{*}{0.07} & \multirow{4}{*}{0.59} \\
\hline & & & 48.70 & & & & \\
\hline & & & 40.60 & & & & \\
\hline & & & 42.40 & & & & \\
\hline \multirow{8}{*}{-20} & \multirow{4}{*}{ Pre-Snug } & \multirow{4}{*}{4} & 43.00 & \multirow{4}{*}{40.85} & \multirow{4}{*}{1.05} & \multirow{4}{*}{0.05} & \multirow{4}{*}{0.55} \\
\hline & & & 39.20 & & & & \\
\hline & & & 42.50 & & & & \\
\hline & & & 38.70 & & & & \\
\hline & & & 39.60 & & & & \\
\hline & & & 41.30 & & & & \\
\hline & Coide-sing & & 37.60 & & & & \\
\hline & & & 39.20 & & & & \\
\hline
\end{tabular}

$T_{c}=$ Calibrated tension, $T_{m}=$ Specified minimum pretention $(39 \mathrm{kips}), T_{u}=$ ultimate tensile strength in direct tension (tested average $=74.5 \mathrm{kips}$ ) 


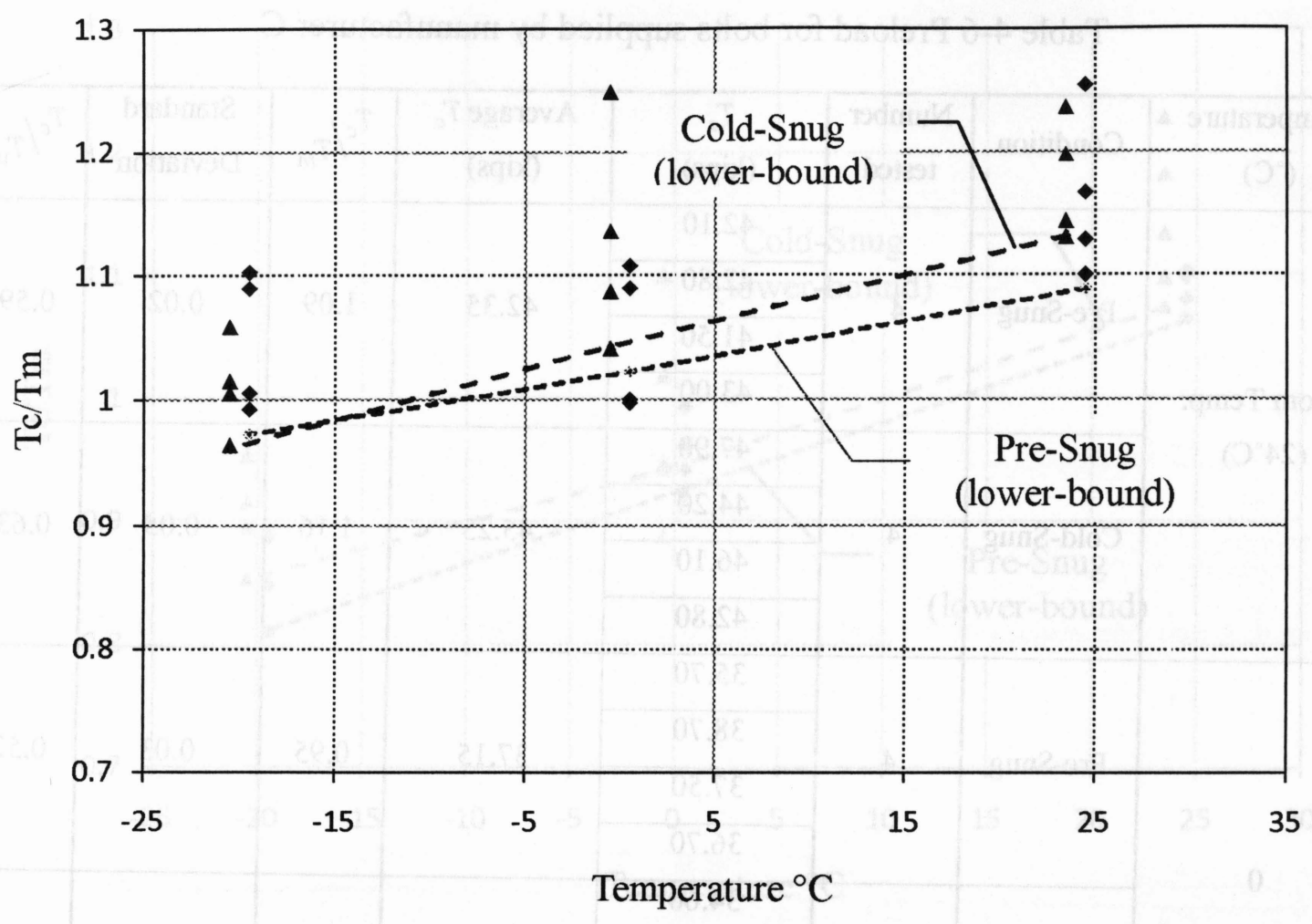

Figure 4-8 Preload vs. Temperature relationship for bolts supplied by manufacturer B along with proposed lower-bound equations 
Table 4-6 Preload for bolts supplied by manufacturer C

\begin{tabular}{|c|c|c|c|c|c|c|c|}
\hline $\begin{array}{c}\text { Temperature } \\
\left({ }^{\circ} \mathrm{C}\right)\end{array}$ & Condition & $\begin{array}{c}\text { Number } \\
\text { tested }\end{array}$ & $\begin{array}{c}T_{c} \\
\text { (kips) }\end{array}$ & $\begin{array}{c}\text { Average } T_{c} \\
\text { (kips) }\end{array}$ & $T_{c} / T_{m}$ & $\begin{array}{l}\text { Standard } \\
\text { Deviation }\end{array}$ & $T_{c} / T_{u}$ \\
\hline \multirow{8}{*}{$\begin{array}{l}\text { Room Temp. } \\
\qquad\left(24^{\circ} \mathrm{C}\right)\end{array}$} & \multirow{4}{*}{ Pre-Snug } & \multirow{4}{*}{4} & 42.10 & \multirow{4}{*}{42.35} & \multirow{4}{*}{1.09} & \multirow{4}{*}{0.02} & \multirow{4}{*}{0.59} \\
\hline & & & 42.80 & & & & \\
\hline & & & 41.50 & & & & \\
\hline & & & 43.00 & & & & \\
\hline & \multirow{4}{*}{ Cold-Snug } & \multirow{4}{*}{4} & 47.90 & \multirow{4}{*}{45.25} & \multirow{4}{*}{1.16} & \multirow{4}{*}{0.05} & \multirow{4}{*}{0.63} \\
\hline & & & 44.20 & & & & \\
\hline & & & 46.10 & & & & \\
\hline & & & 42.80 & & & & \\
\hline \multirow{8}{*}{0} & \multirow{4}{*}{ Pre-Snug } & \multirow{4}{*}{4} & 35.70 & \multirow{4}{*}{37.15} & \multirow{4}{*}{0.95} & \multirow{4}{*}{0.03} & \multirow{4}{*}{0.52} \\
\hline & & & 38.70 & & & & \\
\hline & & & 37.50 & & & & \\
\hline & & & 36.70 & & & & \\
\hline & \multirow{4}{*}{ Cold-Snug } & \multirow{4}{*}{4} & 34.60 & \multirow{4}{*}{38.53} & \multirow{4}{*}{0.99} & \multirow{4}{*}{0.08} & \multirow{4}{*}{0.53} \\
\hline & & & 42.90 & & & & \\
\hline & & & 39.70 & & & & \\
\hline & & & 36.90 & & & & \\
\hline \multirow{8}{*}{-20} & \multirow{4}{*}{ Pre-Snug } & \multirow{4}{*}{4} & 33.10 & \multirow{4}{*}{33.5} & \multirow{4}{*}{0.86} & \multirow{4}{*}{0.03} & \multirow{4}{*}{0.46} \\
\hline & & & 34.70 & & & & \\
\hline & & & 34.60 & & & & \\
\hline & & & 31.60 & & & & \\
\hline & & & 34.90 & & & & \\
\hline & & & 35.70 & & & & \\
\hline & Cord-snug & 4 & 34.90 & 30.00 & 0.91 & 0.02 & \\
\hline & & & 37.20 & & & & \\
\hline
\end{tabular}

$T_{c}=$ Calibrated tension, $T_{m}=$ Specified minimum pretention $(39 \mathrm{kips}), T_{u}=$ ultimate tensile strength in direct tension (tested average $=72.1 \mathrm{kips}$ ) 


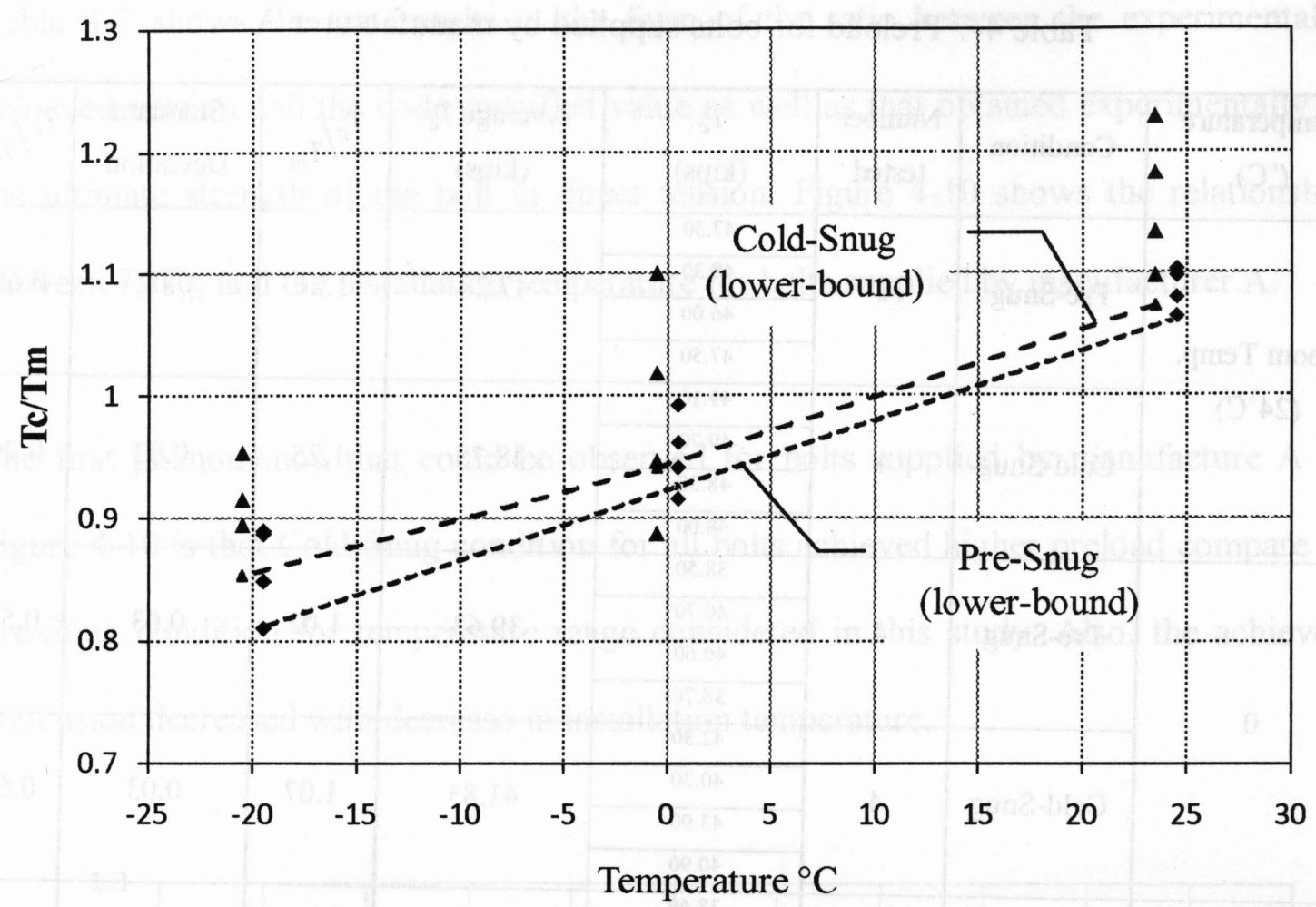

Figure 4-9 Preload vs. Temperature relationship for bolts supplied by manufacturer C along with proposed lower-bound equations

Based on the initial results, declining patterns in achieved pretension were observed in assemblies for bolts supplied by all manufacturers as the temperature level decreased. Since achieved tension dropped below the minimum requirement, other temperature levels were considered to observe this pattern more deeply. As mentioned earlier, the goal in this study was to find the temperature/temperatures beyond which, assemblies fail to obtain minimum specified tension in RCSC specification. Furthermore, it was intended to develop an equation to calculate the achieved tension in bolt assemblies when temperature levels vary. This could help engineers and designers to calculate the tension in assemblies based on installation temperature. For bolts supplied by manufacturer A, two additional temperature levels were considered, namely: $-10^{\circ} \mathrm{C}$ and $-15^{\circ} \mathrm{C}$. 
Table 4-7 Preload for bolts supplied by manufacturer A

\begin{tabular}{|c|c|c|c|c|c|c|c|}
\hline $\begin{array}{c}\text { Temperature } \\
\left({ }^{\circ} \mathrm{C}\right)\end{array}$ & Condition & $\begin{array}{c}\text { Number } \\
\text { tested }\end{array}$ & $\begin{array}{c}T_{c} \\
\text { (kips) }\end{array}$ & $\begin{array}{c}\text { Average } T_{c} \\
\text { (kips) }\end{array}$ & $T_{c} / T_{m}$ & $\begin{array}{l}\text { Standard } \\
\text { Deviation }\end{array}$ & $T_{c} / T_{u}$ \\
\hline \multirow{8}{*}{$\begin{array}{c}\text { Room Temp. } \\
\left(24^{\circ} \mathrm{C}\right)\end{array}$} & \multirow{4}{*}{ Pre-Snug } & \multirow{4}{*}{4} & 47.30 & \multirow{4}{*}{47.28} & \multirow{4}{*}{1.21} & \multirow{4}{*}{0.02} & \multirow{4}{*}{0.68} \\
\hline & & & 48.30 & & & & \\
\hline & & & 46.00 & & & & \\
\hline & & & 47.50 & & & & \\
\hline & \multirow{4}{*}{ Cold-Snug } & \multirow{4}{*}{4} & 49.10 & \multirow{4}{*}{48.78} & \multirow{4}{*}{1.25} & \multirow{4}{*}{0.02} & \multirow{4}{*}{0.70} \\
\hline & & & 49.70 & & & & \\
\hline & & & 48.30 & & & & \\
\hline & & & 48.00 & & & & \\
\hline \multirow{8}{*}{0} & \multirow{4}{*}{ Pre-Snug } & \multirow{4}{*}{4} & 38.50 & \multirow{4}{*}{39.63} & \multirow{4}{*}{1.02} & \multirow{4}{*}{0.03} & \multirow{4}{*}{0.57} \\
\hline & & & 40.70 & & & & \\
\hline & & & 40.60 & & & & \\
\hline & & & 38.70 & & & & \\
\hline & \multirow{4}{*}{ Cold-Snug } & \multirow{4}{*}{4} & 42.30 & \multirow{4}{*}{41.85} & \multirow{4}{*}{1.07} & \multirow{4}{*}{0.03} & \\
\hline & & & 40.30 & & & & 060 \\
\hline & & & 43.90 & & & & \\
\hline & & & 40.90 & & & & \\
\hline & & & 38.60 & & & & \\
\hline & Pre_Snug & 4 & 37.70 & 2008 & 100 & 003 & 056 \\
\hline & 110-sing & & 40.60 & & & & \\
\hline-10 & & & 39.40 & & & & \\
\hline-10 & & & 41.20 & & & & \\
\hline & Cold_Snuo & 4 & 41.80 & 4095 & 105 & 002 & 059 \\
\hline & & & 41.40 & & & & \\
\hline & & & 39.40 & & & & \\
\hline & & & 35.90 & & & & \\
\hline & Pre_Snug & 4 & 33.90 & 3563 & 0.91 & 0.04 & 051 \\
\hline & & & 34.60 & & & & \\
\hline-15 & & & 38.10 & & & & \\
\hline & & & 34.90 & 60 & 29 & 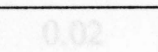 & 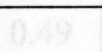 \\
\hline & Cold Snu & 4 & 34.00 & 3503 & 0.07 & 005 & 052 \\
\hline & Cord-sinug & 4 & 35.40 & 53.95 & 0.72 & & \\
\hline & & & 39.40 & & & & \\
\hline & & & 33.80 & & & & \\
\hline & Pre_Snuб & 4 & 32.80 & 3400 & 087 & 003 & 049 \\
\hline & & & 33.60 & & & & \\
\hline-20 & & & 35.80 & & & & \\
\hline & & & 36.70 & & & & \\
\hline & Cold Snu & 4 & 37.20 & 3623 & 0.93 & 000 & 052 \\
\hline & Coid-sing & & 35.60 & & & & \\
\hline & & & 35.40 & & & & \\
\hline
\end{tabular}

$T_{c}=$ Calibrated tension, $T_{m}=$ Specified minimum pretention ( $\left.39 \mathrm{kips}\right), T_{u}=$ ultimate tensile strength in direct tension (tested average $=69.5 \mathrm{kips}$ ) 
Table 4-7 shows the test results in the form of the ratio between the experimentally achieved tension and the code specified value as well as that obtained experimentally to the ultimate strength of the bolt in direct tension. Figure 4-10 shows the relationship between $T_{c} / T_{m}$ and the installation temperature for bolts supplied by manufacturer A.

The first phenomenon that could be observed for bolts supplied by manufacture A in Figure 4-10 is that Cold-Snug condition for all bolts achieved higher preload compare to Pre-Snug condition for temperature range considered in this study. Also, the achieved pretension decreased with decrease in installation temperature.

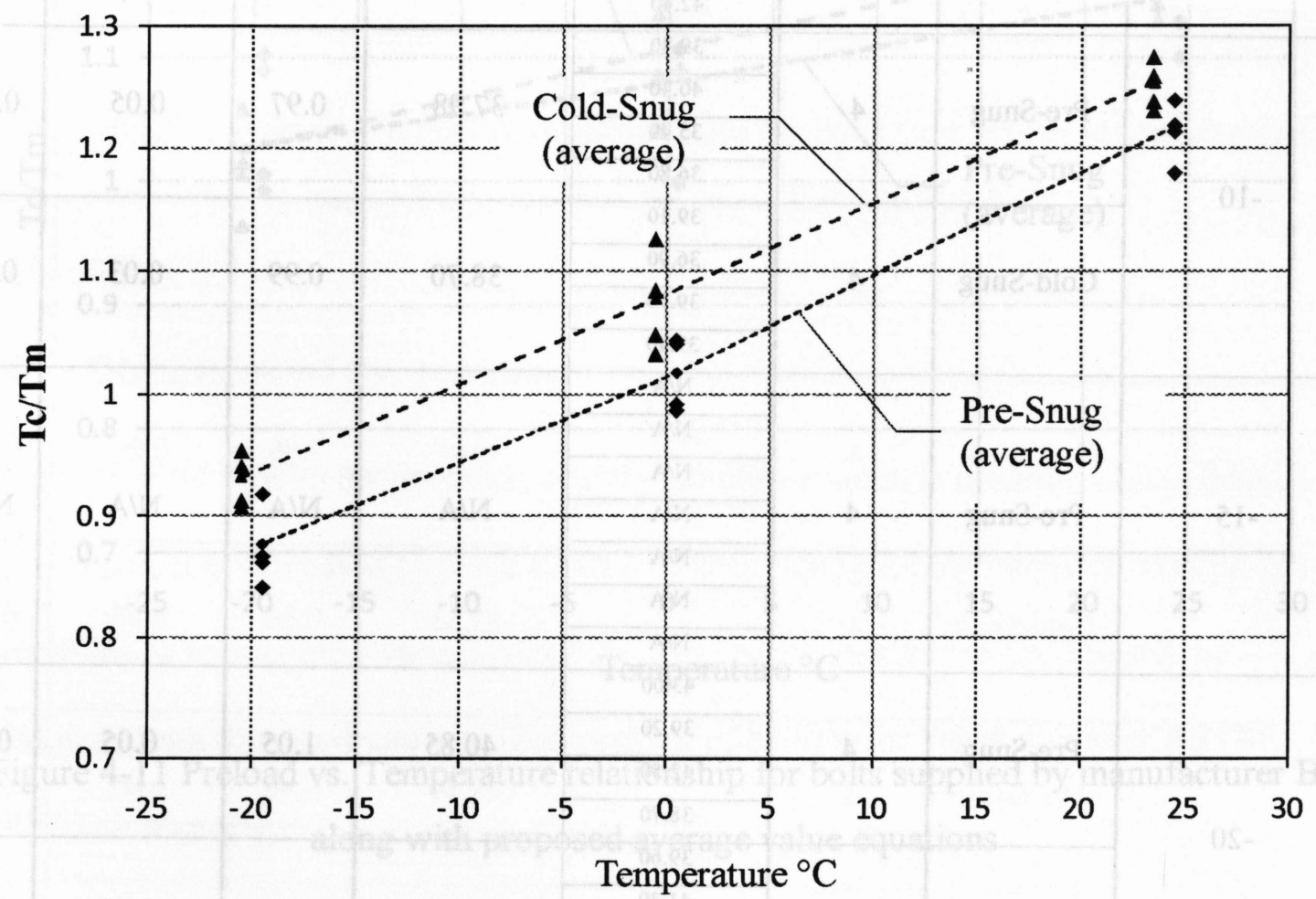

Figure 4-10 Preload vs. Temperature relationship for bolts supplied by manufacturer A along with proposed average value equations 
Table 4-8 Preload for bolts supplied by manufacturer B

\begin{tabular}{|c|c|c|c|c|c|c|c|}
\hline $\begin{array}{c}\text { Temperature } \\
\left({ }^{\circ} \mathrm{C}\right)\end{array}$ & Condition & $\begin{array}{c}\text { Number } \\
\text { tested }\end{array}$ & $\begin{array}{c}T_{c} \\
\text { (kips) }\end{array}$ & $\begin{array}{c}\text { Average } T_{c} \\
\text { (kips) }\end{array}$ & $T_{c} / T_{m}$ & $\begin{array}{l}\text { Standard } \\
\text { Deviation }\end{array}$ & $T_{c} / T_{u}$ \\
\hline \multirow{7}{*}{$\begin{array}{l}\text { Room Temp. } \\
\qquad\left(24^{\circ} \mathrm{C}\right)\end{array}$} & \multirow{3}{*}{ Pre-Snug } & \multirow{3}{*}{4} & 44.00 & \multirow{3}{*}{45.33} & \multirow{3}{*}{1.16} & \multirow{3}{*}{0.03} & \multirow{3}{*}{0.61} \\
\hline & & & 48.90 & & & & \\
\hline & & & $\begin{array}{l}42.90 \\
4550\end{array}$ & & & & \\
\hline & \multirow{4}{*}{ Cold-Snug } & \multirow{4}{*}{4} & 44.60 & \multirow{4}{*}{45.90} & \multirow{4}{*}{1.18} & \multirow{4}{*}{0.06} & \multirow{4}{*}{0.62} \\
\hline & & & 46.70 & & & & \\
\hline & & & 48.20 & & & & \\
\hline & & & 44.10 & & & & \\
\hline \multirow{8}{*}{0} & \multirow{4}{*}{ Pre-Snug } & \multirow{4}{*}{4} & 38.90 & \multirow{4}{*}{40.90} & \multirow{4}{*}{1.05} & \multirow{4}{*}{0.05} & \multirow{4}{*}{0.55} \\
\hline & & & 43.20 & & & & \\
\hline & & & 39.00 & & & & \\
\hline & & & 42.50 & & & & \\
\hline & \multirow{4}{*}{ Cold-Snug } & \multirow{4}{*}{4} & 44.30 & \multirow{4}{*}{44.00} & \multirow{4}{*}{1.13} & \multirow{4}{*}{0.07} & \multirow{4}{*}{0.59} \\
\hline & & & 48.70 & & & & \\
\hline & & & 40.60 & & & & \\
\hline & & & 42.40 & & & & \\
\hline & & & 39.30 & & & & \\
\hline & & & 40.40 & 3798 & & & 051 \\
\hline & Pre-snug & 4 & 35.40 & & 0.91 & 0.05 & 0.01 \\
\hline 10 & & & 36.80 & & & & \\
\hline-10 & & & 39.10 & & & & \\
\hline & Cold-Snug & 4 & 36.90 & 38.70 & 0.99 & 0.03 & 0.52 \\
\hline & & & 39.70 & & & & \\
\hline & & & 39.10 & & & & \\
\hline & & & $\mathrm{N} / \mathrm{A}$ & & & $\mathrm{F}-2+3$ & \\
\hline & & & $\mathrm{N} / \mathrm{A}$ & & & & \\
\hline & & & N/A & & & & \\
\hline-15 & Pre-Snug & 4 & $\mathrm{~N} / \mathrm{A}$ & N/A & N/A & N/A & N/A \\
\hline & & & $\mathrm{N} / \mathrm{A}$ & & & & \\
\hline & & & $\mathrm{N} / \mathrm{A}$ & & & & \\
\hline & & & $\mathrm{N} / \mathrm{A}$ & & & & \\
\hline & & & 43.00 & & & & \\
\hline & Pre-Snug & 4 & 39.20 & 40.85 & 105 & 0.05 & 0.55 \\
\hline & & & 42.50 & & & & \\
\hline-20 & & & 38.70 & & & & \\
\hline & Cold Snu & & 41.30 & 2012 & & & \\
\hline & Cord-snug & 4 & 37.60 & 39.43 & 1.01 & 0.04 & 0.53 \\
\hline & & & 39.20 & & 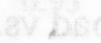 & & \\
\hline
\end{tabular}

$T_{c}=$ Calibrated tension, $T_{m}=$ Specified minimum pretention $(39 \mathrm{kips}), T_{u}=$ ultimate tensile strength in direct tension (tested average $=74.5 \mathrm{kips}$ ) 
Table 4-8 shows test results for bolts supplied by manufacturer B in the form of $T_{c} / T_{m}$ and $T_{c} / T_{u}$ ratios at different temperature levels. While Figure 4-1 depicts the relationship between $T_{c} / T_{m}$ and the installation temperature. Similar trend to bolts supplied by manufacturer A was observed in case of bolts supplied by manufacturer B expect that results at $-10{ }^{\circ} \mathrm{C}$ showed less values than those at $-20{ }^{\circ} \mathrm{C}$. Similar observations were noticed in Table 4-9 and Figure 4-12 for bolts supplied by manufacturer C.

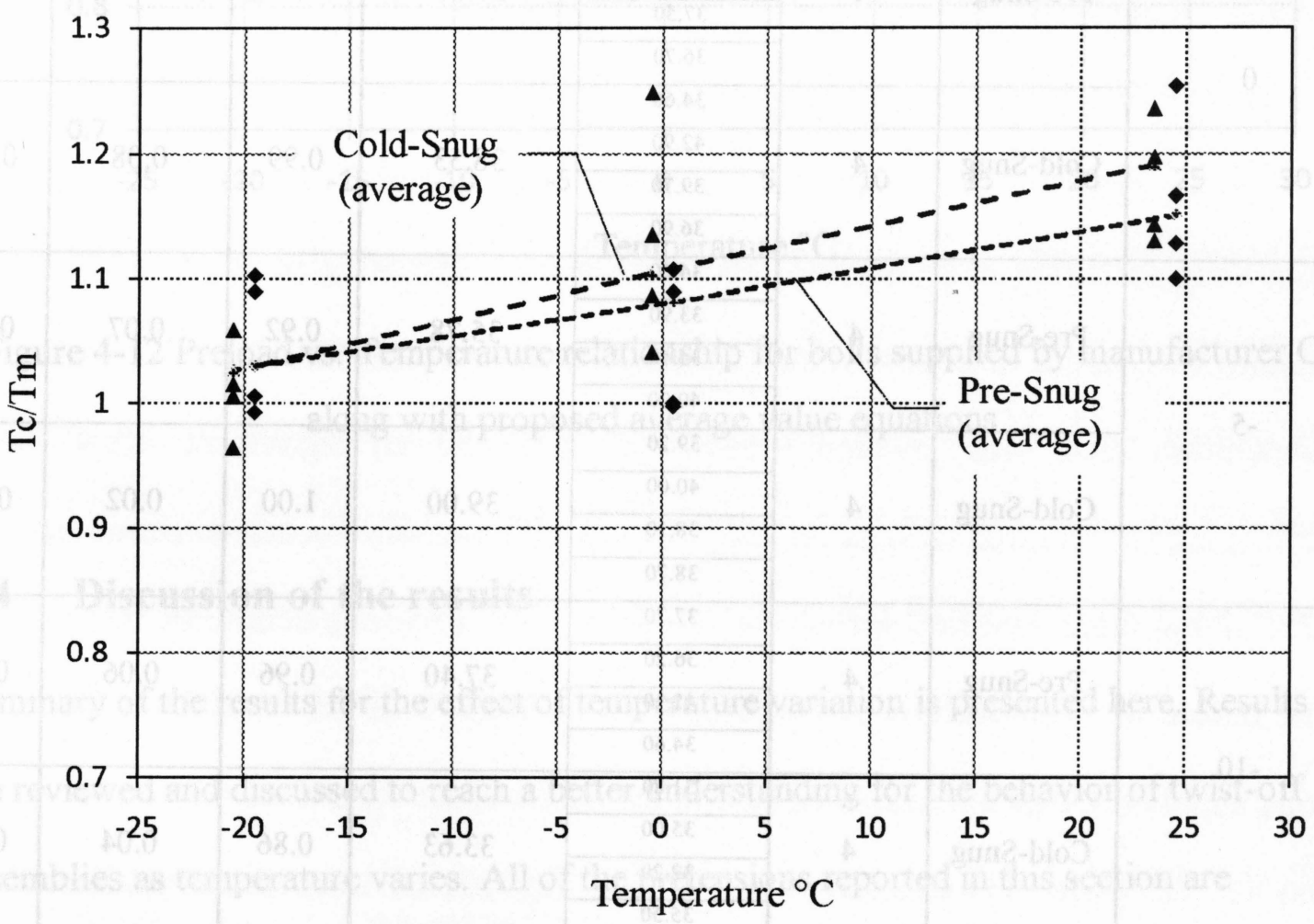

Figure 4-11 Preload vs. Temperature relationship for bolts supplied by manufacturer B along with proposed average value equations 
Table 4-9 Preload for bolts supplied by manufacturer C

\begin{tabular}{|c|c|c|c|c|c|c|c|}
\hline $\begin{array}{c}\text { Temperature } \\
\left({ }^{\circ} \mathrm{C}\right)\end{array}$ & Condition & $\begin{array}{c}\text { Number } \\
\text { tested }\end{array}$ & $\begin{array}{c}T_{c} \\
\text { (kips) }\end{array}$ & $\begin{array}{c}\text { Average } T_{c} \\
\quad \text { (kips) }\end{array}$ & $T_{c} / T_{m}$ & $\begin{array}{l}\text { Standard } \\
\text { Deviation }\end{array}$ & $T_{c} / T_{u}$ \\
\hline \multirow{8}{*}{$\begin{array}{l}\text { Room Temp. } \\
\qquad\left(24^{\circ} \mathrm{C}\right)\end{array}$} & \multirow{4}{*}{ Pre-Snug } & \multirow{4}{*}{4} & 42.10 & \multirow{4}{*}{42.35} & \multirow{4}{*}{1.09} & \multirow{4}{*}{0.02} & \multirow{4}{*}{0.59} \\
\hline & & & 42.80 & & & & \\
\hline & & & 41.50 & & & & \\
\hline & & & 43.00 & & & & \\
\hline & \multirow{4}{*}{ Cold-Snug } & \multirow{4}{*}{4} & 47.90 & \multirow{4}{*}{45.25} & \multirow{4}{*}{1.16} & \multirow{4}{*}{0.05} & \multirow{4}{*}{0.63} \\
\hline & & & 44.20 & & & & \\
\hline & & & 46.10 & & & & \\
\hline & & & 42.80 & & & & \\
\hline \multirow{8}{*}{0} & \multirow{4}{*}{ Pre-Snug } & \multirow{4}{*}{4} & 35.70 & \multirow{4}{*}{37.15} & \multirow{4}{*}{0.95} & \multirow{4}{*}{0.03} & \multirow{4}{*}{0.52} \\
\hline & & & 38.70 & & & & \\
\hline & & & 37.50 & & & & \\
\hline & & & 36.70 & & & & \\
\hline & \multirow{4}{*}{ Cold-Snug } & \multirow{4}{*}{4} & 34.60 & \multirow{4}{*}{38.53} & \multirow{4}{*}{0.99} & \multirow{4}{*}{0.08} & \\
\hline & & & 42.90 & & & & 053 \\
\hline & & & 39.70 & & & & 0.35 \\
\hline & & & 36.90 & & & & \\
\hline & & & 34.60 & & & & \\
\hline & & 4 & 33.90 & 3578 & 0.92 & 0.07 & 050 \\
\hline & Pre-snug & 4 & 34.40 & 35.78 & 0.92 & 0.07 & 0.50 \\
\hline-5 & & & 40.20 & & & & \\
\hline & & & 39.20 & & & & \\
\hline & Cold-Snug & 4 & 40.00 & 39.00 & 1.00 & 0.02 & 0.54 \\
\hline & & & 38.10 & & & & \\
\hline & & & 38.70 & & & & \\
\hline & & & 37.70 & & & & \\
\hline & Pre-Snuo & 4 & 36.20 & 37.40 & 0.96 & 0.06 & 0.52 \\
\hline & & & 41.10 & 37.40 & 0.96 & & \\
\hline & & & 34.60 & & & & \\
\hline-10 & & & 31.80 & & & $7 x$ & \\
\hline & Cold_Snuo & 4 & 35.00 & 3363 & 086 & 004 & 047 \\
\hline & & & 32.20 & & & & \\
\hline & & & 35.50 & & & & \\
\hline & & & 33.10 & & & & \\
\hline & Pre-Snur & 4 & 34.70 & 33.50 & 0.86 & 0.03 & 0.46 \\
\hline & Pre-Snug & & 34.60 & 35.50 & 0.86 & 0.05 & 0.40 \\
\hline-20 & & & 31.60 & & & & \\
\hline & & 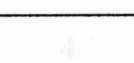 & 34.90 & & & & \\
\hline & Cold_Snuo & 4 & 35.70 & 3568 & 091 & 002 & 049 \\
\hline & Cold-snug & 4 & 34.90 & 35.08 & & & 0.49 \\
\hline & & & 37.20 & & & & \\
\hline
\end{tabular}

$T_{c}=$ Calibrated tension, $T_{m}=$ Specified minimum pretention $(39 \mathrm{kips}), T_{u}=$ ultimate tensile strength in direct tension (tested average $=72.1$ kips) 


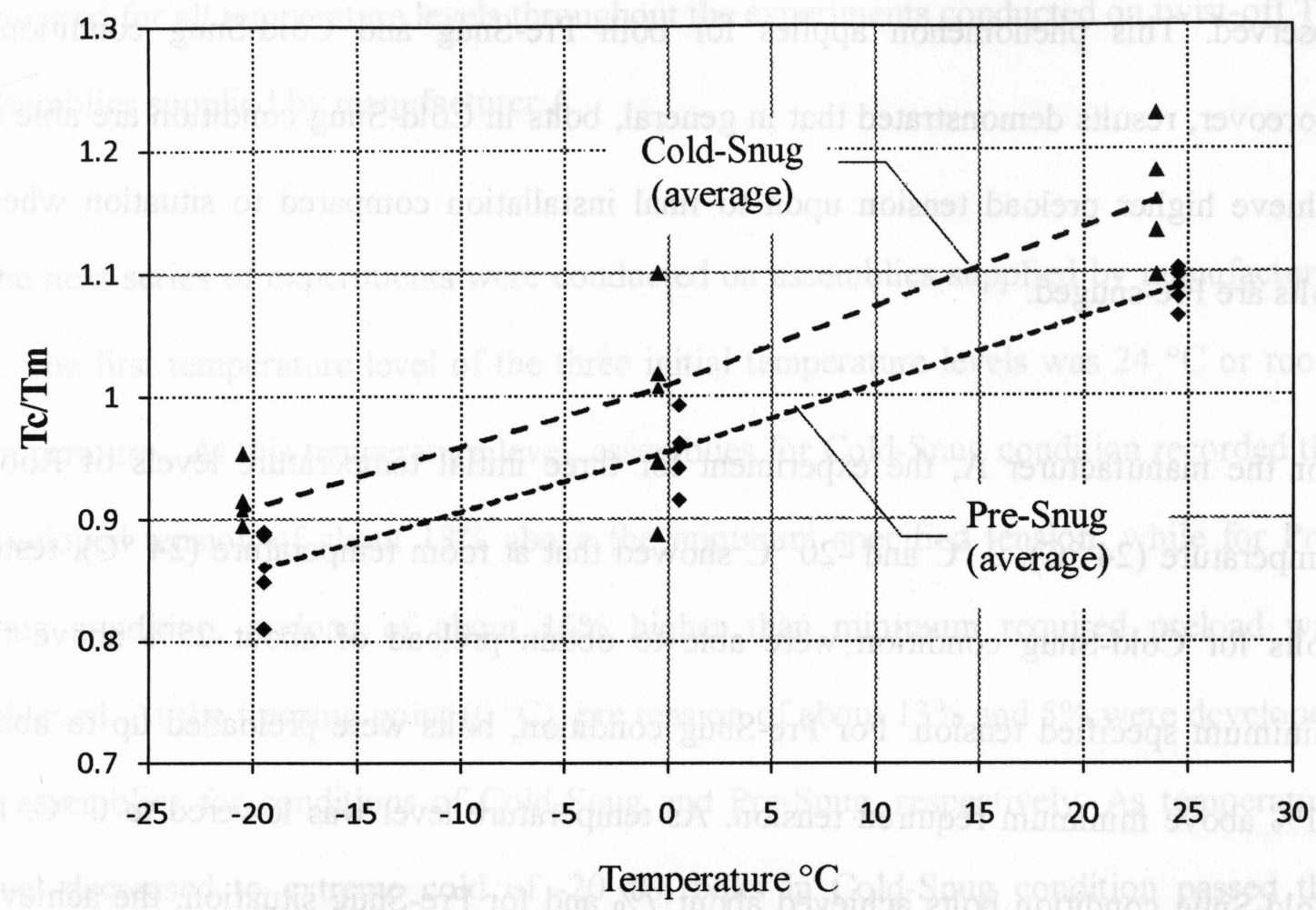

Figure 4-12 Preload vs. Temperature relationship for bolts supplied by manufacturer C along with proposed average value equations

\subsection{Discussion of the results}

Summary of the results for the effect of temperature variation is presented here. Results are reviewed and discussed to reach a better understanding for the behavior of twist-off assemblies as temperature varies. All of the pretensions reported in this section are referenced with the minimum specified preload of 39 kips for $7 / 8$ in diameter ASTM F1852 bolt assemblies.

As it can be observed from results presented in Chapter 4, cold temperature had an extremely negative effect on the achieved pretension for all manufacturers. As temperature level decreases a declining pattern on achieved tension in bolts can be 
observed. This phenomenon applies for both Pre-Snug and Cold-Snug conditions. Moreover, results demonstrated that in general, bolts in Cold-Snug condition are able to achieve higher preload tension upon to final installation compared to situation where bolts are Pre-snuged.

For the manufacturer A, the experiment for three initial temperature levels of Room temperature $\left(24{ }^{\circ} \mathrm{C}\right), 0{ }^{\circ} \mathrm{C}$ and $-20^{\circ} \mathrm{C}$ showed that at room temperature $\left(24^{\circ} \mathrm{C}\right)$, tested bolts for Cold-Snug condition were able to obtain preload of about $25 \%$ above the minimum specified tension. For Pre-Snug condition, bolts were preloaded up to about $21 \%$ above minimum required tension. As temperature level was lowered to $0{ }^{\circ} \mathrm{C}$, for Cold-Snug condition bolts achieved about $7 \%$ and for Pre-Snug situation, the achieved tension was about $2 \%$ above the minimum required tension. However, when the temperature level was lowered to $-20{ }^{\circ} \mathrm{C}$ bolts showed significant drawback in developing the required tension. At $-20{ }^{\circ} \mathrm{C}$, twist-off assemblies achieved about $92 \%$ and $87 \%$ of minimum specified tension for Cold-Snug and Pre-Snug condition, respectively. The failure for manufacturer A confirmed the findings of earlier study by Maleev. For bolts supplied by manufacturer $\mathrm{A}$, two other intermediate temperature levels of $-10^{\circ} \mathrm{C}$ and $-15{ }^{\circ} \mathrm{C}$ were also considered for testing. At $-10{ }^{\circ} \mathrm{C}$, Cold-Snug condition bolts achieved preload of about $5 \%$ above the minimum specified tension, while for Pre-Snug condition, bolts barely made the minimum required tension. At $-15{ }^{\circ} \mathrm{C}$, For both condition of Cold-Snug and Pre-Snug, bolts failed to obtain the required tension by reaching about $92 \%$ and $91 \%$ of the minimum specified tension accordingly. The achieved higher tension in Cold-Snug condition compared to Pre-Snug condition was 
observed for all temperature levels throughout the experiments conducted on twist-off TC assemblies supplied by manufacturer A.

The next series of experiments were conducted on assemblies supplied by manufacturer B. The first temperature level of the three initial temperature levels was $24^{\circ} \mathrm{C}$ or room temperature. At this temperature level, assemblies for Cold-Snug condition recorded the developed tension of about $18 \%$ above the minimum specified tension, while for PreSnug condition, preload of about $16 \%$ higher than minimum required preload was achieved. At the freezing point $\left(0^{\circ} \mathrm{C}\right)$, pre tension of about $13 \%$ and $5 \%$ were developed in assemblies for conditions of Cold-Snug and Pre-Snug, respectively. As temperature level decreased to extreme cold of $-20^{\circ} \mathrm{C}$, bolts in Cold-Snug condition passed the required tension by narrow margin of about $1 \%$ and for Pre-Snug condition this margin was $5 \%$. At $-10^{\circ} \mathrm{C}$, the assemblies failed to maintain minimum specified tension and reached the preload of about $99 \%$ and $97 \%$ of requirement for Cold-Snug and Pre-Snug condition, respectively, leading to odd conclusion regarding the trend of the reduction of the achieved pretension with decrease in temperature.

Twists-off assemblies supplied by manufacturer $\mathrm{C}$ were the last blots to be tested for this part of the experiment. Total of five temperature levels were tested including three main temperature levels as well as two intermediate levels. For the room temperature of $24^{\circ} \mathrm{C}$, all tested bolts were able to achieve the minimum specified tension by means of reaching about $16 \%$ above the requirement for Cold-Snug condition and about $9 \%$ above the requirement for Pre-Snug condition. At the freezing point, bolts failed to reach the 
minimum specified tension. At $-20^{\circ} \mathrm{C}$, bolt assemblies were able to develop about $91 \%$ and $86 \%$ of minimum specified tension for Cold-Snug and Pre-Snug conditions, respectively. At $-5{ }^{\circ} \mathrm{C}$ bolts in Cold-Snug condition barely made the minimum pretension requirement, however for Pre-Snug condition they failed to obtain proper pretensioning by reaching about $92 \%$ of the required tension. At $-10^{\circ} \mathrm{C}$ temperature level achieved bolt tension was about $86 \%$ and $96 \%$ of minimum specified tension for Cold-Snug and PreSnug conditions respectively.

\subsection{Empirical equation for achieved pretension based on installation temperature}

One of the main objectives of this study was to try to develop an empirical equation to assist engineers and fabricators to calculate the pretension developed in tension-control twist-off assemblies that are exposed to the environment effects before and after installation. Based on the data generated from this research few equations were developed using dataFit 9 software as shown in the following subsections.

\subsubsection{Equations for bolts supplied by manufacturer $A, B$ and $C$}

The following equations were developed to present the change in the achieved pretension with the change in installation temperature. 
For bolts supplied by manufacturer A:

For Pre-Snug condition (lower-bound):

$$
P=7.73 \times 10^{-3} \times T+0.99
$$

For Cold-Snug condition (lower-bound):

$$
P=1.04 /\left(1-6.32 \times 10^{-3} \times T\right)
$$

For Pre-Snug condition (average value):

$$
P=\exp \left(1.38 \times 10^{-2}+7.46 \times 10^{-3} \times T\right)
$$

For Cold-Snug condition (average value):

$$
P=7.30 \times 10^{-3} \times(T+147.2)
$$

For bolts supplied by manufacturer B

For Pre-Snug condition (lower-bound):

$$
P=1 /\left(0.98-2.50 \times 10^{-3} \times T\right)
$$

For Cold-Snug condition (lower-bound):

$$
P=\ln \left(2.83+1.10 \times 10^{-2} \times T\right)
$$

For Pre-Snug condition (average value):

$$
P=1 /\left(0.93+2.33 \times 10^{-3} \times T\right)
$$

For Cold-Snug condition (average value):

$$
P=\ln \left(3.01+1.14 \times 10^{-2} \times T\right)
$$


For bolts supplied by manufacturer C

For Pre-Snug condition (lower-bound):

$$
P=5.69 \times 10^{-3} \times T+0.92
$$

For Cold-Snug condition (lower-bound):

$$
P=0.94 /\left(1-5.11 \times 10^{-3} \times T\right)
$$

For Pre-Snug condition (average value):

$$
P=\exp \left(-4.63 \times 10^{-2}+5.34 \times 10^{-3} \times T\right)
$$

For Cold-Snug condition (average value):

$$
P=1 /\left(1-5.44 \times 10^{-3} \times T\right)
$$

Where,

$$
\begin{aligned}
& P=\text { Preload in twist-off tension-control assembly } \\
& T=\text { Temperature }\left({ }^{\circ} \mathrm{C}\right)
\end{aligned}
$$

\subsubsection{General equations for Pre-Snug and Cold-Snug conditions}

Among the developed equations, those which give the most conservative value for developed pretension in assemblies would be safer and more practical to be used in industry. The equations developed for bolts supplied by manufacturer $\mathrm{C}$ provides the lowest achieved pretension in twist-off bolt assemblies. Hence, in general, it would be reasonable to suggest the use of equations (4.9) and (4.10) to calculate the minimum value of the achieved pretension and equations (4.11) and (4-12) to calculate the average value of pretension developed in twist-off assemblies. 


\section{CHAPTER-5}

\section{TENSION CALIBRATORE PERFORMANCE}

\subsection{General}

Skidmore-Wilhelm bolt tension Calibrator is designed for testing a wide variety of fasteners. Skidmore is essentially a hydraulic load cell with a hole in the center for sample assembly to be installed. The pressure is measured by a dial gage in poundstension equivalent to tension created in the fastener.

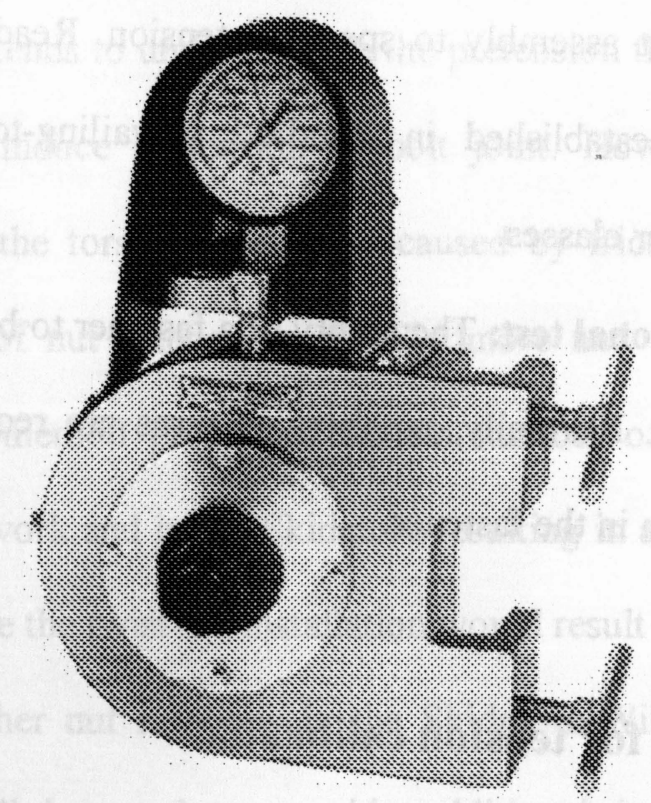

Figure 5-1 View of Skidmore-Wilhelm calibrator

The following tests are possible with the Skidmore-Wilhelm

- Proof load test: Identifying the point at which increasing the applied torque does not increase fastener tension at the same rate. 
- Ultimate strength test: Identifies the amount of tension that causes a bolt to fail.

- Torque-tension relationship: Identifies the amount of torque required to produce a standard tension in a bolt. Joint setup variables such as lubrication, washers, surface texture, paint or plating are taken to account. The calibrator eliminates the inaccuracies that caused from using the equations to calculate torque values.

- Prevailing torque test: For a set number of repetitions, recording maximum and minimum torques applied to tighten and back off a test bolt and nut assembly to specified tension. Readings are to be compared to those established in standard prevailing-torque tables for applicable fastener classes.

- Rotational test: The ability of a fastener to be rotated without stripping or failing. Normally, numbers of turns are required to produce a standard tension in the fastener.

\subsection{Evaluation for tension calibrator}

Based on RCSC specification (2004), a minimum of three fasteners needs to be tested prior to installation in structural steel joints. These assemblies according to RCSC specification must achieve minimum tension of $5 \%$ above the minimum specified tension. In the field, these tests are performed by hydraulic tension calibrator. SkidmoreWilhelm tension calibrator is one of the commonly used hydraulic calibrators in the industry. In this part of research the performance of such calibrator would be evaluated. 


\subsubsection{Calibrator performance}

Previous experiments showed that assemblies tested in Skidmore-Wilhelm calibrator considerably and consistently achieve higher tensions compared to those tested in steel joints. Hence, use of this calibrator could provide misleading values regarding the performance of the bolt assemblies in steel structures. This behavior can be theorized that because of the greater rigidity of the steel plates, less rotation of the nut would be observed during twist-off installation. Less rotation means less stretch in the assembly and therefore, less tension in the assembly. RCSC also recognizes the lower stiffness of the Skidmore- Wilhelm calibrator for the turn-of- method and notes that the reading of a hydraulic tension calibrator tends to underestimate the pretension that a given rotation of the turned element would induce pretension in bolt joint. However, since twist-off installation is governed by the torsional response caused by friction, fasteners do not undergo the same amount of nut rotation in the Skidmore and in steel work. Stated differently, the turn-of-nut method prescribes certain number of nut rotations to be performed both in the steel work and in the Skidmore resulting in a conservative reading in the tension calibrator while the twist-off installation would result in lower nut rotations in more rigid joint and higher nut rotations in the Skidmore-Wilhelm calibrator. The

results from this study will be used to provide additional information about this phenomenon.

\subsubsection{Test specimen and apparatus}

The three plates used in the prototype joint consisted of three solid steel plates $(20 \mathrm{x} 4 \mathrm{x}$ 0.5 inches) with 4 holes in the plates as shown in Figure 5-2. All the edges of the plates 
were sawn or flame cut. The holes were drilled holes, and the size and placement of the hole satisfied the requirements of CAN/CSA-S16-01. All the Individual plates in a joint were identical and fabricated from steel meeting CSA G40.21-M300W. The bolts that were used for this part of the experiment were $7 / 8$ " $\mathrm{x} 3$ " twist-off tension control type from four manufacturers. DTI washers shown in Figure 5-3 were used in this study.

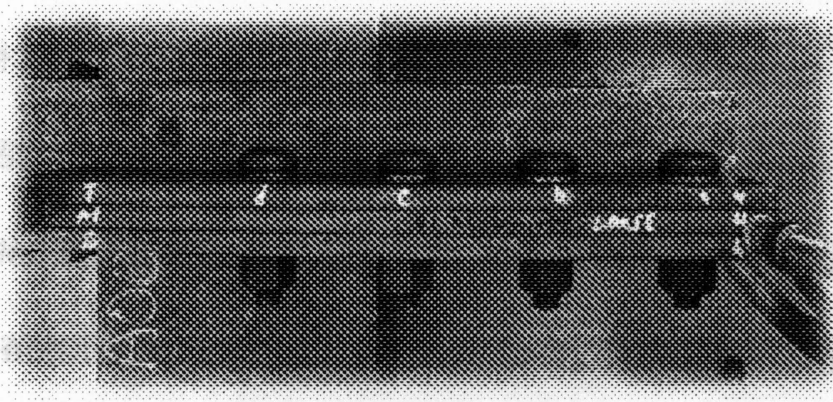

Figure 5-2 View of simulated steel joint

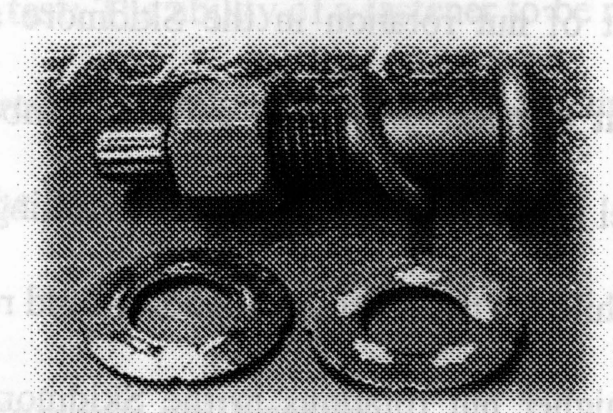

Figure 5-3 View of Twist-off tension control type assembly and DTI washer

\subsubsection{Test procedure and setup}

To examine the variation of the tension results from Skidmore and bolt gage, four different setups were chosen. These setups helped to investigate the performance of Skidmore- Wilhelm calibrator. The first step in this test was to measure the grip length of 
the assemblies in the simulated joint. In order to measure the grip length, assemblies were inserted in the steel joint and were tightened with TC wrench. Bolts and nuts were marked against each others for measurement purposes. Assemblies were removed from the steel joint and nuts were put back on the bolts to the marked position to reach exact same grip length as they were installed in the steel joint. Grip lengths of assemblies were measured and followed in all test setups. Having consistent grip length is essential in order to compare mentioned setups to investigate the calibrator behavior. As mentioned earlier, different grip length would cause different stiffness in assemblies and ultimately various pretensions in bolts would be observed. In the first setup, the assemblies were installed with two steel washers per assembly in simulated steel joint. Bolts were inserted in the steel joint and with use of regular spud wrench, bolts were snug tightened. Bolts and nuts were marked against each other. TC wrench was implemented to apply final torque and complete the installation. At this point, the rotation of nuts against the bolts was measured with respect to snug condition. Then, bolt elongation and the achieved tension were calculated. Figure 5-2 and 5-4 show view of the first setup.

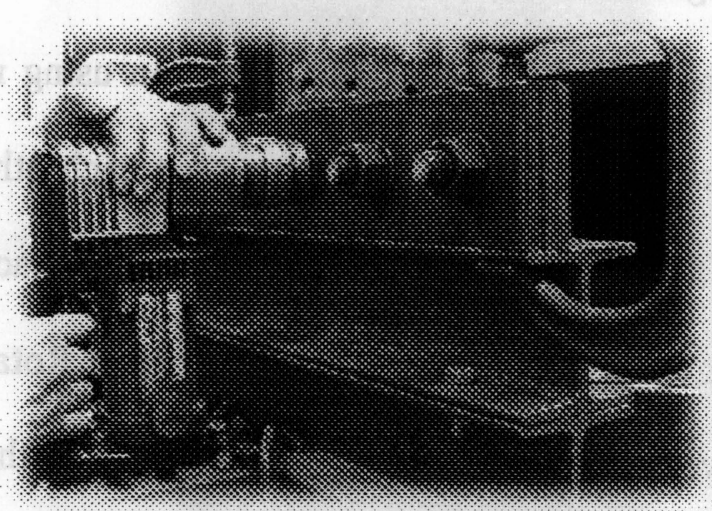

a)

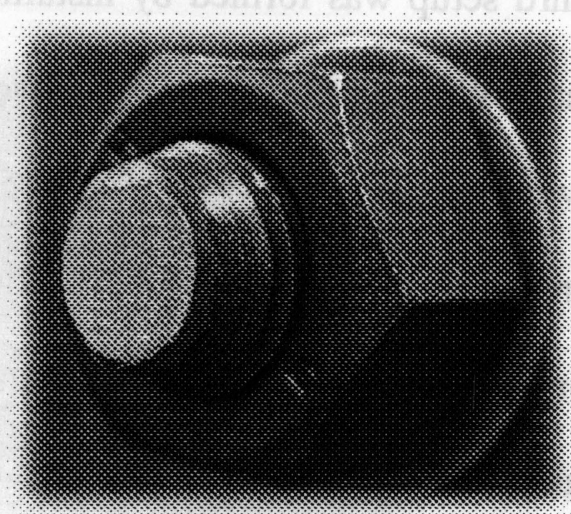

b)

Figure 5-4 View of Setup No.1 of the steel joint for Calibrator Verification 
The second setup was intended to install assemblies with one steel washer and one soft washer referred as "DTI washer". It is believed that this setup would provide softer joint compare to steel joint with two steel washers. Following the same procedure as previous setup, bolts were installed in the steel joint, snug tightened with spud wench and fully installed with TC wrench. Rotation of nuts against the bolt as well as the elongations was measured. Figure 5-5 shows view of the second setup with DTI washers.

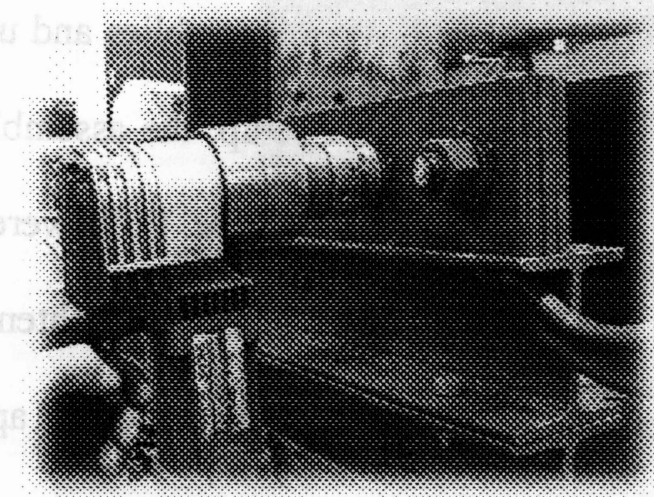

a)

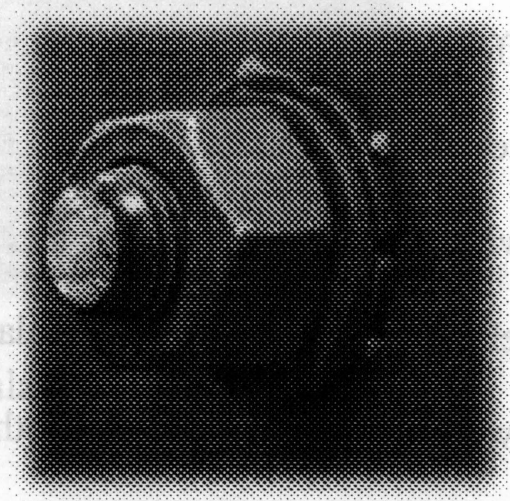

b)

Figure 5-5 View of Setup No. 2 of the steel joint with DTI washer

The third setup was formed by installing the assemblies with two steel washers in the Skidmore-Wilhelm calibrator. Bolts were brought to snug tight condition using regular spud wrench. Same as other setups, bolts and nuts were marked against each other and TC wrench was used for final installation. In Skidmore-Wilhelm calibrator, the achieved tension can be directly read from the gage mounted on top of the equipment. Rotation of nut against bolt and developed preload were recorded. Figure 5-6 shows view of the setup No.3 with the calibrator. 


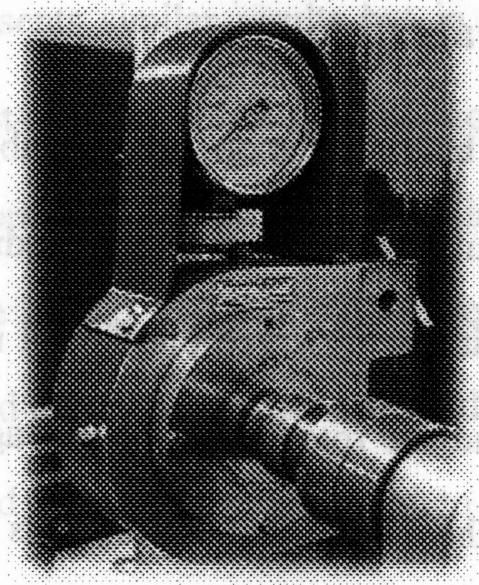

a)

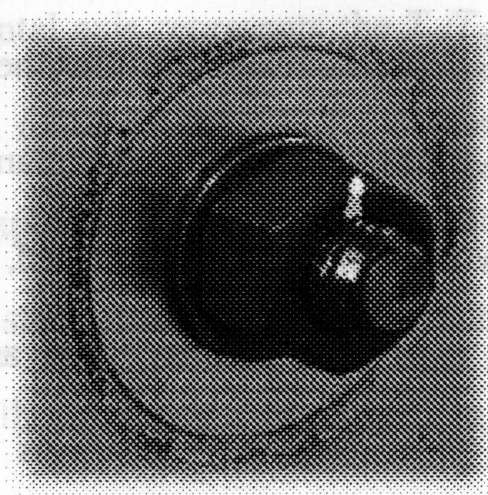

b)

Figure 5-6 View of Setup No. 3 of the Calibrator

The fourth setup involved assembling the bolt in the Skidmore-Wilhelm along with one steel washer and one soft washer (DTI washer). Same as the last setup, bolts were inserted in Skidmore-Wilhelm and installed with spud wrench and TC wrench. The rotations of nuts against the bolt as well as the achieved tension were recorded. Figure 57 shows view of the Skidmore calibrator with DTI washer in the bolt assembly.

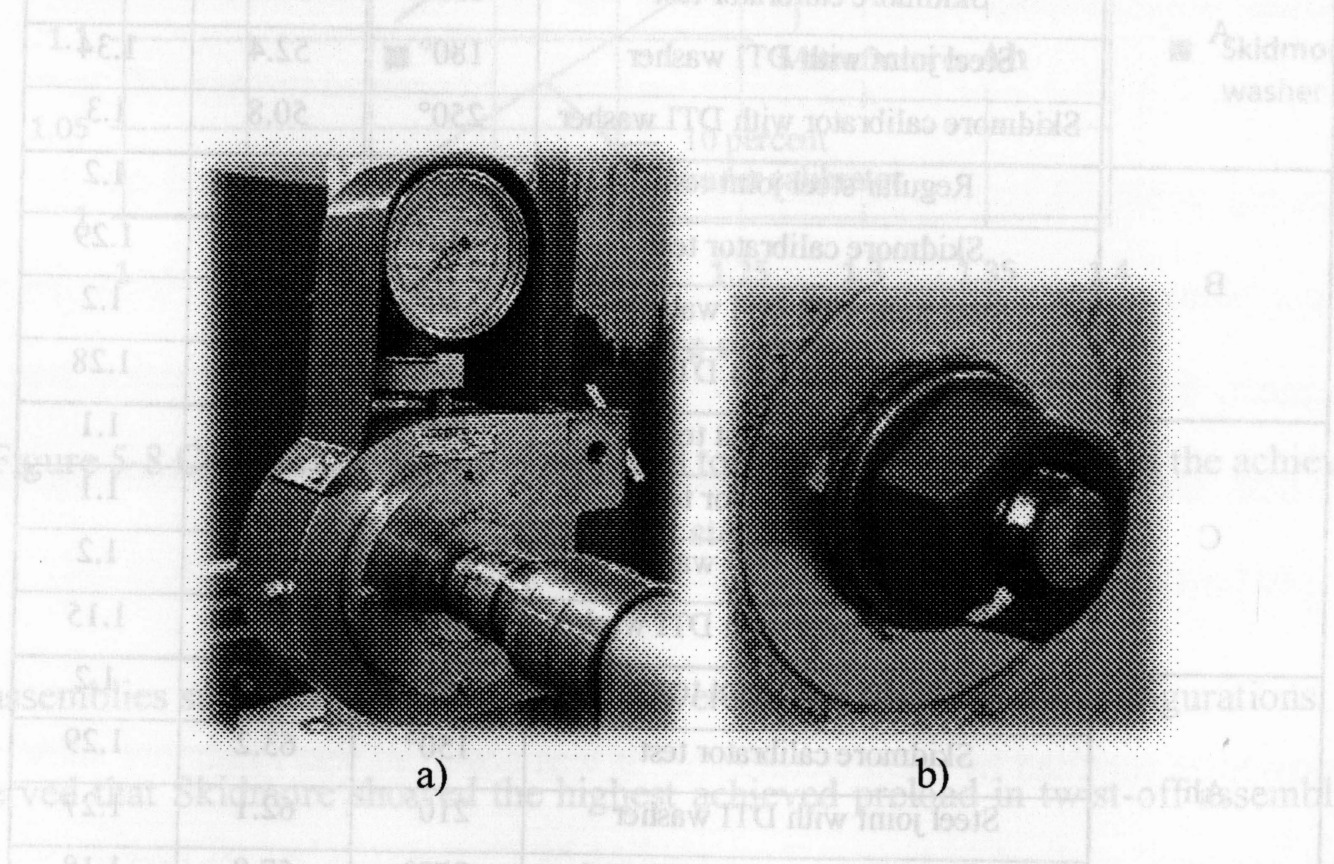

Figure 5-7 View of Setup No. 4 of the Calibrator with the DTI washer in the assembly 


\subsubsection{Results for tension calibrator evaluation}

Table 5-1 demonstrates the results for four the bolt installation setups established for four bolt lots obtained from three different manufacturers to evaluate Skidmore-Wilhelm tension calibrator performance. As expected, it was observed that for all manufacturers, as the simulated steel joint became softer and the rotation of the nut against the bolt became greater. This observation confirms the theory that claims nuts of assemblies achieve higher rotation in softer joints compare to more rigid joints. Regarding the achieved tension in assemblies for different setups, the results for all the manufacturers confirmed that achieved tension in steel joint was less than tension measured by the tension calibrator.

Table 5-1 Preload for Different bolt assembly Setups

\begin{tabular}{|c|c|c|c|c|}
\hline Manufacturer & Installation setup & Rotation & $\begin{array}{c}\text { Tension } \\
\text { (kips) }\end{array}$ & Tc/Tm \\
\hline \multirow{4}{*}{ A } & Regular steel joint test & $50^{\circ}$ & 48.2 & 1.24 \\
\cline { 2 - 5 } & Skidmore calibrator test & $130^{\circ}$ & 53.5 & 1.37 \\
\cline { 2 - 5 } & Steel joint with DTI washer & $180^{\circ}$ & 52.4 & 1.34 \\
\cline { 2 - 5 } & Skidmore calibrator with DTI washer & $250^{\circ}$ & 50.8 & 1.3 \\
\hline \multirow{4}{*}{ B } & Regular steel joint test & $50^{\circ}$ & 46.3 & 1.2 \\
\cline { 2 - 5 } & Skidmore calibrator test & $110^{\circ}$ & 50.2 & 1.29 \\
\cline { 2 - 5 } & Steel joint with DTI washer & $180^{\circ}$ & 47.1 & 1.2 \\
\cline { 2 - 5 } & Skidmore calibrator with DTI washer & $240^{\circ}$ & 49.8 & 1.28 \\
\hline \multirow{4}{*}{ C } & Regular steel joint test & $50^{\circ}$ & 42.4 & 1.1 \\
\cline { 2 - 5 } & Skidmore calibrator test & $90^{\circ}$ & 43.2 & 1.1 \\
\cline { 2 - 5 } & Steel joint with DTI washer & $180^{\circ}$ & 47.4 & 1.2 \\
\cline { 2 - 5 } & Skidmore calibrator with DTI washer & $210^{\circ}$ & 45 & 1.15 \\
\hline \multirow{4}{*}{ Ah } & Regular steel joint test & $70^{\circ}$ & 60.2 & 1.2 \\
\cline { 2 - 5 } & Skidmore calibrator test & $150^{\circ}$ & 63.2 & 1.29 \\
\cline { 2 - 5 } & Steel joint with DTI washer & $210^{\circ}$ & 62.1 & 1.27 \\
\cline { 2 - 5 } & Skidmore calibrator with DTI washer & $270^{\circ}$ & 57.8 & 1.18 \\
\hline
\end{tabular}


Figure 5-8 presents similar results but in different format. It illustrates the developed preload in twist-off assemblies. The horizontal axis represents the $T_{c} / T_{m}$ obtained from Skidmore calibrator while the vertical axis represents the $T_{c} / T_{m}$ obtained for different steel joint type shown in Table 5-1. As expected, the tension calibrator tends to give higher indicated tensions compared to solid steel plated Joints. The graph shows that this value is around $10 \%$ higher compared to the pretension developed in simulated steel joints.

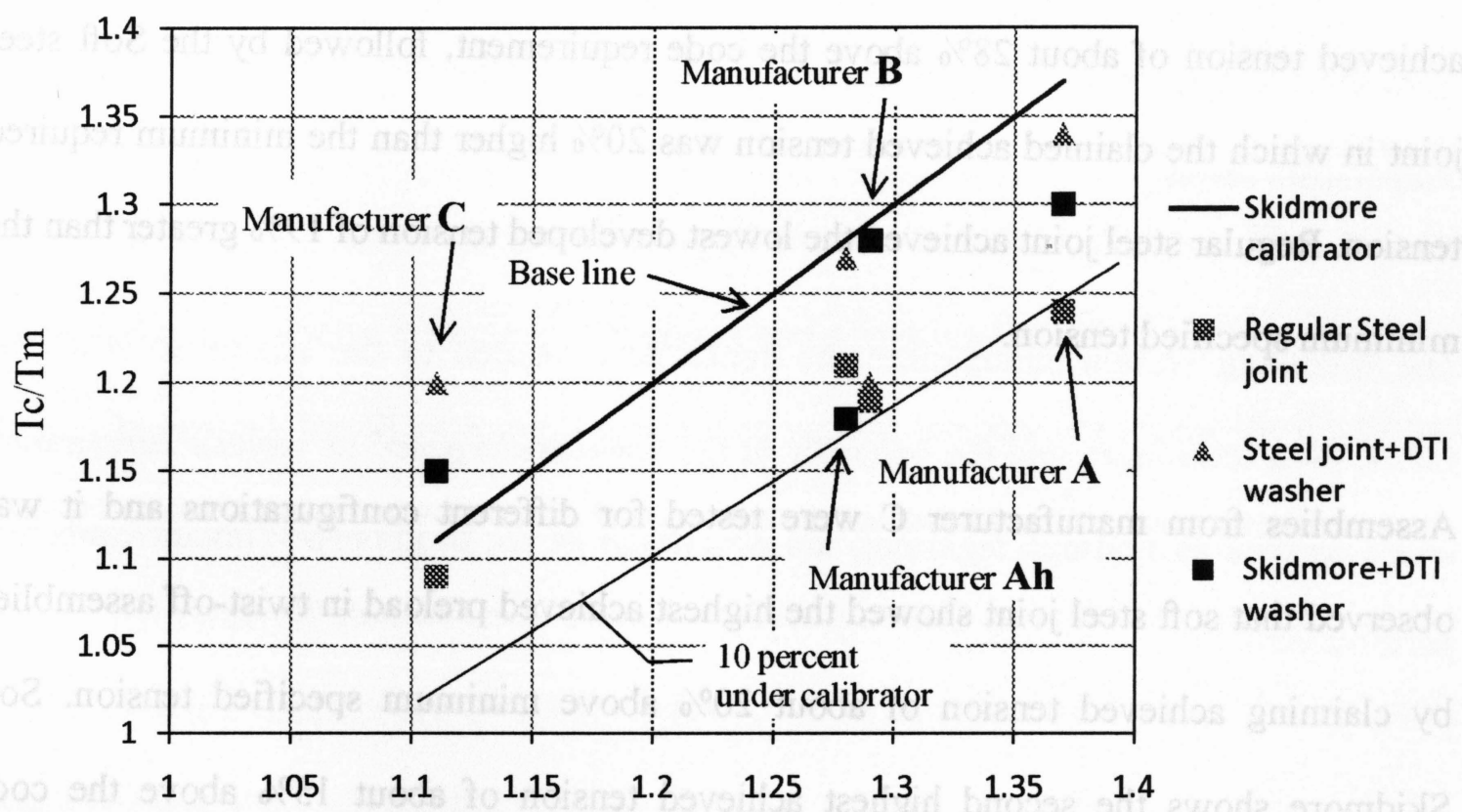

$\mathrm{Tc} / \mathrm{Tm}$ using Skidmore calibrator

Figure 5-8 Comparison between recorded torsion in the calibrator and the achieved tension in steel joint

As assemblies supplied by manufacturer A were tested for different configurations, it was observed that Skidmore showed the highest achieved preload in twist-off assemblies by claiming achieved tension of about $37 \%$ above minimum specified tension. Soft steel 
joint shows the second highest achieved tension of about $34 \%$ above the code requirement, followed by the Soft Skidmore in which the claimed achieved tension was $30 \%$ higher than the minimum required tension. Regular steel joint achieved the lowest developed tension of $24 \%$ greater than the minimum specified tension.

For assemblies supplied by manufacturer B, it was observed that Skidmore showed the highest achieved preload in twist-off assemblies by claiming achieved tension of about $29 \%$ above minimum specified tension. Soft Skidmore shows the second highest achieved tension of about $28 \%$ above the code requirement, followed by the Soft steel joint in which the claimed achieved tension was $20 \%$ higher than the minimum required tension. Regular steel joint achieved the lowest developed tension of $19 \%$ greater than the minimum specified tension.

Assemblies from manufacturer $\mathrm{C}$ were tested for different configurations and it was observed that soft steel joint showed the highest achieved preload in twist-off assemblies by claiming achieved tension of about $20 \%$ above minimum specified tension. Soft Skidmore shows the second highest achieved tension of about $15 \%$ above the code requirement, followed by the Skidmore in which the claimed achieved tension was $11 \%$ higher than the minimum required tension. Regular steel joint achieved the lowest developed tension of $9 \%$ greater than the minimum specified tension.

For assemblies supplied by manufacturer Ah, it was observed that Skidmore showed the highest achieved preload in twist-off assemblies by claiming achieved tension of about 
$29 \%$ above minimum specified tension. Soft steel joint shows the second highest achieved tension of about $27 \%$ above the code requirement, followed by the regular steel joint in which the claimed achieved tension was $20 \%$ higher than the minimum required tension. Soft Skidmore achieved the lowest developed tension of $18 \%$ greater than the minimum specified tension. 


\section{CHAPTER-6 \\ CONCLUSIONS}

\subsection{Summary}

The main objective of the current research was to study the practical aspect of the installation behavior of 7/8 in. diameter ASTM F1852 twist-off type tension control bolts with focus directed to understand the behavior of the these bolts exposed to various temperature levels. Based on finding of current research, an equation was developed to calculate the preload in twist-off assembles as they are exposed to various installation temperature levels.

The following section summarizes the conclusions related to the qualification of the verification techniques and the behavior of the fasteners exposed to various temperature levels as well as findings regarding the evaluation of the Skidmore-Wilhelm calibrator performance. 


\subsection{Conclusions}

Based on the data generated from this research, the following conclusion can be drawn.

1. All of the twist-off assemblies tested in this research satisfied the bolt dimensional requirements specified in ASTM F1852.

2. The laboratory direct tension tests were performed following the specification of ASTM F606 and all twist-off assemblies achieved the tensile strength requirements of ASTM F1852.

3. All as-received twist-off assemblies obtained from three manufacturers claimed to achieve pretension of at least $10 \%$ above the minimum specified tension as required in RCSC specification when calibrated using Skidmore-Wilhelm calibrator. This may be attributed to the relative stiffness of the components forming the bolted joint.

4. In general, for all assemblies exposed to various temperature levels, the developed preload in Cold-Snug condition was higher than that achieved in Pre-Snug condition.

5. All twist-off assemblies showed a declining pattern in achieved installed tension as the exposed temperature decreases below $0^{\circ} \mathrm{C}$ irrespective of whether the assembly was Pre-Snug and Cold-Snug.

6. All assemblies showed inadequate developed tension at temperature below freezing.

7. An empirical equation of the achieved pretension in bolt assembly is proposed as a function of the installation temperature for Pre-Snug and Cold-Snug conditions. 


\subsection{Recommendations for future study}

Conducted experiments showed that the Hydraulic Tension Calibrator tends to give higher value for the achieved tension in bolt. Therefore, further research can be conducted to study the factors affecting the tension calibrator performance and perhaps offer a solution. 


\section{REFERENCES}

ASTM A325-01. Standard Specification for Structural Bolts, Steel, 120/105 ksi Minimum Tensile Strength. American Society for Testing and Materials.

ASTM E18-02. Standard Test Methods for Rockwell Hardness and Rockwell Superficial Hardness of Metallic Materials. American Society for Testing and Materials.

ASTM F959-02. Standard Specification for Compressible-Washer-Type Direct Tension Indicators for Use with Structural Fasteners. American Society for Testing and Materials.

ASTM F1852-05. Standard Specification for "Twist Off" Type Tension Control Structural Bolt/Nut/Washer Assemblies, Steel, Heat Treated, 120/105 ksi Minimum Tensile Strength. American Society for Testing and Materials.

Bickford, J. H., 2008. Introduction to the Design and Behaviour of Bolted Joints, 4th Edition. CRC Press, Taylor and Francis Group, New York.

CISC, 2009. Handbook of Steel Construction, 9th Edition. Canadian Institute of Steel Construction.

Grgas, N., 1990. Field Investigation and Evaluation of the Pretension of High Strength. A Draft Thesis. Department of Civil Engineering, University of Toronto, Toronto, Ontario, Canada.

Kulak, G. L., and Birkemoe, P. C., 1993. Field Studies of Bolt Pretension. Jurnal of Construction. Steel Research 25: 95-106.

Kulak, G. L., Fisher, J. W. and Struik, J. H., 1994. Guide to Design Criteria for Bolted and Riveted Joints, Second Edition. American Institute of Steel Construction, Inc. 
Kulak, G. L., and Grondin, G.Y., 2002. Limits States Design in Structural Steel. Canadian Institute of Steel Construction.

Kulak, G. L., and Obaia, K. H., 1992. A field study of fastener tension in high strength bolts. Structural Engineering Report No. 177, Department of Civil Engineering, University of Alberta, Alberta, Ontario, Canada.

Kulak, G. L., and Undershute, T.S., 1994. Strength and Installation Characteristics of Tension-Control Bolts. Structural Engineering Report No. 201. Department of Civil Engineering, University of Alberta, Alberta, Canada.

RCSC, 2004. Specification for Structural Joints Using ASTM A325 or A490 Bolts. Research Council on Structural Connections. Available online at www.boltcouncil.org.

Shigley, J.E., and Mischke, C. R., 2001. Mechanical Engineering Design. Seventh Edition, McGraw-Hill, New York.

Schnupp, K. O., and Murray, T. M., 2003. Effects of Head Size on the Performance of Twist-off Bolts, Research Report. Department of Civil and Environmental Engineering, Virginia Polytechnic Institute and State University, USA.

Tan, W., 2004. Installation Behaviour of ASTM F1852 Twist-Off Type Tension Control Bolts. Master of Applied Science Thesis, Department of Civil Engineering, University of Toronto, Ontario, Canada.

V. Maleev, 2007. Installation Behaviour of ASTM F1852 Twist-Off Type Tension Control Bolts. Master of Engineering Report Department of Civil Engineering, University of Toronto. 